\title{
Performance of HUD-Affiliated Properties During the January 17, 1994 Northridge Earthquake
}

\section{Diana Todd}

Erik Anderson, Nicholas Carino, Geraldine Cheok, Riley Chung, John Gross, Long Phan, Arturo E. Schultz, Harry W. Shenton III, Andrew Taylor, Charles W.C. Yancey

Building and Fire Research Laboratory

Gaithersburg, Maryland 20899

QC

100

.056

N0.5488

1994

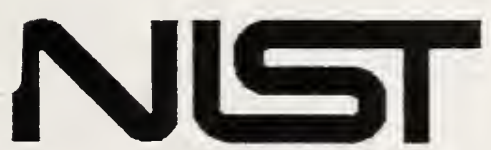

United States Department of Commerce

Technology Administration

National Institute of Standards and Technology 


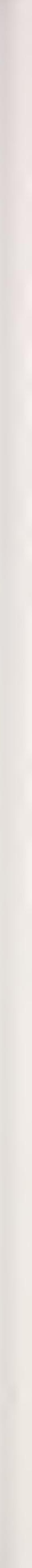




\section{Performance of HUD-Affiliated Properties During the January 17, 1994 Northridge Earthquake}

Diana Todd

Erik Anderson, Nicholas Carino, Geraldine Cheok, Riley Chung, John Gross, Long Phan, Arturo E. Schultz, Harry W. Shenton III, Andrew Taylor, Charles W.C. Yancey

\section{August 1994}

Building and Fire Research Laboratory

National Institute of Standards and Technology

Gaithersburg, MD 20899
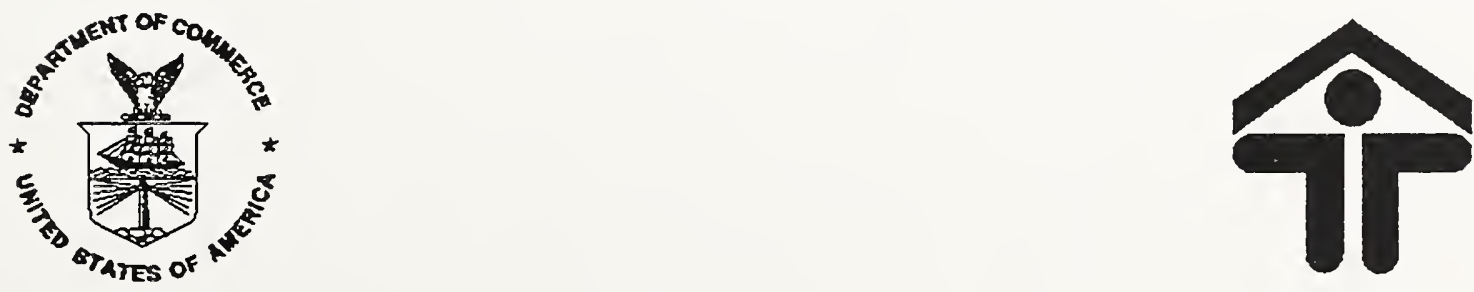

U.S. Department of Commerce

Prepared for:

Ronald H. Brown, Secretary

U.S. Department of

Technology Administration

Housing and Urban

Mary L. Good, Under Secretary for Technology

Development

National Institute of Standards and Technology

Arati A. Prabhakar, Director 



\title{
ACKNOWLEDGEMENTS
}

This report was prepared under Interagency Agreement Number DU100I940000027 between the U.S. Department of Housing and Urban Development (HUD) and the National Institute of Standards and Technology (NIST). Mr. Bill Freeborne, HUD, was the Project Officer. The assistance of HUD personnel from the Los Angeles Regional Office is gratefully acknowledged. Special thanks are extended to Mr. Charles Ming, Director, Ms. Adrienne Loughlin, Deputy Director, Mr. Malcolm Findley, Mr. Bill Christiansen, Ms. Beverly Kendrick, and their staffs.

The cooperation of the property management companies and the residents of the buildings examined for this study is gratefully acknowledged.

The following NIST personnel participated in this study:

\author{
Erik Anderson \\ Nicholas Carino \\ Geraldine Cheok \\ Riley Chung \\ John Gross \\ H.S. Lew \\ Long Phan \\ Arturo E. Schultz \\ Harry W. Shenton III \\ Andrew Taylor \\ Diana Todd \\ Charles Yancey
}




\begin{abstract}
The magnitude 6.8 January 17, 1994 Northridge Earthquake was centered under the densely populated San Fernando Valley northeast of Los Angeles, California. At the request of the Department of Housing and Urban Development (HUD), the Building and Fire Research Laboratory (BFRL) of the National Institute of Standards and Technology (NIST) conducted field observations of multi-family residences three stories or more in height in the affected area for the purposes of identifying common damage states in residential construction. Sixty-nine HUD-affiliated sites, totalling 425 buildings and over 10,000 living units, were visually examined from the exterior and interior. Buildings were selected for observation based on distance from the epicenter and amount of damage. Examinations were documented on a data collection form and with photographs. By collecting information primarily on damaged buildings, it was possible to identify typical types and degrees of damage to residential buildings. Only a few HUD-affiliated buildings were severely damaged. By and large the damage observed was minor and cosmetic, consisting largely of cracks to interior and exterior wall surfaces. Nevertheless, this type of nonstructural damage will be costly to repair. Documentation of the costs of repairing Northridge earthquake damage would greatly expand the existing body of knowledge on this subject. The damage observations suggest that further studies of the social and economic costs of earthquake damage are needed, along with studies of the costs and benefits of more stringent seismic design and construction requirements. These studies would illuminate many of the issues surrounding the current debate over whether seismic requirements for new and renovated construction should be upgraded to mandate property protection as well as protection of human life.
\end{abstract}




\section{TABLE OF CONTENTS}

ACKNOWLEDGEMENTS $\ldots \ldots \ldots \ldots \ldots \ldots$. . . . . . . . . . .

ABSTRACT $\ldots \ldots \ldots \ldots \ldots \ldots \ldots \ldots \ldots \ldots \ldots \ldots$

I. INTRODUCTION $\ldots \ldots \ldots \ldots \ldots \ldots \ldots \ldots \ldots$

A. Introduction to the earthquake $\ldots \ldots \ldots \ldots \ldots$

B. Introduction to the project $\ldots \ldots \ldots \ldots \ldots$

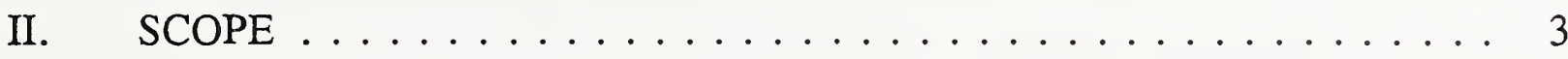

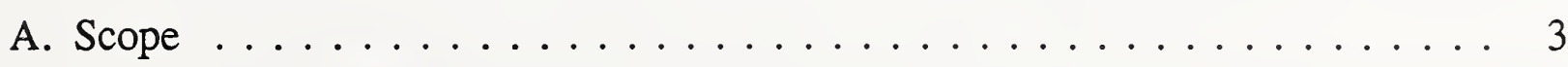

B. Limitations . . . . . . . . . . . . . . . 3

III. METHODOLOGY .................... 3

A. Selection of buildings $\ldots \ldots \ldots \ldots \ldots \ldots$

B. Survey methodology $\ldots \ldots \ldots \ldots \ldots \ldots \ldots$

C. Data assessment techniques .................... 8

IV. OBSERVATIONS AND ASSESSMENTS ............. 11

A. General . . . . . . . . . . . . . . . . 11

B. Comparison of technical subsets . . . . . . . . . . . 37

V. CONCLUSIONS AND RECOMMENDATIONS . . . . . . . . . . 43

A. Conclusions . . . . . . . . . . . . . . . . . 43

B. Recommendations . . . . . . . . . . . . . . . . 45

VI. REFERENCES . . . . . . . . . . . . . . . . . . . 49

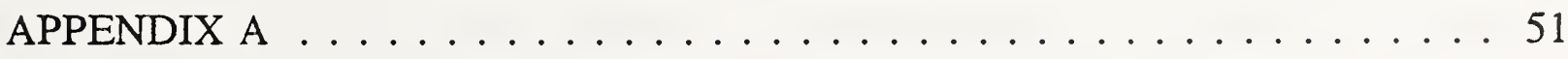




\section{LIST OF FIGURES}

Figure 1 Residential construction . . . . . . . . . . . . . 11

Figure 2 Typical nonstructural damage in residential buildings $\ldots \ldots \ldots \ldots 12$

Figure 3 Movement of a rooftop water tank . . . . . . . . . . . 13

Figure 4 An unreinforced masonry (URM) building under demolition $\ldots \ldots 14$

Figure 5 Loss of portions of the parapet and wall at Uptown Manor . . . . . . 14

Figure 6 A three-story wood-frame building declared potentially unsafe $\ldots \ldots 16$

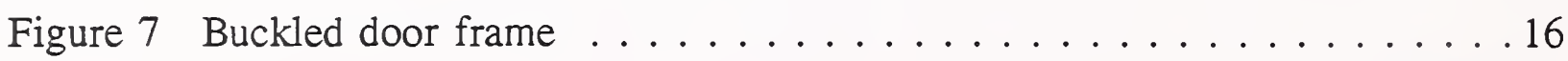

Figure 8 Pre-earthquake seismic rehabilitation of URM buildings $\ldots \ldots \ldots 17$

Figure 9 Parapet bracing on a URM building $\ldots \ldots \ldots \ldots \ldots$

Figure 10 A concrete shear wall building $\ldots \ldots \ldots \ldots \ldots$

Figure 11 Distribution of structural types $\ldots \ldots \ldots \ldots$

Figure 12 Diagonal cracks in a concrete shear wall . . . . . . . . . 22

Figure 13 Diagonal cracks under repair $\ldots \ldots \ldots \ldots . \ldots . \ldots 22$

Figure 14 Diagonal cracks in concrete columns . . . . . . . . . . 23

Figure 15 Diagonal cracks above a doorway in a concrete shear wall . . . . 23

Figure 16 Cracks above doors being repaired using expoxy injection . . . . . . . 24

Figure $17 \mathrm{X}$-cracking in the masonry facade between windows of a concrete frame building . . . . . . . . . . . . . 24

Figure 18 An inclined vertical crack in a reinforced masonry building . . . . . . 27

Figure 19 An unreinforced masonry building under demolition . . . . . . . . . 29

Figure 20 Cracking of the inside corner of a T-shaped URM building $\ldots \ldots 30$

Figure 21 A URM building that suffered no structural damage and only minor nonstructural damage $\ldots \ldots \ldots \ldots \ldots \ldots$ 
Figure 22 Damage to the wood-framed, stucco-clad elevator penthouse on the roof of a 3 -story URM building . . . . . . . . . 31

Figure 23 Cracks in the short walls at the inside corner of a T-shaped URM . . . 32

Figure 24 Cracks in the interior plaster of a URM building . . . . . . . . . 32

Figure 25 Significant racking and permanent offsets in a two-story wood frame building . . . . . . . . . . . . . . 33

Figure 26 Cracks in the gypsum wallboard at a wood frame building . . . . . 34

Figure 27 Horizontal cracks in exterior stucco where the wood frame wall joins the concrete foundation wall . . . . . . . . . . 34

Figure 28 Diagonal cracks in exterior stucco at window openings in a wood frame building . . . . . . . . . . . . . . 35

Figure 29 Scatter plots and coefficients of correlation . . . . . . . . . . 38

Figure 30 Average ATC-13 damage states by structural system . . . . . . . . 39

\section{LIST OF TABLES}

Table A Site Identification .................... 6

Table B ATC-13 Damage Scale Used in this Study . . . . . . . . . . . 9

Table $C$ Values of Evaluated Parameters by Building Site . . . . . . . 36

Table D Coefficient of Correlation $r \ldots \ldots \ldots \ldots \ldots$

Table E Average ATC-13 Damage State by Structural System . . . . . . . . 39 



\section{INTRODUCTION}

\section{A. Introduction to the earthquake}

A strong earthquake centered under the community of Northridge in the San Fernando Valley shook the entire Los Angeles area at 4:31 a.m. local time on Monday, January 17,1994 . The surface wave magnitude, originally estimated at 6.6 , was later revised upward to 6.8. January 17 was a Federal holiday (Martin Luther King's Birthday) and, because of this and the early morning hour, most non-residential buildings were empty and traffic was light. This fortuitous circumstance helped limit the number of deaths and injuries.

This earthquake, though not as large as the 1989 magnitude 7.1 Loma Prieta earthquake, affected more people and caused more damage because it occurred in a heavily populated area. The epicenter of the Loma Prieta quake was about $95 \mathrm{~km}$ from downtown San Francisco, in a sparsely populated region of the Santa Cruz mountains. The epicenter of the Northridge quake was directly beneath a suburban area of houses, apartment buildings, shopping malls, hospitals, schools, and a university campus. With damages estimated at $\$ 30$ billion, the earthquake seems likely to become the United States' most costly natural disaster to date.

The impact on the built environment was high. Many two and three-story apartment buildings collapsed or were severely damaged. Hundreds of single-family homes suffered minor, but disruptive damage. Several large commercial buildings collapsed. Hundreds of shops and offices were closed because of nonstructural damage such as fallen ceiling tiles and broken glass. Several hospitals were forced to evacuate their patients. The entire Los Angeles County school system was shut down to allow for cleanup and damage repair. Eight large public parking garages suffered partial or complete collapse. Seven major highway bridges were severely damaged or destroyed by the shaking. Water mains broke and flooded streets; gas lines broke and in some instances started significant fires. The entire Los Angeles area lost electric power.

As of Feb. 14, the Los Angeles Department of the Coroner had attributed a total of 58 deaths to the earthquake. About 1,500 people were admitted to hospitals with major injuries; another 16,000 or so were treated and released. Estimates of the number of people temporarily or permanently displaced because of damage to their houses or apartments ranged from 80,000 to 125,000 . As of early February, over 400,000 people had registered for various types of Federal disaster assistance.

Although the earthquake caused significant damage and disruption, it also created an unprecedented opportunity to learn about earthquake mechanisms and effects.

\section{B. Introduction to the project}

Following the Northridge earthquake, the Department of Housing and Urban Development (HUD) entered into an agreement with the Building and Fire Research Laboratory (BFRL) of the National Institute of Standards and Technology (NIST) to 
document damage in residential buildings of three stories or more in height. Usually, the focus of immediate post-earthquake reconnaissance activities is on documenting cases of spectacular or unusual damage to structures. The HUD/BFRL study was intended to identify common, rather than spectacular, damage in multi-family residential construction.

The Northridge earthquake was unique in the history of the United States in that it was centered under a heavily populated area. More buildings of varying ages and structural types were severely shaken by the Northridge earthquake than in any previous seismic event in this country. Spectacular damage was limited to the collapse of a handful of concrete commercial buildings and to a number of three-story apartment buildings in the epicentral area. Less spectacular but nevertheless disruptive and costly damage was widespread. By documenting the types of damage that occurred in multi-family residential buildings, the HUD/BFRL study collected information that can be used for identifying possible weaknesses in current design codes and standards for new residential buildings, appraising the impact of rehabilitation requirements for existing buildings, and assessing potential improvements to HUD program requirements.

HUD funded two additional studies of the performance of residential buildings in the Northridge earthquake. The first was a study of the behavior of low-rise (two stories or fewer) single and multi-family residences, conducted by the National Association of Home Builders Research Center (NAHB RC). The core of the NAHB RC study consisted of an examination of the performance of a statistically random sample of single-family homes in the earthquake-affected area. The second study was conducted by the consulting firm of Wiss, Janney, Elstner Associates, Inc. In this study, earthquake and fire damage to manufactured housing was investigated. 


\section{SCOPE}

The goal of the HUD/BFRL study is to document typical damage in multi-family residential construction, in order to capture transient information generated by the Northridge earthquake that could be used for further, in-depth studies of technical and policy issues.

\section{A. Scope}

The study was organized to concentrate on multi-family residences three stories or higher that had been affected by the Northridge earthquake. No restrictions were placed on the age or structural type of the buildings to be examined; a goal was established to investigate broad spectrum of building types. HUD-affiliated buildings formed the pool of candidate structures.

The study was designed to focus on damaged buildings. Documentation of a small number of buildings with exceptionally good performance was established as a secondary goal.

\section{B. Limitations}

The group of buildings inspected in this study is not a statistically random sample of multi-family residences in the affected area. The study was not designed to provide estimates of the extent or probability of damage. Rather, the study is intended to serve as documentation of building performance in damaged multi-family residential buildings. Therefore, only qualitative conclusions can be drawn from this sample about the likelihood of damage to certain classes of construction in future earthquakes.

Building performance was documented on data-collection forms during on-site inspections. Where available, building plans were examined to verify data on structural types, configuration, dimensions and other parameters. Engineering analyses of the buildings were not performed.

\section{METHODOLOGY}

\section{A. Selection of buildings}

In order to make best use of resources and time available, HUD and BFRL agreed that the study should focus on damaged buildings, rather than attempting a comprehensive survey of building performance. Much of the information of interest from a technical perspective is rapidly lost in the days and weeks following an earthquake, as damaged buildings are repaired or demolished. Lack of damage in an earthquake is not a transient condition requiring immediate action; information on undamaged buildings can be collected at any time. Therefore, the focus in this study was on damaged buildings. 
Several sources of information on damaged buildings were assessed for their usefulness in identifying buildings for inclusion in the study. These included a list, generated by the Los Angeles HUD office, of HUD-affiliated buildings damaged by the earthquake, and the California Office of Emergency Services/Earthquake Engineering Research Institute Clearinghouse list of damaged buildings. The list of HUD-affiliated properties was chosen as the primary source for selecting buildings for the study. The assistance of the Los Angeles HUD office made it possible to arrange for the BFRL inspection teams to examine the interiors of these buildings.

The list of HUD-affiliated damaged buildings provided to BFRL originally contained about 200 sites. These sites were screened by reviewing HUD damage reports and performing drive-by inspections. Buildings two stories or less in height were generally eliminated from the list of candidate buildings. (The names and locations of all two-story buildings were forwarded to NAHB RC for their information.) Buildings with very minor or no damage were eliminated from the list. A few buildings with exceptionally good performance (very minor damage in neighborhoods where more extensive damage was common) were retained on the list of candidate buildings.

A few sites with two-story buildings were retained in the sample. Some sites from the HUD list included three- and two-story buildings at a single site. These sites were included in the final sample. At some sites, there were two-story buildings with strong structural and architectural resemblances to three-story buildings. In these cases, the decision was made to retain the site in the study. At other sites, because of sloped lots or lower level parking, determining the number of stories was not straightforward. When a building could be considered as either two or three stories, it was retained in the sample.

The Los Angeles HUD office provided the BFRL investigation team with contacts for each of the candidate sites. The BFRL team arranged for inspection, preferably in the company of a site representative (building manager, engineer, etc.), of as many candidate sites as possible. Only rarely did the local building manager decline to cooperate with the study.

After a majority of the sites had been visited, the national HUD office in Washington, $D C$ was briefed on preliminary findings. At the suggestion of the national HUD office, Public Housing projects were substituted into the list of buildings to be examined for damage in lieu of some of the remaining sites from the original list. The HUD-affiliated sites visited in the early stages of the investigation were generally pre-existing when they entered a HUD program. Public Housing projects were typically newly built under HUD programs. The national HUD office wished to include buildings constructed specifically under HUD programs in the survey. With cooperation from the local Public Housing Authorities, inspections were arranged at 14 Public Housing projects, consisting of 231 buildings. The sites were selected by the local Public Housing Authorities, and included several projects with two-story buildings. Although public housing projects are affiliated with HUD programs, for 
some comparisons in this report, public housing projects $(\mathrm{PH})$ are considered separately from the other types of HUD-affiliated (HA) buildings.

During the early stages of planning the study, HUD requested that non-HUD-affiliated buildings be included in the study. Preliminary field work indicated that the HUDaffiliated buildings selected for study were generally representative of the overall building population in the affected area. At a meeting in Washington, DC on March 24, 1994, both HUD and BFRL agreed that there was no reason to believe that the construction of the HUD-affiliated properties differed significantly from non-HUDaffiliated buildings. The relatively ready access to the interior of HUD-affiliated buildings made the expected quality of data available from these buildings very high compared to data that could be acquired from exterior-only inspection of non-HUDaffiliated buildings. Therefore, emphasis on non-HUD buildings was reduced. The BFRL investigation teams did document on film and in field notes the condition of particularly noteworthy examples of damage in the vicinity of the HUD-affiliated buildings, but formal files with data-collection forms were not created.

A total of 69 sites were included in the study. The sites collectively contained 425 buildings and a total of over 10,000 living units. A list of buildings surveyed is included in Table A.

\section{B. Survey methodology}

\section{Selection of data-collection format}

To ensure uniformity of data-collection, a common format for use by the BFRL investigation teams was needed. BFRL evaluated several existing data-collection forms and considered the option of developing a new form specifically for this project.

The data-collection form used by NAHB in their study of low-rise residential buildings was considered and rejected. The form, while appropriate for documenting the condition of simple wood-frame and masonry structures, did not provide a framework sufficient for documenting larger, more complex structures or structures built of other materials.

An Applied Technology Council (ATC) document, known as ATC-20 [1], which is the basis for most post-earthquake damage assessments performed by building inspectors, was also considered. This form is intended to be used in a very rapid screening process to separate buildings which are clearly hazardous from those which are clearly safe. This form was judged to be inadequate for documenting the more detailed examination that BFRL would be performing.

Very shortly after the earthquake, ATC initiated a project to collect data on the performance of buildings that had been seismically instrumented, and the adjacent buildings. BFRL reviewed the form used for this effort, and determined that it was well-suited to the needs of the HUD/BFRL study. With the permission of ATC and 
Table A - Site Identification

\begin{tabular}{|c|c|c|c|c|}
\hline NAME & ADDRESS & CITY & UNTTS & BLDGS \\
\hline Aliso Apts & 1 st \& Clarence Sts & L.A. & 336 & 22 \\
\hline Angelus Plaza N. & 200 S. Olive St. & L.A. & 330 & 1 \\
\hline Beverly Hills Senior. & $225 \mathrm{~N}$. Crescent Dr. & Bev.Hills & 151 & 1 \\
\hline Beverly Manor Apts. & 334 N. Normandie Ave & L.A. & 59 & 1. \\
\hline Beverly Towers & 1315 W. Beverly Blvd. & Montebello & 189 & 1 \\
\hline Casa de la Paloma & 133 S. Kenwood St. & Glendale..... & 167 & 1 \\
\hline Casa La Merced. & 140 N Montebello BIV & Montebello & 130 & 1 \\
\hline Castle Argyle Apts. & 1919 N. Argyle Ave. & L.A. & 98 & 1 \\
\hline Cathay Manor & $600 \mathrm{~N}$ Broadway & L.A. & 270 & 1 \\
\hline Estrada Courts & 8th Street & L.A. & 214 & 30 \\
\hline Estrada Couns Extension & Olympic Blvd \& Lorena Sireet & L.A. & 200 & 37 \\
\hline Fairtax Towers & 1222 N. Fairtax Ave. & w. Hollywd & 153 & 1 \\
\hline Fallbrook Square & 22851 VanOwen & Canoga Park & 16 & 1 \\
\hline Fickett Towers & 14801 Sherman Way & Van Nuys & 306 & 1 \\
\hline Foothills Gardens & 7687 Foothill Blvd. & Tujunga & 54 & 1 \\
\hline Geneva Plaza & $1437-4921 \mathrm{st}$ St. & Sta Monica & 100 & 1 \\
\hline Granada Gardens & 16700 Chatsworth St. & Granada H & 169 & 51 \\
\hline Harvard Plaza & 340 Harvard Rd. & Burbank & 150 & $\ldots$ \\
\hline Hollywood East Apts. & 4612 Lexington St. & Hollywood & 22 & 1 \\
\hline Hollywood East Apts. & 4829 Lexington Ave. & Hollywood & 43 & 1 \\
\hline Hollywood Fountain No. & 6217-47 Fountain Ave. & Hollywood & 88 & $\dddot{1}$ \\
\hline Hollywood Fountain So. & $6210-34$ Fountain Ave. & Hollywood & 73 & 1 \\
\hline Hollywood Knickerbocker & $1714 \mathrm{~N}$ Ivar Ave. & L. A. & 284 & 1 \\
\hline Hollywood Plaza & $1637 \mathrm{~N}$ Vine & L.A. & 153 & 1 \\
\hline Marina Manor "A" & 3401 Via Dolce & Manina del Rey & 112 & 1 \\
\hline Marina Manor " $\mathrm{B}$ " & 3401 Via Dolce & Marina del Rey & 71 & 1 \\
\hline Menorah House & 19206 Sherman way & Resoda & 51 & 1 \\
\hline Miramar Manor & 1422/1430 Miramar St. & L.A. & 49 & 2 \\
\hline Mountain View Estates & 10655 Tujunga Blvd. & L.A. & 23 & 1 \\
\hline Oakwood Toluca & 3600 Barham Blvd & L.A. & 1151 & 23 \\
\hline Oakwood Van Nuys & 15454 Sherman Way & Van Nuys & 390 & 4 \\
\hline Oakwood Woodl Hills E & 22122 Victory Blvd. & Woodland $\mathrm{H}$ & 883 & 26 \\
\hline Oakwood Woodl Hills W & 22222 Victory Blvd & Woodland $H$ & 446 & 17 \\
\hline Orchard Arms & 23500 Wiley Cyn Rd & Valencia & 183 & 4 \\
\hline Owensmouth Gardens & 6300 Owensmouth Ave & L.A. & 381 & $\dddot{6}$ \\
\hline Pacific Manor & $609 \mathrm{~N}$. Glenoaks Blvd & Burbank & 169 & $\ldots$ \\
\hline Palm & 959 Palm Ave & W. Hollywood & 127 & 1 \\
\hline Panorama View & 9222 Van Nuys Blvd. & Panorama & 87 & 3 \\
\hline Park Paseo & 123 S. Isabel St. & Glendale & 98 & 1 \\
\hline Parthenia Manor & 14906 Parthenia St. & Van Nuys & 89 & 6 \\
\hline Pledgerville Senior & 11060 Norris Ave. & Pacoima & 94 & 1 \\
\hline Plummer Park Apts. & 17051 Plummer St. & Northridge & 40 & 1 \\
\hline Ramona Gardens & Ramona Blvd \& Indiana St & 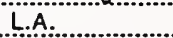 & 610 & 101 \\
\hline Reseda East & 18450 Ingomar st & Resoda & 70 & $\ldots . .1$ \\
\hline Reseda Manor & 7725 Reseda Blvd & Reseda & $40^{\circ}$ & 1 \\
\hline Roseda Park & 6505 Reseda Blyd. & Reseda & 156 & 2 \\
\hline Santa Monica Christ. & 12336 th St. & Sta Monica & 167 & 1 \\
\hline Sherman Park Apts. & 17960-64 Sherman Way & Reseda & 135 & 2 \\
\hline Simpson Saticoy & 7541 Simpson Ave & Resoda & 35 & 1 \\
\hline Sunland Park & 10836 Roycraft St. & Sun Valley & 120 & 14 \\
\hline Sunset Apts. $b$ & 4363 Lockwood Ave. & L.A. & 24 & 1 \\
\hline Sunset Apts. & 1023 N Coronado & L.A. & 18 & 1 \\
\hline Tujunga Gardens & 6643 Foothill Blvd. & Tujunga & 54 & 1 \\
\hline Union Towers & 455 Union Ave & L.A. & 200 & 1 \\
\hline Uptown Manor & 1354 Nonh Harper & W. Hollywd & 60 & 1 \\
\hline Vadehra III & 668 S. Rampart & L.A. & 44 & 1 \\
\hline Vadehra III b & 246 S. Kenmore & L.A. & 30 & 1 \\
\hline Vadehra IV & 5846 Carlton Way & L.A. & .72 & 1 \\
\hline Vadehra Va & 1848 Gramercy St. & L.A. & 40 & 1 \\
\hline Vadehra Vb & 1848 Gramercy St. & L.A. & 40 & 1 \\
\hline Vadehra VI & 711 S. Rampart & L.A. & 39 & 1 \\
\hline Vadhera IV b & 5607 La Mirada & L.A. & 40 & 1 \\
\hline Villa Park Merridy & 3748 w. 9ih St. & L.A. & 20 & 1. \\
\hline Villa Raymond & $455 \mathrm{~N}$ Raymond Ave. & Pasadena & 23 & 1 \\
\hline Vista (VPH Adult Ret. Ctr.) & 15211 Sherman Way & Van Nuys & 84 & 1 \\
\hline West Valley Towers & 14650 Sherman Way & Northridge & 97 & 1 \\
\hline Westminster Towers & $112.7 t h$ Si. & Sta Monica & 285 & ......... \\
\hline William Meade & North Main \& Ann Sts & L.A. & 449 & 24 \\
\hline Wilshire Villa North & 1933 N. Bronson Ave. & L.A. & 88 & 1 \\
\hline
\end{tabular}


the concurrence of HUD, this form was selected for use. (The form is included in Appendix A.) An additional benefit of using this form is that the collected data is in a format that can be directly compared to the information collected by ATC.

The form uses the common differentiation of building components into structural, nonstructural, and equipment categories. Structural components and systems are those elements of a building, such as beams, columns, and diaphragms, that resist the gravity and lateral loads. Nonstructural elements and systems are not designed to be part of the load resisting system. Nonstructural elements can be exterior cladding, interior non-loadbearing partitions, and other functional or decorative building components such as ceilings, parapets, porches, and so on. Equipment includes heating, cooling, plumbing, electrical and similar systems.

By using the form as a guide, the investigator collects both general and detailed data. Basic information such as number of stories, number of living units, dates of design and construction, overall plan dimensions, and foundation type are recorded. The building is categorized by Model Building Type (MBT) using the basic 15 model building types that are used for categorization throughout the series of FEMAproduced technical documents on seismic issues in existing buildings, for example, Rapid Visual Screening of Buildings for Potential Seismic Hazards, [2]. Vertical and plan irregularities, such as discontinuous columns or open building fronts, are noted, along with the pre-earthquake condition of the building. The material used for typical nonstructural elements such as exterior cladding, interior partitions, and ceilings, is noted.

In completing the form, the investigator must make judgements on several broad issues, such as the approximate amount of time needed to restore building function. The overall damage state for structural elements, nonstructural elements, equipment, and contents is noted, using damage states ranging from 1 for no damage ( 0 percent) to 7 for total damage (100 percent) (See Table B). These damage states were originally defined in ATC-13 [3], and have been used in other studies as well [4].

The form aids the investigator in recording a detailed description of the damage. For each major building direction (e.g. north-south and east-west) the investigator records damage states and percent of systems affected for numerous specific items concerning vertical and horizontal elements, connections, foundation, and equipment. For moderate and heavy damage states, further information is recorded on a separate sheet.

\section{Team operations}

Twelve people were involved in performing the study. Several steps were taken to ensure consistent collection, recording, and interpretation of information.

Prior to departure for the Los Angeles area, all team members jointly reviewed methods for identifying building types and interpreting damage, and familiarized themselves with the data collection form. Slides of damaged buildings that had been 
taken by NIST personnel in the days immediately following the earthquake were used in exercises to familiarize all personnel with the data collection method, and to establish a common understanding of damage levels.

In the field, inspections were performed by teams of at least two people. Evening meetings were held each day at which teams reported on their observations, using instant photographs to illustrate key points. These daily reviews allowed the investigators to adjust their rating of damage states to conform to a uniform scale, to acquire additional insight into particularly interesting or challenging technical issues, and to share suggestions on dealing with non-technical issues. The pairings of investigators were regularly rotated to maximize the consistency of the evaluations between the teams.

\section{Field data collection}

Inspections were scheduled with a request that a building manager, engineer, or other knowledgeable person be available to escort the investigation team. The building was examined from the exterior and interior, and all known damage sites were documented. At sites consisting of a large number of living units and/or additional undamaged buildings, not all units/buildings were inspected. Non-living space, such as basements, attics, utility rooms, and stairwells, received particular attention. These spaces, when they lack architectural finishes such as ceilings and wall paneling, allow investigators to directly view the structure of the building. In instances where building plans were available, these were reviewed to verify observations about structural types, dimensions, and other items of interest.

Documentation consisted of three parts: instant photographs, slides, and written information (including the completed data collection form and field notes, sketches, and measurements of key items of interest). The instant photographs were immediately labeled and added to the field file for the site. These photographs were used in nightly reviews of findings. A limited number of instant photographs were taken at each site. Slides were used for more thorough visual documentation.

\section{Data assessment techniques}

As described below under Observations and Assessments, five of the sites selected by public housing authorities for inspection by the BFRL team did not show evidence of having been damaged by the earthquake. These sites were removed from the sample prior to analysis. Thus, although the field inspections covered 69 sites with 464 buildings and 10,893 living units, the data analyses covered only 64 sites, which consisted of 211 buildings containing a total of 9,430 living units.

Upon completion of the field data collection phase, key aspects of the collected information were entered into a database. Because the sample was intentionally biased towards damaged structures, damage distribution in the entire building population in the affected area will not be the same as the distribution in this sample. However, the data can be grouped, sorted, and examined to illuminate qualitative 
correlations among parameters. The parameters selected for study included: structural system, number of stories, age, and distance from epicenter. These parameters were compared to numerical ratings of damage to structural systems, nonstructural systems, and equipment.

The numerical damage ratings were determined during field observation, using a damage scale originally used in ATC-13 [3].

Table B: ATC-13 Damage Scale Used in this Study

\begin{tabular}{|c|ll|}
\hline $\begin{array}{c}\text { Damage } \\
\text { Rating }\end{array}$ & \multicolumn{2}{|c|}{$\begin{array}{c}\text { Relative Amount of } \\
\text { Damage }\end{array}$} \\
\hline \hline 1 & None & $0 \%$ \\
\hline 2 & Slight & $0 \%-1 \%$ \\
\hline 3 & Light & $1 \%-10 \%$ \\
\hline 4 & Moderate & $10 \%-30 \%$ \\
\hline 5 & Heavy & $30 \%-60 \%$ \\
\hline 6 & Major & $60 \%-100 \%$ \\
\hline 7 & Destroyed & $100 \%$ \\
\hline
\end{tabular}

Techniques used in the attempt to identify trends included production of sorted data tables, generation of scatter plots, and regression analysis. In scatter plots, the two parameters of interest, for example building age and structural damage state, become the axes of a graph (see fig. 29 for examples of scatter plots). Each site becomes a single point on the plot, corresponding to the appropriate age and numerical damage state. If strong trends exist, they usually become apparent in the grouping or clustering of the plotted points. For example, if a strong trend existed linking building age and structural damage, such that younger buildings suffered less damage and older buildings suffered more damage, the scatter plot would show a distinct clustering of the points along the diagonal. A uniform distribution of points throughout the graph area indicates that no trends exist.

A regression analysis was performed for each of the pairs of parameters that were examined (see fig. 29), except for comparisons involving structural type. The correlation coefficient was calculated to determine if there was any statistically valid correlation between the parameters. Because structural type is a qualitative rather than a quantitative variable, regression analysis is not possible for that parameter. For these comparisons, averages of damage states for each of the structural types were calculated and compared. 
These analyses represent a first cut examination of the data, evaluating the influence of only a single variable at a time (e.g. age or number of stories). The number of data points in the sample did not justify multi-variable analysis (considering the combined effects of parameters in attempting to identify trends). 


\section{OBSERVATIONS AND ASSESSMENTS}

\section{A. General}

Typical characteristics of multi-family residential buildings are multiple interior partitions and frequent openings in walls. The massive amount of wall surface such systems create is vulnerable to cosmetic, but nonetheless expensive-to-repair, damage. Rectilinear door and window openings create stress concentrations at each corner, making these locations particularly vulnerable to cracking (fig. 1). The damaged multi-family residences observed by the BFRL team following the Northridge earthquake typically had cracks in plaster or gypsum board interior wall surfaces, especially at the corners of door and window openings and along vertical and horizontal joints in wall sheathing (fig. 2). Less common was damage to the structural system.

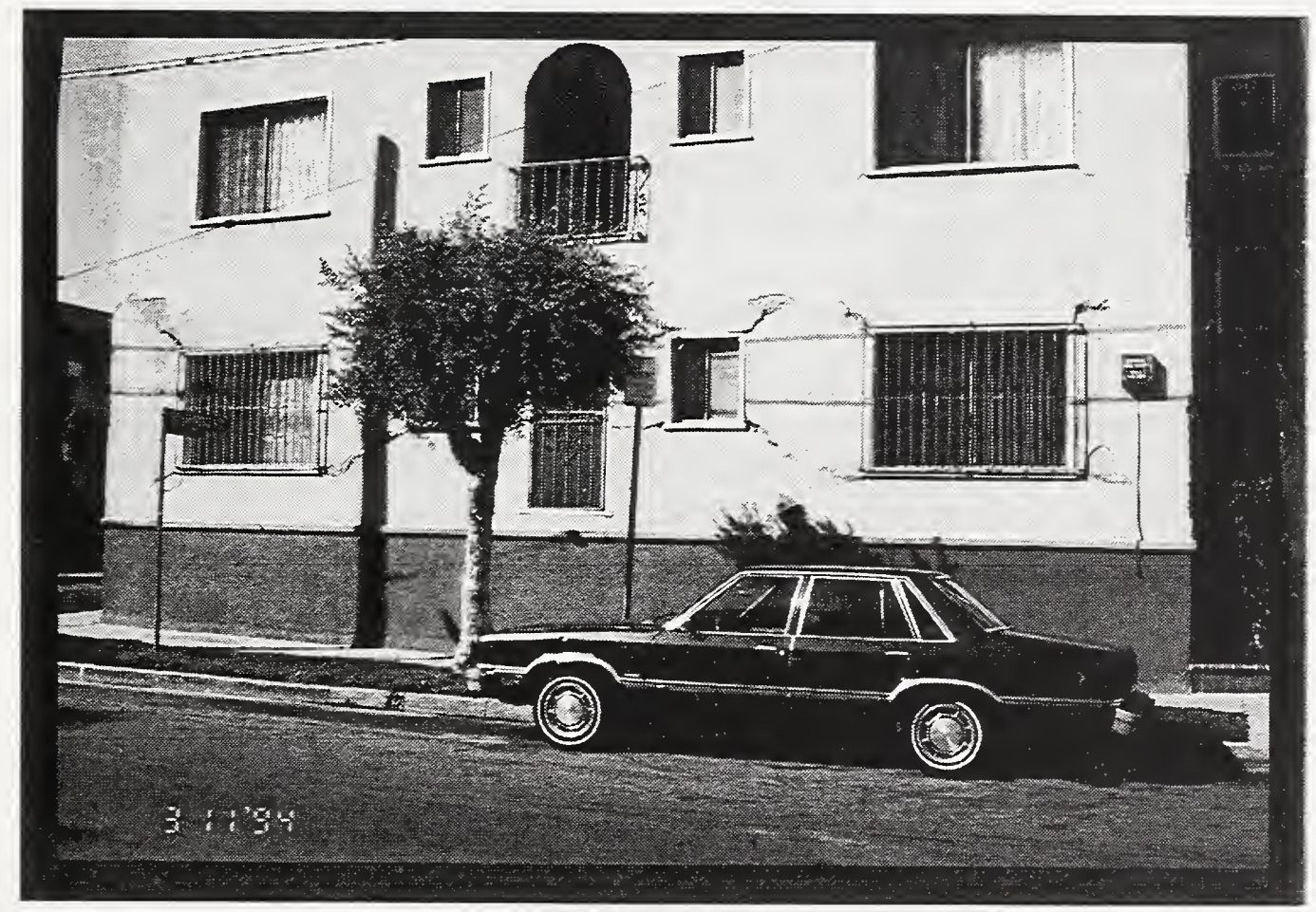

Figure 1 Residential construction is characterized by multiple door and window openings. The corners of these rectilinear openings create stress concentrations, making these locations particularly vulnerable to cracking.

Non-structural systems do not contribute to the seismic resistance of a structure, therefore the decision to repair this type of damage is based on considerations other than the seismic stability of the structure. Any damage to a building's structural system can be assumed to reduce the building's original seismic-resistant capacity. However, the system may still have enough residual strength to resist future earthquakes without collapsing. Therefore, the need for repair of structural damage must be evaluated on a case-by-case basis. 


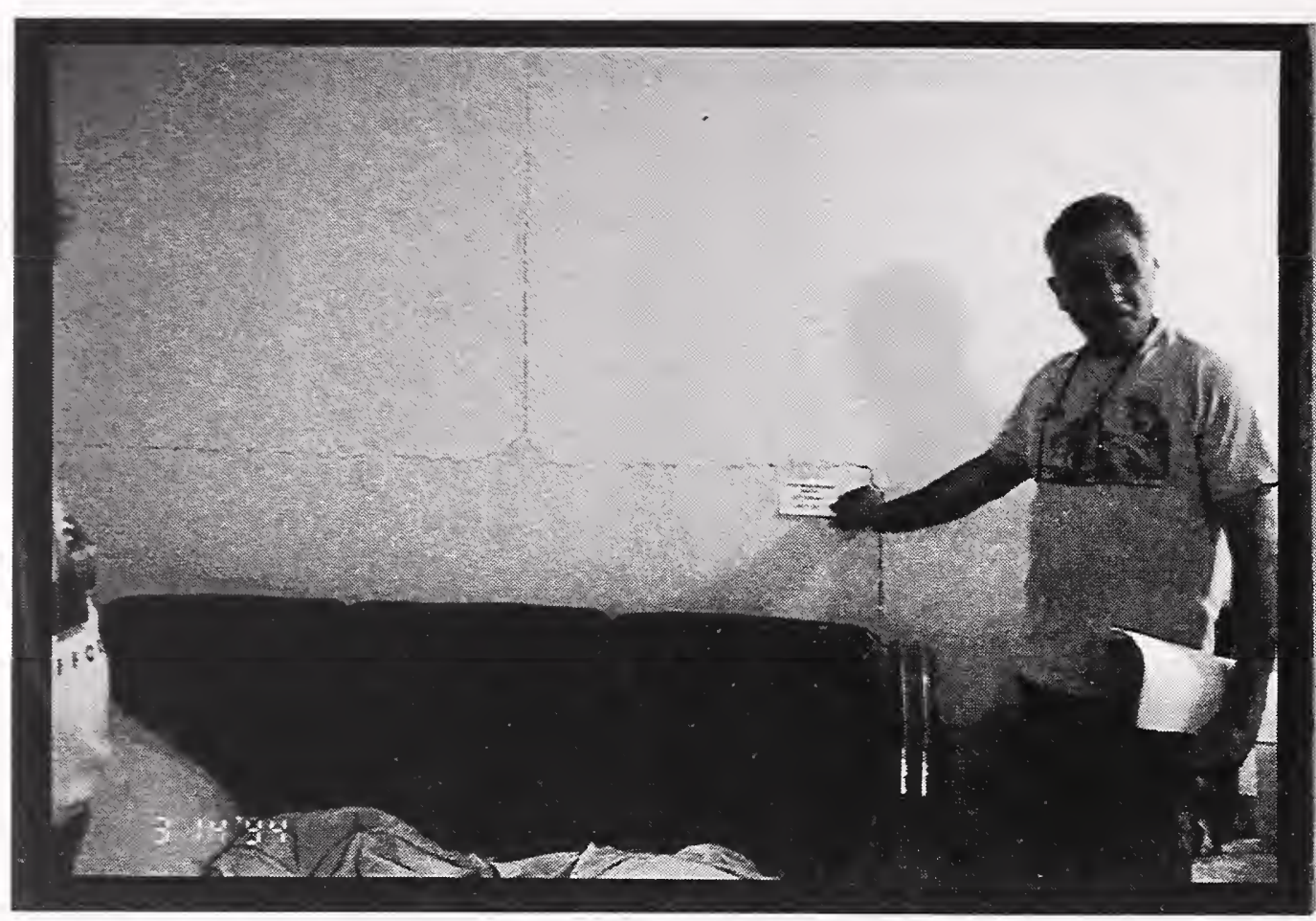

Figure 2 Typical nonstructural damage caused by the Northridge earthquake in residential buildings included cracks in interior partition walls, such as these horizontal and vertical cracks at the edges of the gypsum wallboard panels.

Damage to equipment, such as water heaters or air conditioning units, occurred at slightly more than half the sites. The damage was usually minor, such as equipment shifting off supports. Occasionally, these movements led to collateral damage, such as gas or water leaks from ruptured pipelines. An example occurred at Fickett Towers, a 12-story concrete shear wall building about $8 \mathrm{~km}$ from the epicenter. A 130,000 liter (35,000 gallon) water tank on the roof shifted, severing the attached water pipes (fig. 3). The resulting discharge of the tank contents caused water damage to walls, ceiling, and carpet at all levels.

Five of the 14 sites selected by local public housing authorities for inspection by the BFRL team did not have damage that could be clearly attributed to the earthquake. Three of the sites had reinforced masonry buildings; two had wood frame structures. These sites were removed from the database prior to analysis, leaving 211 buildings at 64 sites in the final set of data.

HUD can potentially influence the construction of public housing projects, which are newly built under HUD programs. In other HUD programs, many buildings are preexisting when they enter the program, so HUD can have no influence on their basic design and construction. All HUD-assisted buildings, including public housing projects (according to local public housing officials), must meet the building regulations of the local jurisdiction. For the buildings in this study, when only the clearly earthquake-damaged sites were considered, there was no difference discernable in performance of buildings in public housing projects and buildings at other HUDaffiliated sites. 


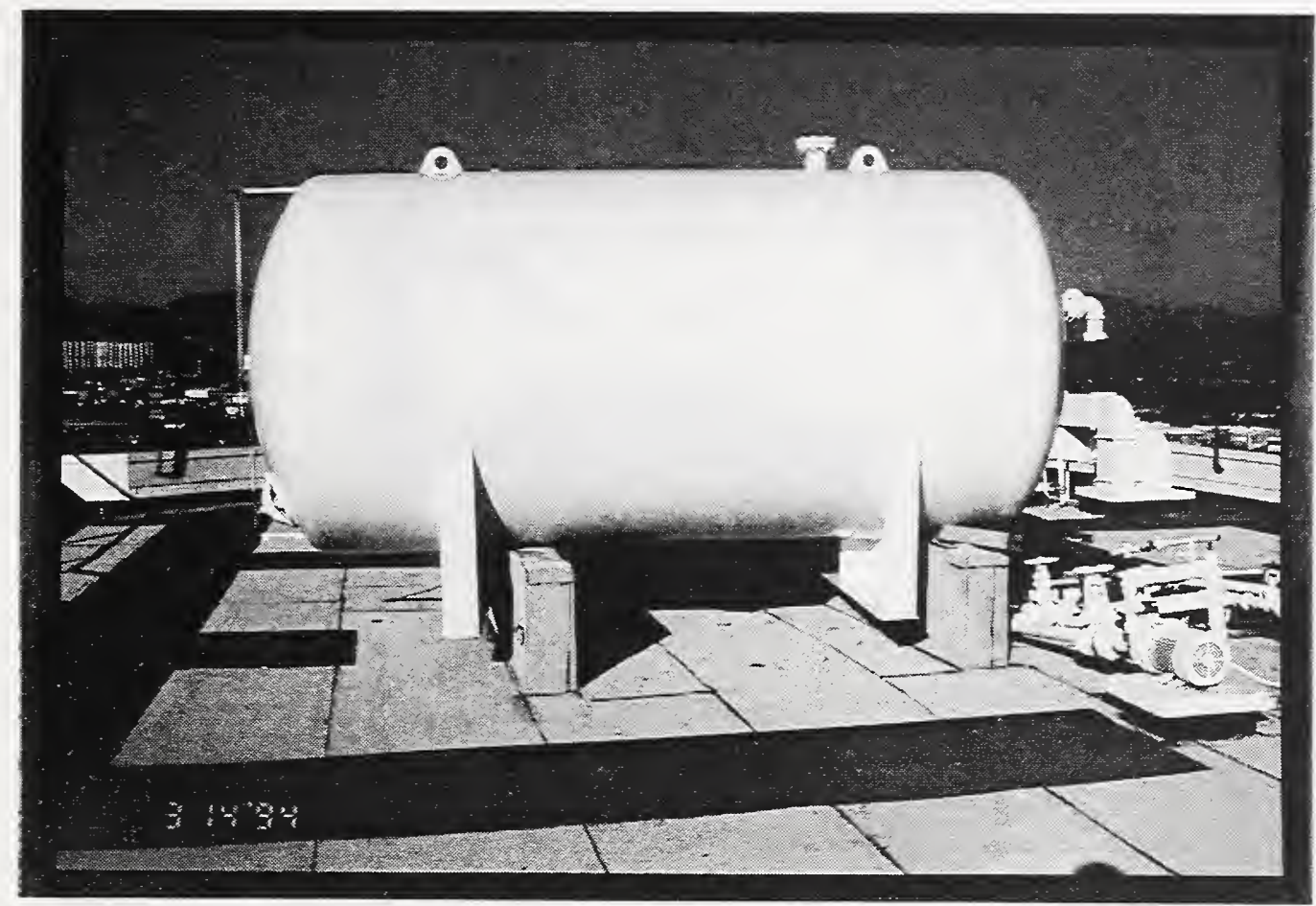

Figure 3 Movement of equipment, such as this 130,000 liter rooftop water tank at Fickett Towers, caused collateral damage in some cases. When this tank dropped from its supports, rupturing a water pipe, water damage to the building interior resulted.

Of the over 200 buildings in the sample at the 64 damage sites, only two buildings were damaged by fire. These both occurred at Grenada Gardens, a complex of woodframe two-story apartment buildings located about $6.5 \mathrm{~km}$ from the epicenter. Most of the 51 buildings at this particular site were heavily damaged (see the section below on wood frame buildings for a more detailed discussion). The fires were reportedly caused by ruptured gas lines.

Buildings at 8 of the 64 sites in the sample were permanently or temporarily unusable because of damage. (Buildings which were vacated for only a few hours or days pending inspection are not included in this number.) Two of the uninhabitable sites, labeled Vadehra IV and Vadehra $\mathrm{Vb}$, each consisted of a single unreinforced masonry building about 70 years old that had been condemned and was under demolition at the time of the inspection (fig. 4). A third unreinforced masonry building of the same vintage, Uptown Manor, suffered damage to a few of the top-story units, which had been evacuated (fig. 5). The majority of the 60 living units in the building remained usable. A fourth unreinforced masonry building, Vadehra IVb, had been yellow tagged by the city, meaning that the building was judged to be potentially hazardous and should not be occupied until a more detailed analysis showed the building was safe or the damage was repaired. About four percent of the 285 living units in Westminster Towers, a concrete frame building about $20 \mathrm{~km}$ from the epicenter, were unusable due to damage. One site with a single wood frame building, Sherman Park Apartments, suffered damage requiring 10 out of 135 living units to be evacuated for one week while repairs were made. At another site with a single wood frame building, Sunset E, the city had yellow tagged the building, requiring evacuation of 


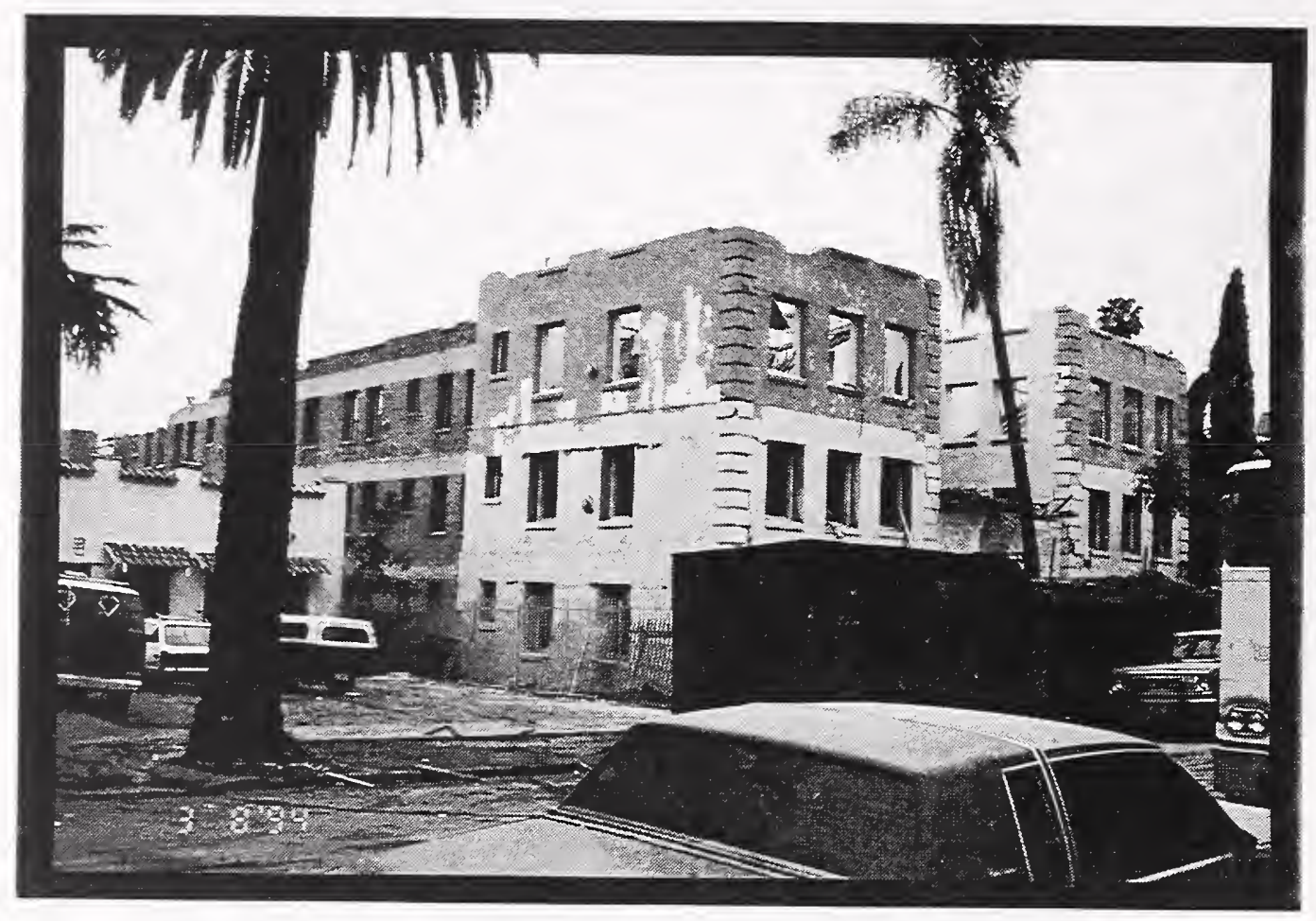

Figure $4 \quad$ Vadehra IV, an unreinforced masonry building, was condemned because of extensive earthquake damage. When this photograph was taken, the top story had already been removed by the demolition team.

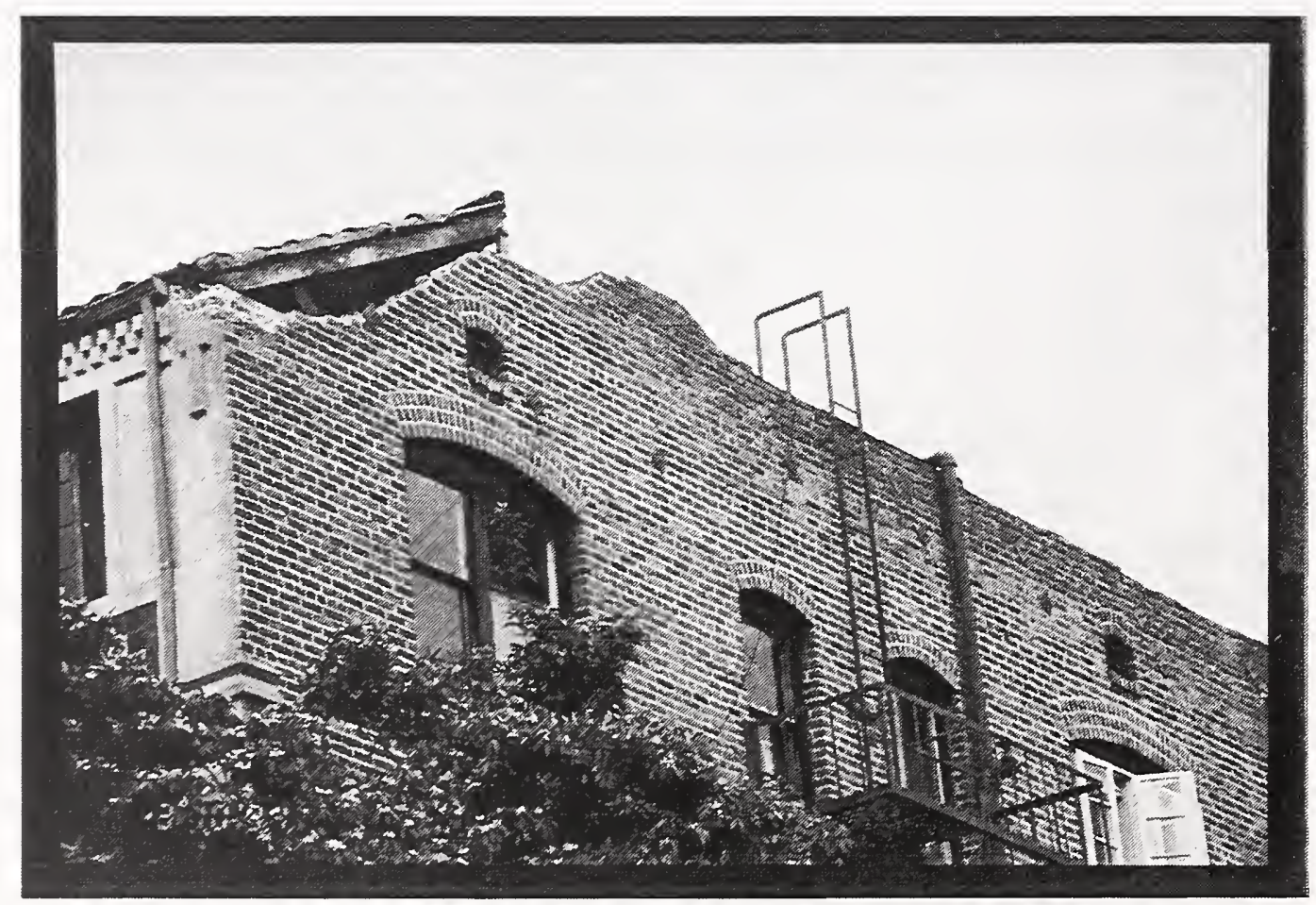

Figure 5 Loss of portions of the parapet and wall at Uptown Manor, an unreinforced masonry building, caused several living units to be declared unsafe by city inspectors. 
all 18 units pending more thorough evaluation (fig. 6). By far the largest number of unusable units in the survey occurred at Granada Gardens, a site of 51 wood frame buildings about $6.5 \mathrm{~km}$ from the epicenter. At this site, 120 of the 169 living units had to be evacuated due to structural damage.

In total, approximately 300 of the over 9,000 living units at damage sites, or about three percent of the total, were rendered unusable due to damage. Note that this percentage relates to the number of units at that were uninhabitable at sites with damage. It is not a measure of the percent of total available living units that became uninhabitable. Note that 97 percent of damaged living units remained inhabitable.

Systematic collection of information on injuries was not included in the scope of this project, but investigators noted anecdotal information when it was available. The BFRL team found that only two fatalities were associated with the buildings in the sample, both heart attacks, one at Castle Argyle Apartments and one at Sherman Park Apartments. At no site were the investigators told of major injuries. However, many residents told of being temporarily trapped in their apartments by jammed doors (fig. 7). Broken glass and fallen contents produced hazards in many buildings. The physical hazards produced by these impediments were exacerbated by the lack of illumination due to the loss of electricity.

Two of the buildings in the sample were instrumented with strong motion recorders that were reported to have been activated by the earthquake. This provides an opportunity for future in-depth study of the behavior of these buildings. The instrument at 16-story Cathay Manor, about $33 \mathrm{~km}$ from the epicenter, was installed and maintained by Kinemetrics Inc. of Pasadena, California. The instrument at 10story Pacific Manor, about $21.5 \mathrm{~km}$ from the epicenter, is part of the California Strong Motion Instrumentation Program, and is identified as CSMIP Station No. 24385.

Almost all of the unreinforced masonry buildings in the sample were observed to have been rehabilitated prior to the earthquake using bolts, outfitted with steel plate washers, that pierced the masonry at the lines of the floors and roof (fig. 8). Parapet bracing was also ob-served (fig. 9). The City of Los Angeles has a mandatory seismic rehabilitation ordinance for unreinforced masonry buildings constructed prior to 1934 that applies to apartment buildings that have five or more living units. Surrounding jurisdictions do not have similar mandatory requirements. In some instances the Los Angeles ordinance, known colloquially as Division 88, requires the addition of new cross walls, supplementary vertical supports, and other strengthening actions in addition to the commonly required through-bolts and parapet bracing. While the BFRL investigators did note the presence of through-bolts and parapet bracing, they did not determine whether the rehabilitation effort conformed with the requirements of Division 88.

Of the buildings that were constructed of materials other than unreinforced masonry, investigators found none that clearly had been rehabilitated prior to the earthquake. 


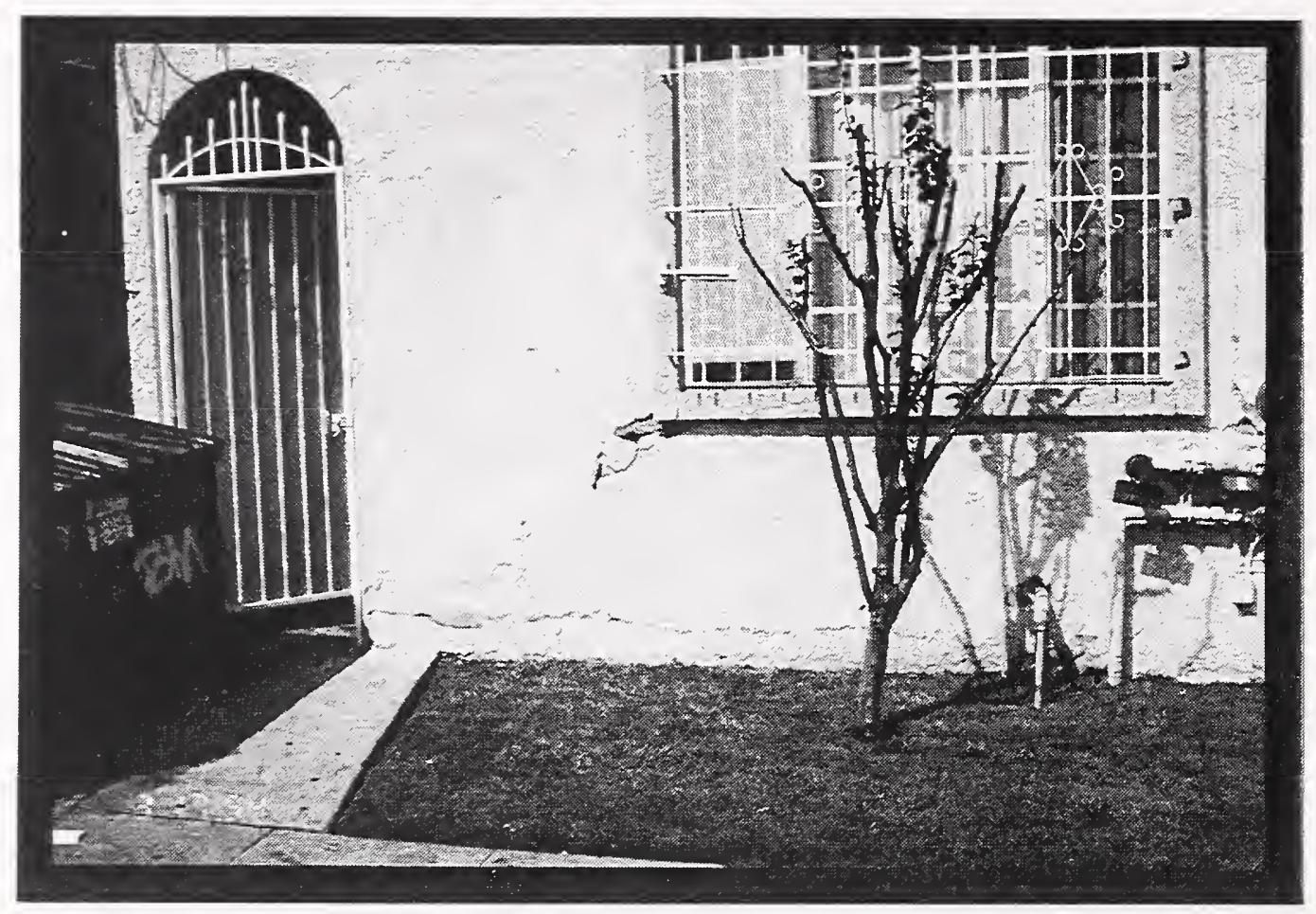

Figure $6 \quad$ Sunset Apartments E, a three-story wood-frame apartment building, was declared by city inspectors to be potentially unsafe pending more detailed evaluation (yellow tagged). Note the horizontal crack in the stucco at the foundation line, the vertical crack to the right of the window, and the diagonal crack and buckled area of stucco at the lower corner of the window.

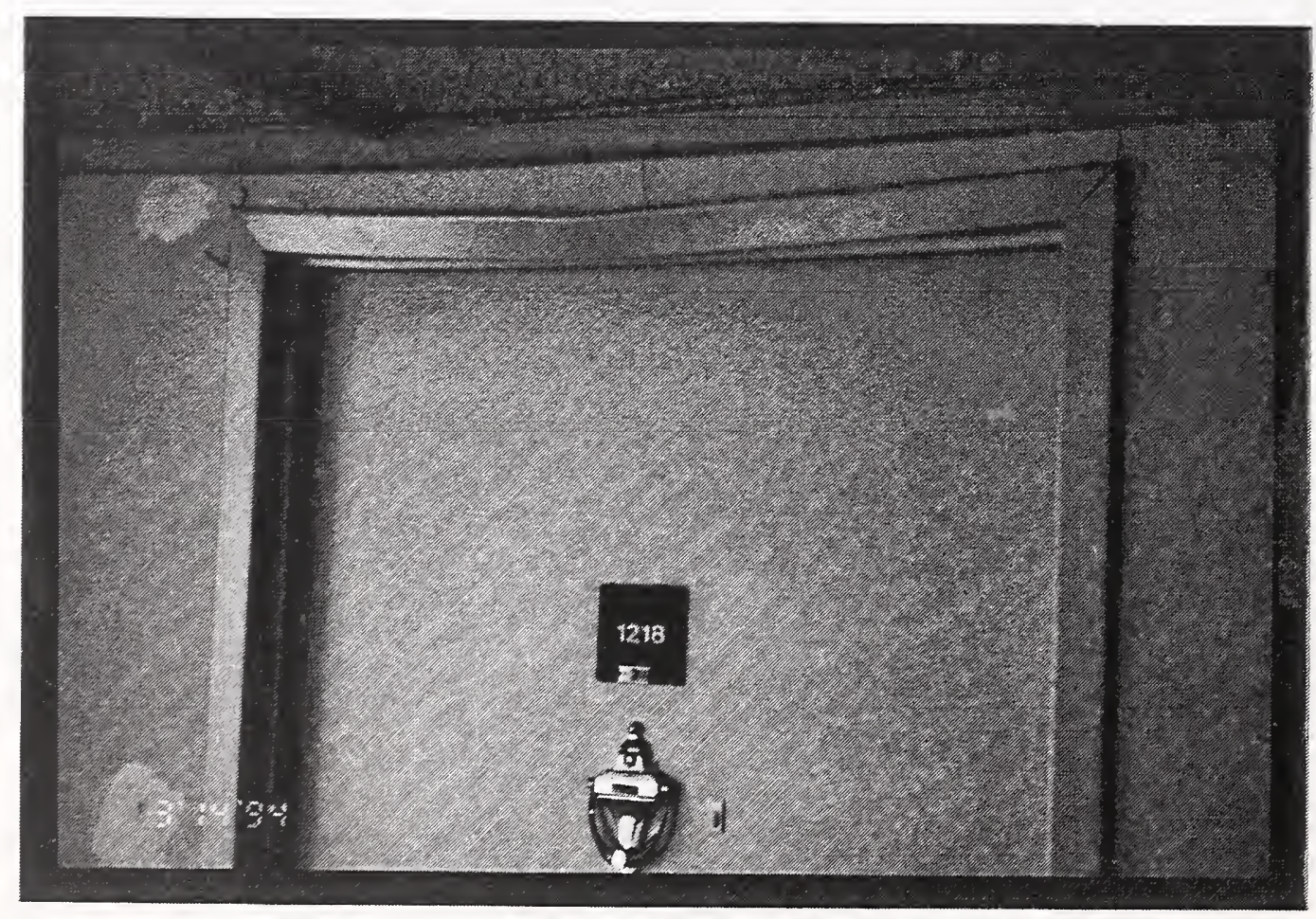

Figure $7 \quad$ Buckled door frames occurred in several buildings. 
Figure 8 Pre-earthquake seismic rehabilitation of unreinforced masonry buildings typically included face plates and through-bolts anchoring the walls to the floor and roof joists.
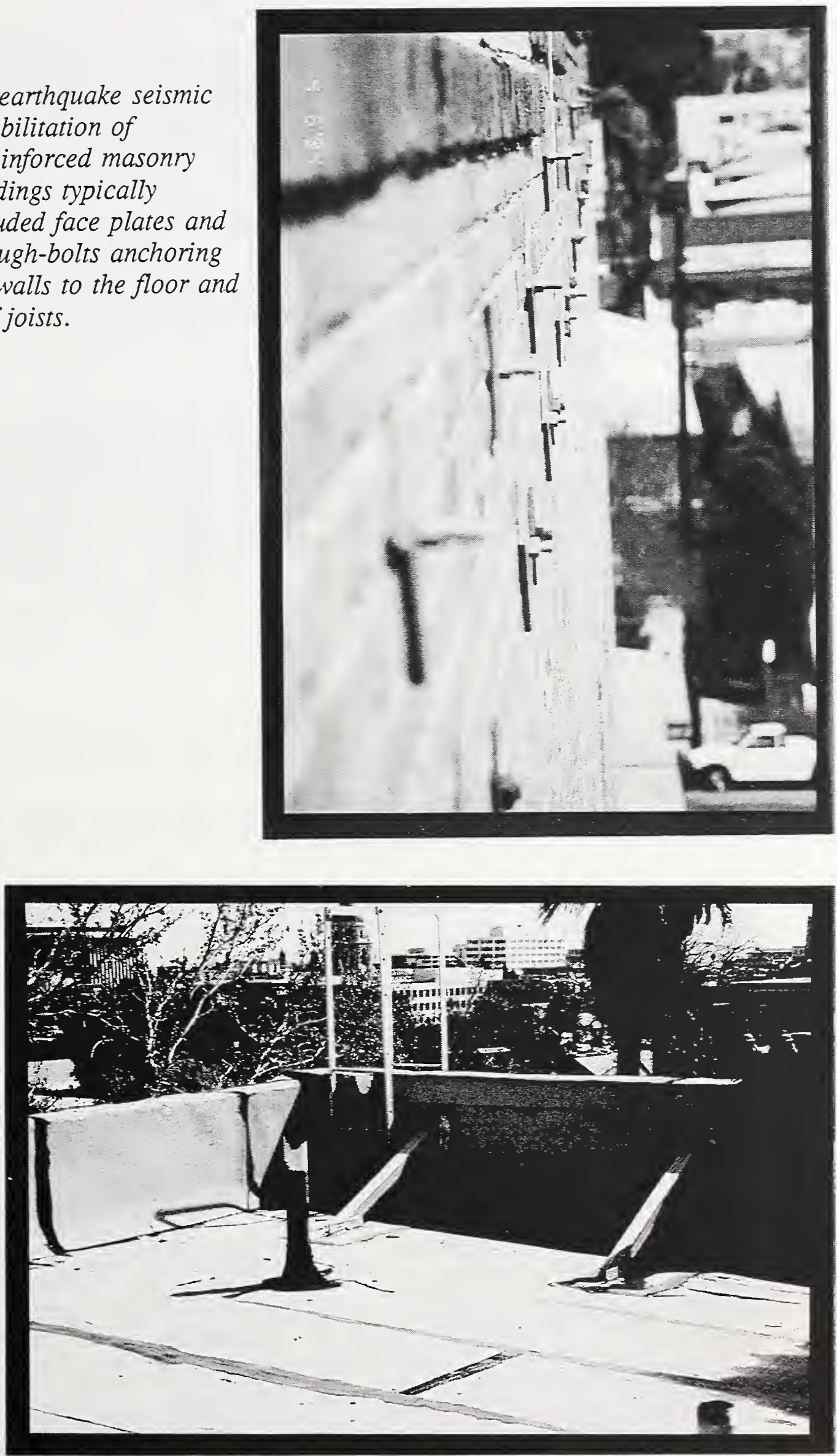

Figure 9 Unreinforced masonry buildings that had been rehabilitated prior to the earthquake typically had had their parapets braced. 
There were no steel frame buildings in the candidate group of damaged buildings. One of the buildings in the inventory was originally misidentified as a steel frame structure. The building manager had stated that Cathay Manor, a 16-story building about $33 \mathrm{~km}$ from the epicenter, had a steel frame. When the BFRL investigators arrived at the site, the plans of the structural system were not available. The investigators found no evidence to suggest that the building was a steel frame building. Their observations led them to conclude that the building was a concrete shear wall building, and it has been classified as such in this study (fig. 10). The building suffered cracks in the shear walls and nonstructural walls similar to those observed in concrete buildings.

Only two of the damaged buildings were reinforced masonry. However, the dearth of examples of damaged buildings with steel or reinforced masonry systems in the sample does not necessarily imply that these types of structural systems performed particularly well during the quake. Because a reliable estimate of numbers of damaged and undamaged buildings is not available partitioned into structural type, it is impossible to determine whether the small number of damaged buildings with these structural systems indicates good performance by these type of buildings, or whether it merely reflects a small number of buildings in the housing inventory with these systems.

Common types of damage observed are described below, grouped by building structural system. Figure 11 illustrates the distribution in the sample of structural systems, by site and by number of living units.

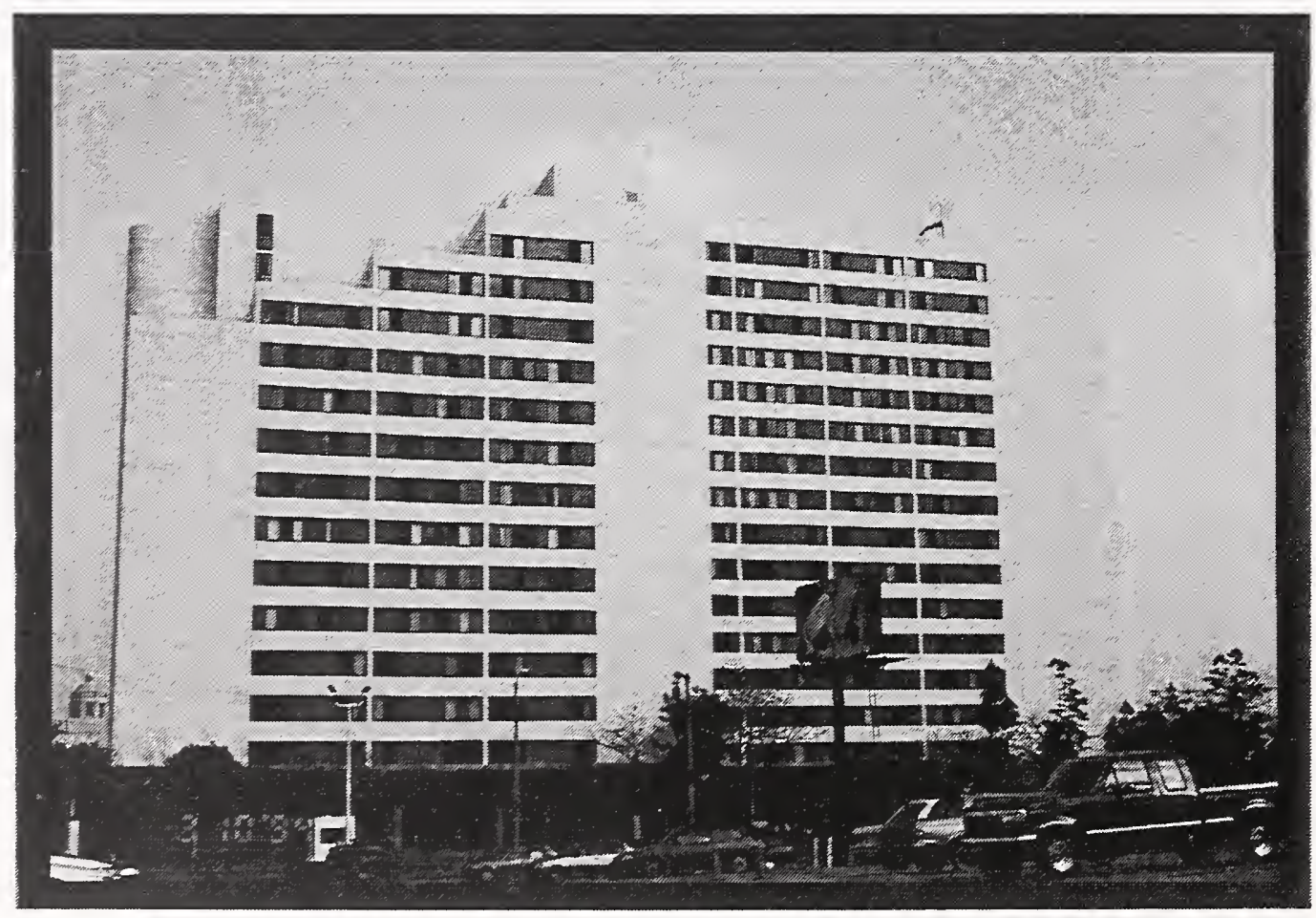

Figure 10 Cathay Manor, a 16-story building about $33 \mathrm{~km}$ from the epicenter, was determined to be a concrete shear wall building. 


\section{Distribution of Structural Types \\ By Site}

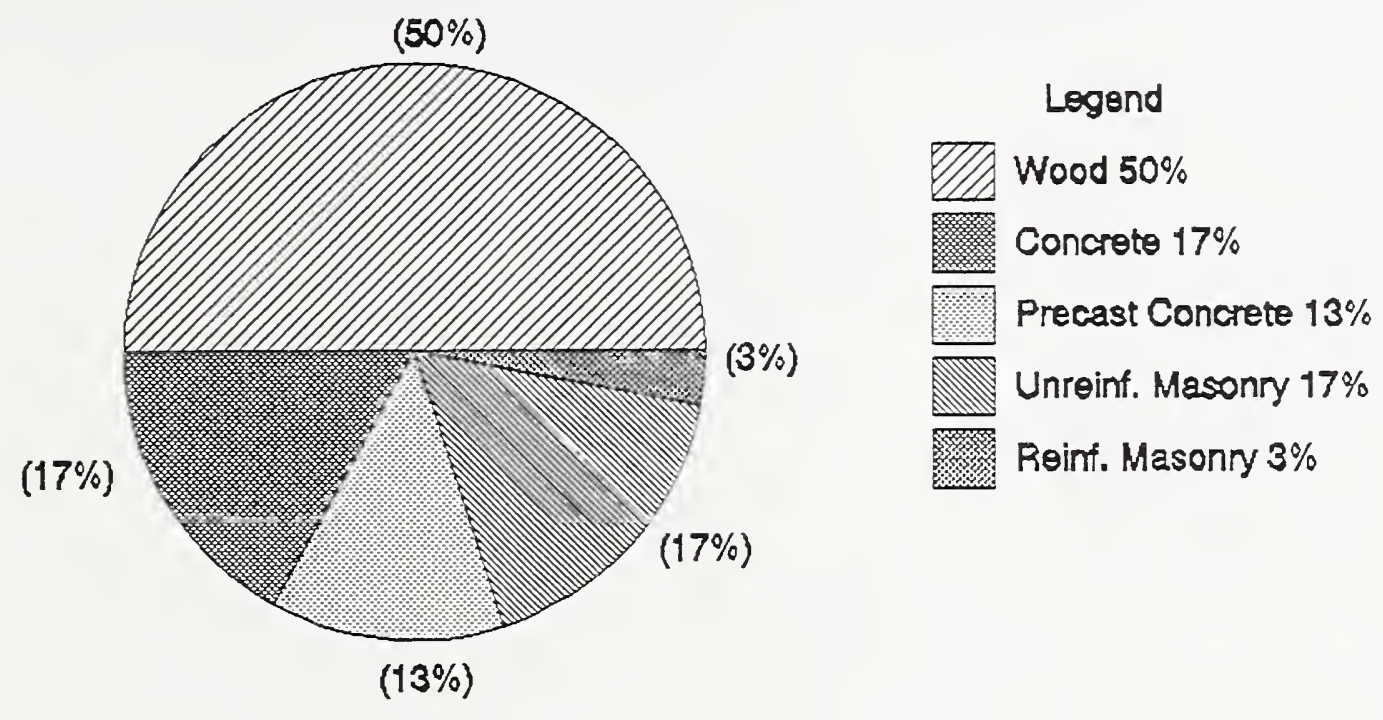

\section{Distribution of Structural Types}

\section{By Units}

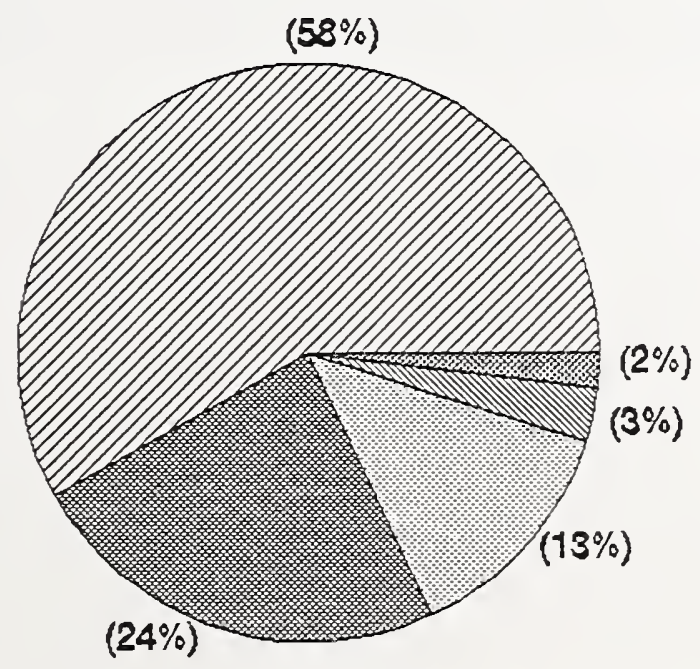

Legend

Wood $58 \%$

Concrete $24 \%$

Precast Concrete 13\%

Unreinf. Masonry 3\%

Reinf. Masonry $2 \%$

Figure 11 Above, distribution of structural types in the buildings in the sample when tabulated by site; below, distribution of structural types by number of living units. 


\section{Concrete Buildings}

Eleven damaged concrete buildings were visited (not including precast concrete buildings, which are discussed later in this report). Two had concrete moment resisting frames, seven were concrete shear wall buildings, and two were concrete frame buildings with masonry infill walls.

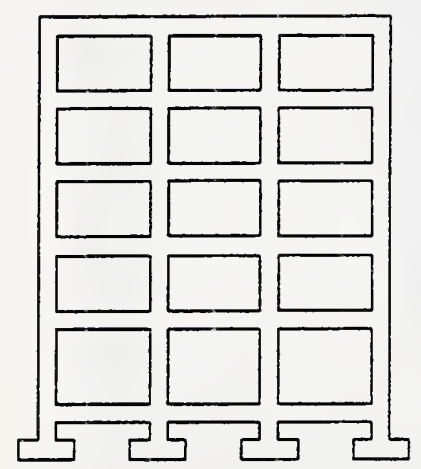

moment-resisting frame

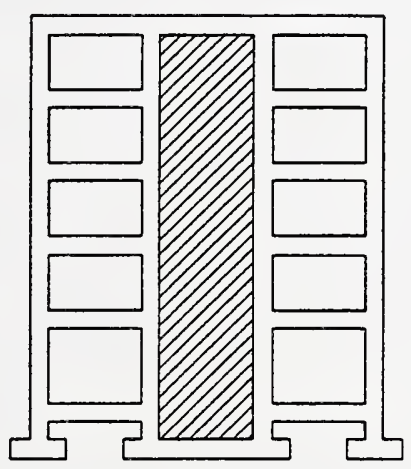

shear wall

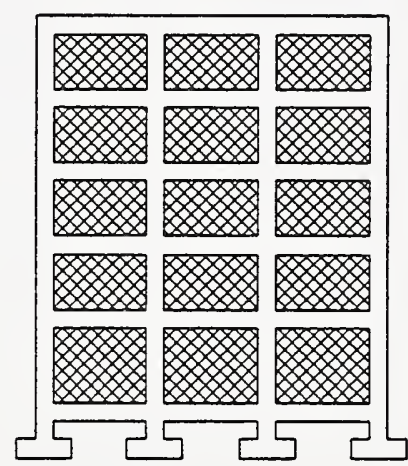

frame with masonry infill

Common structural damage included diagonal cracks in shear walls and columns (figs. 12, 13, and 14). Two of the shear wall buildings, Santa Monica Christian, a 13-story building about $22 \mathrm{~km}$ from the epicenter, and Fickett Towers, a 12-story building about $8 \mathrm{~km}$ from the epicenter, had classic diagonal cracking in the coupling beams between shear walls (figs. 15 and 16). (Coupling beams often occur in the areas of concrete between stacks of door or window openings in shear walls.) Only one of the ten buildings, Westminster Towers, a 17-story building about $20 \mathrm{~km}$ from the epicenter, had any units that were uninhabitable because of damage.

Common nonstructural damage included cracks in surfaces of interior walls, both along horizontal and vertical lines at joints in the gypsum board and diagonally at corners of door and window openings. Cracks in external surfaces such as stucco were also common. Separation of external cladding occurred at some of the buildings. At the Hollywood Knickerbocker, a 63-year old concrete frame building about $23.5 \mathrm{~km}$ from the epicenter, the non-structural masonry facade displayed Xcracking between some of the windows (fig. 17). Movement of mechanical equipment occurred at roof levels in some of these buildings. At Westminster Towers, the concrete building with the most extensive nonstructural damage, many of the bathtubs had shifted $10-20 \mathrm{~mm}$ from their original positions, and shower tiles had been dislodged. 


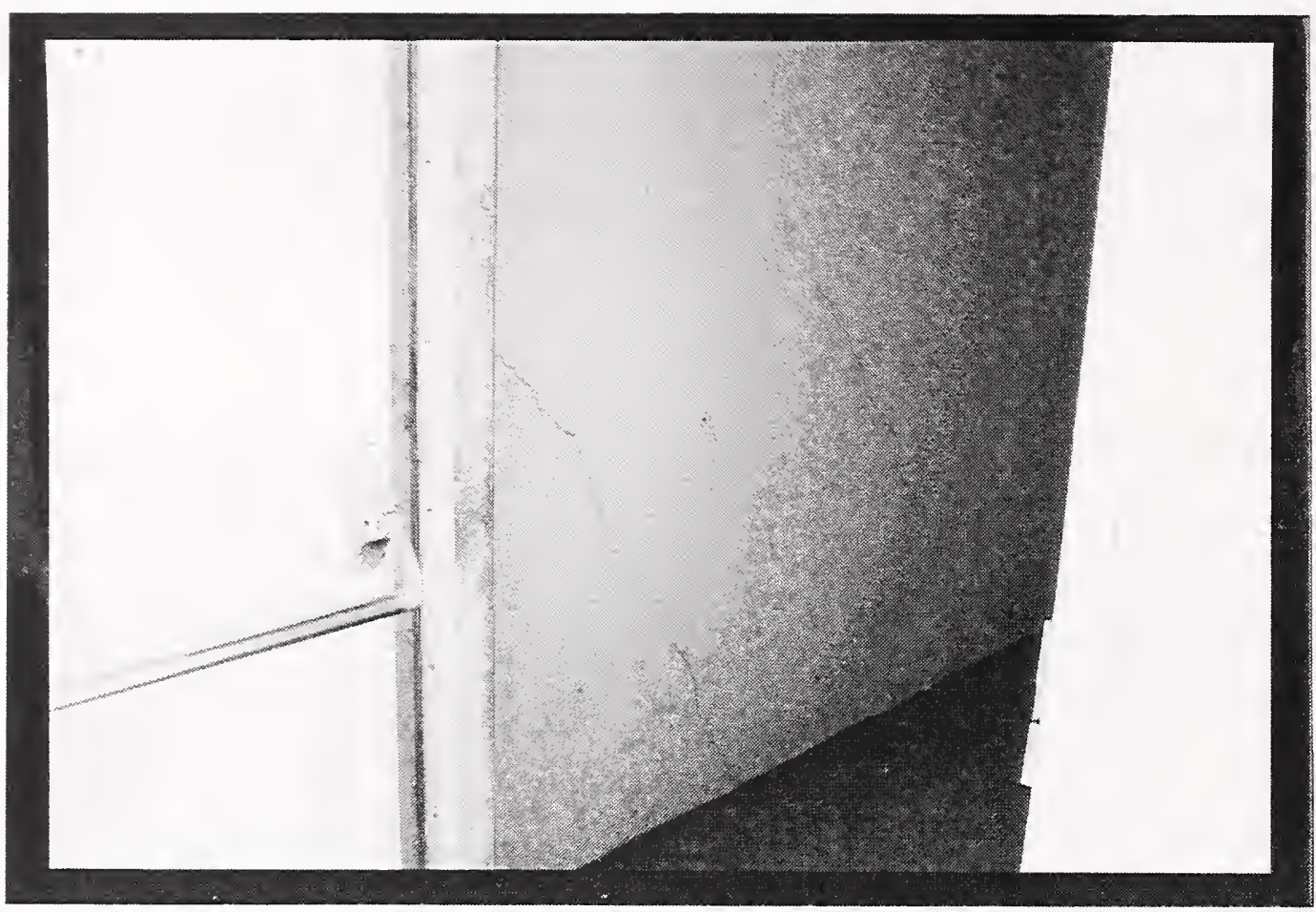

Figure 12 Structural damage in concrete buildings included diagonal cracks in shear walls, such as these in Beverly Towers.

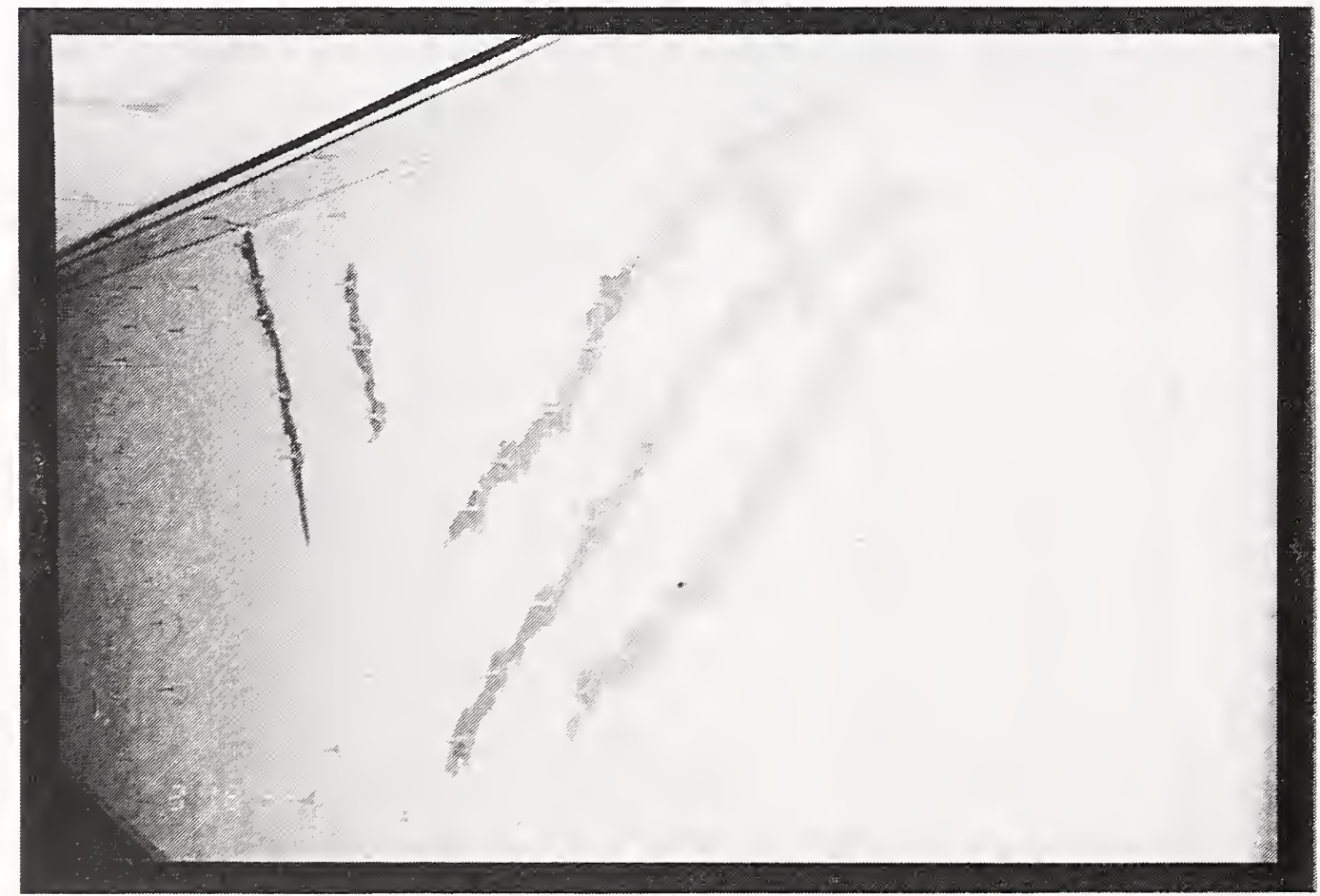

Figure 13 Some of the diagonal cracks in concrete shear walls were already under repair at the time of this study. At Santa Monica Christian apartments, cracks were being repaired using an epoxy injection technique. 


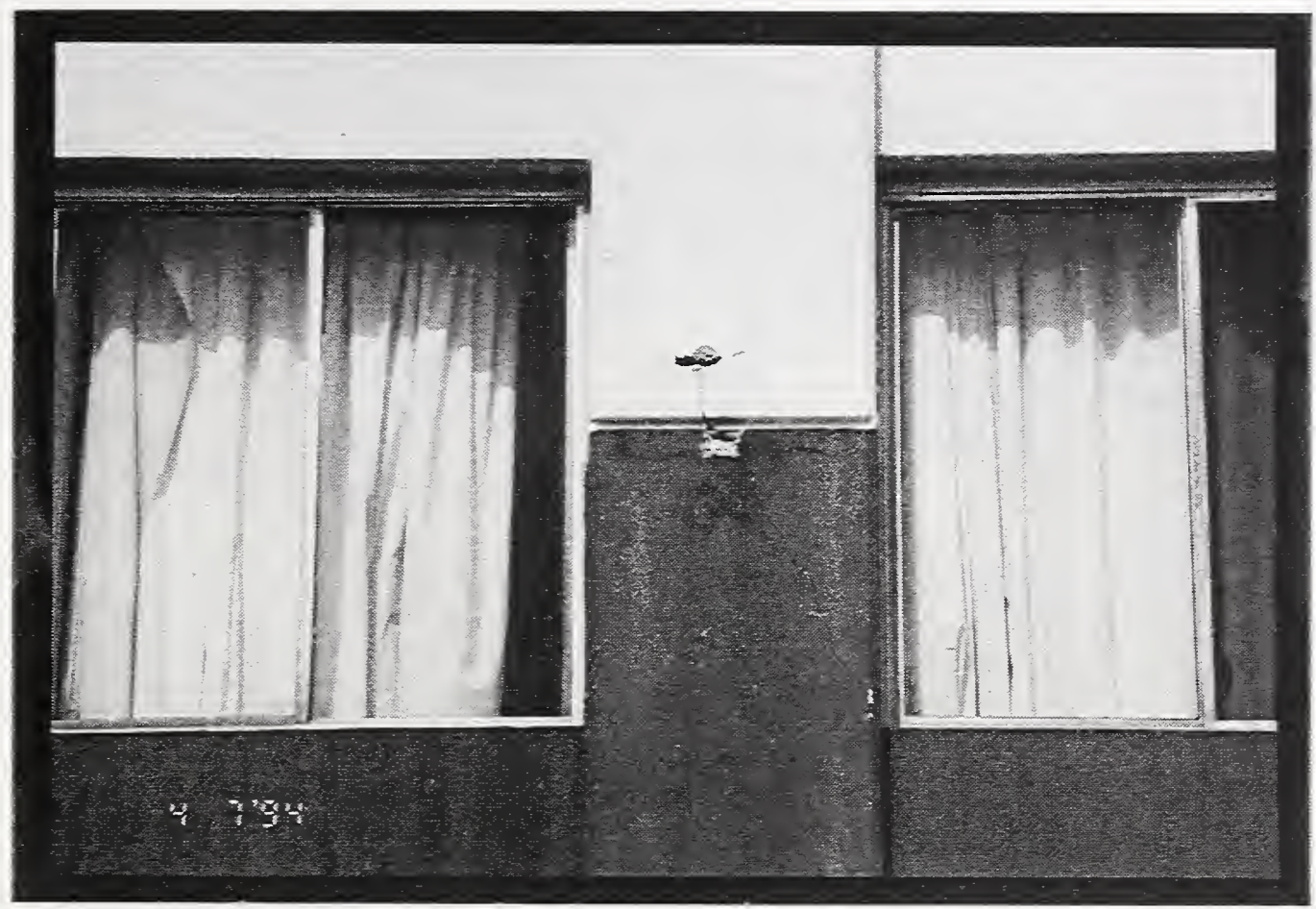

Figure 14 In concrete frame buildings, such as Westminster Towers, diagonal cracks in concrete columns were observed.

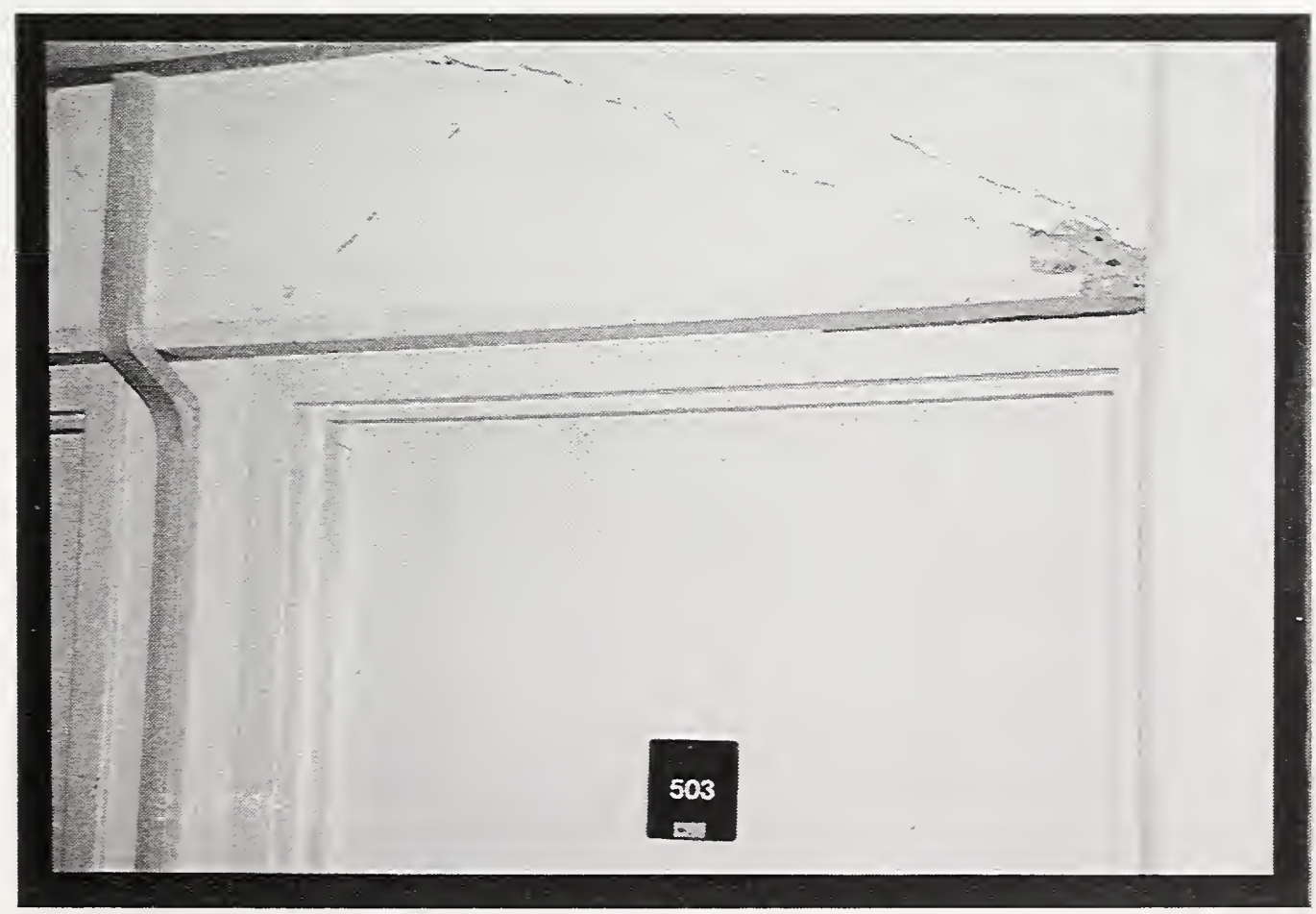

Figure 15 Diagonal cracks between openings in shear walls, such as these above a doorway at Fickett Tower, are examples of commonly observed earthquake damage in concrete shear wall buildings. 


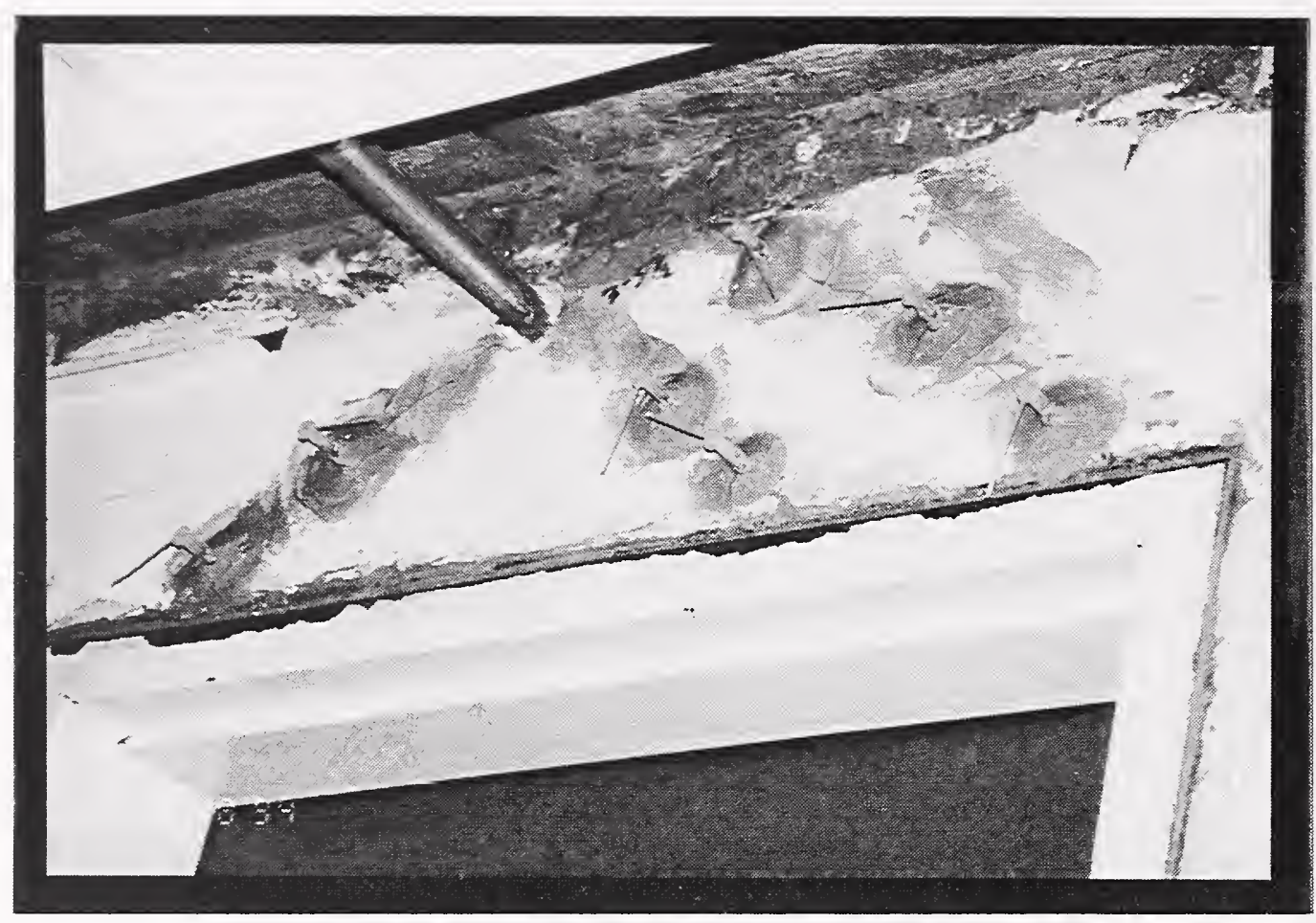

Figure 16 Diagonal cracks in the portions of the concrete shear wall above the doors at Santa Monica Christian apartments were being repaired using expoxy injection. This photograph shows the injection ports.

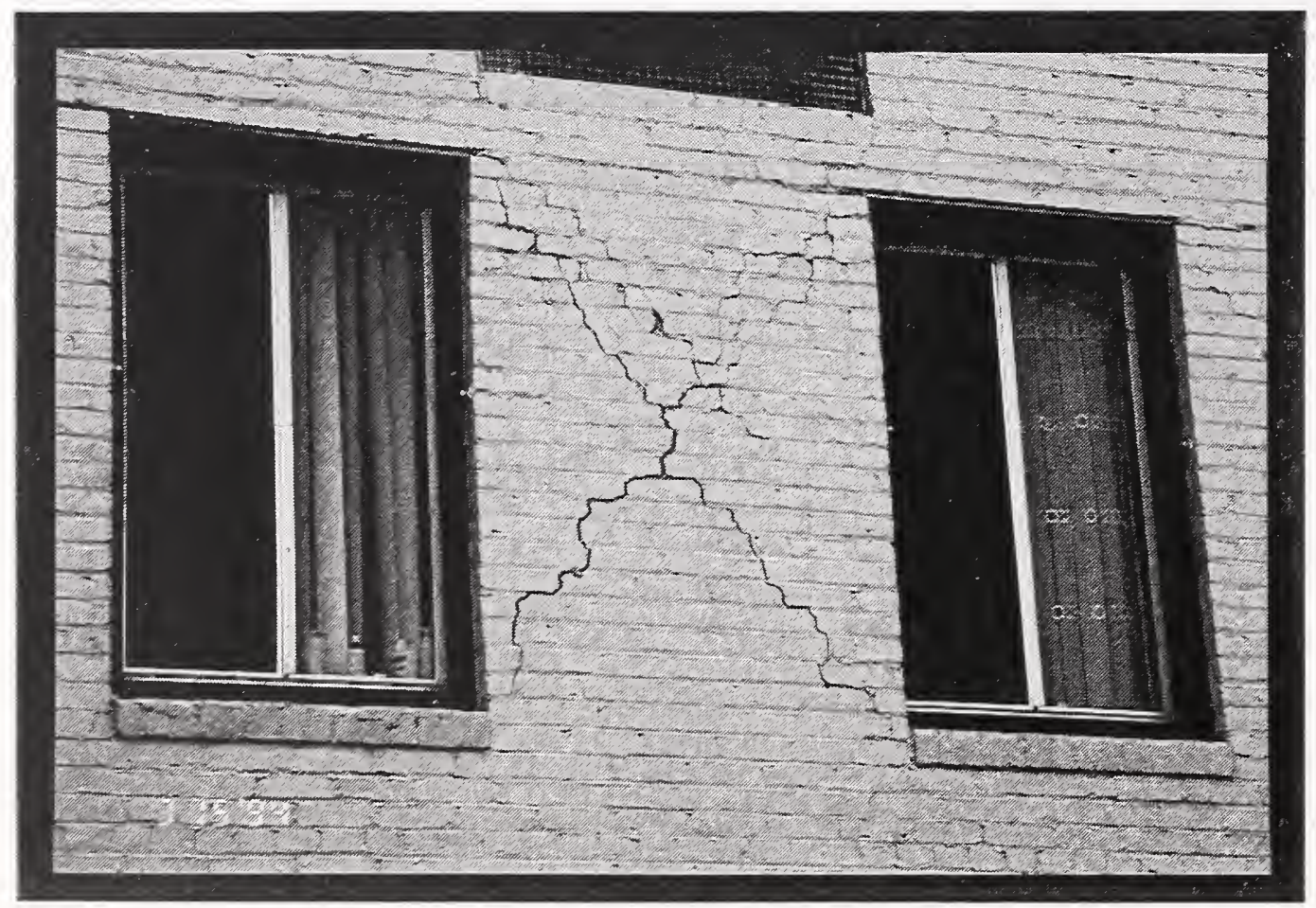

Figure 17 The masonry facade between windows at the Hollywood Knickerbocker, a 63-year old concrete frame building, displayed earthquake-induced $X$ cracking. 


\section{Precast Concrete Buildings}

Eight precast concrete buildings were inspected. Interior partitions had typical diagonal cracks at door and window openings. Cracks and separation at the intersection of interior gypsum board/wood stud walls and precast concrete walls occurred in many locations. Structural damage included minor cracking in shear wall panels and stairwell floor planks.

Three buildings had badly damaged rooftop stairwell enclosures. At Geneva Plaza, an 8story building about $21.5 \mathrm{~km}$ from the epicenter, both penthouse stairway covers had been badly damaged and were demolished by the time the inspection team reached the site. The two penthouse stairwell enclosures at Casa de la Paloma, a 9-story building about $28 \mathrm{~km}$ from the epicenter, had been offset from the precast panels below them, and were quickly demolished. The offset at the top of the penthouses relative to their base was reported to have been about $150 \mathrm{~mm}$. At Park Paseo, an 8 -story building about $28 \mathrm{~km}$ from the epicenter, the single penthouse stairway enclosure had experienced similar displacement, resulting in a permanent lean. This penthouse had also been demolished by the time of the inspection. 


\section{Reinforced Masonry Buildings}

Five sites had reinforced masonry buildings. Three of the sites were from the stock of public housing; the sites had been selected for inspection by local public housing officials. The three public housing sites (Aliso Apartments, Ramona Gardens, and William Meade Apartments), each about $35 \mathrm{~km}$ from the epicenter, had 147 buildings

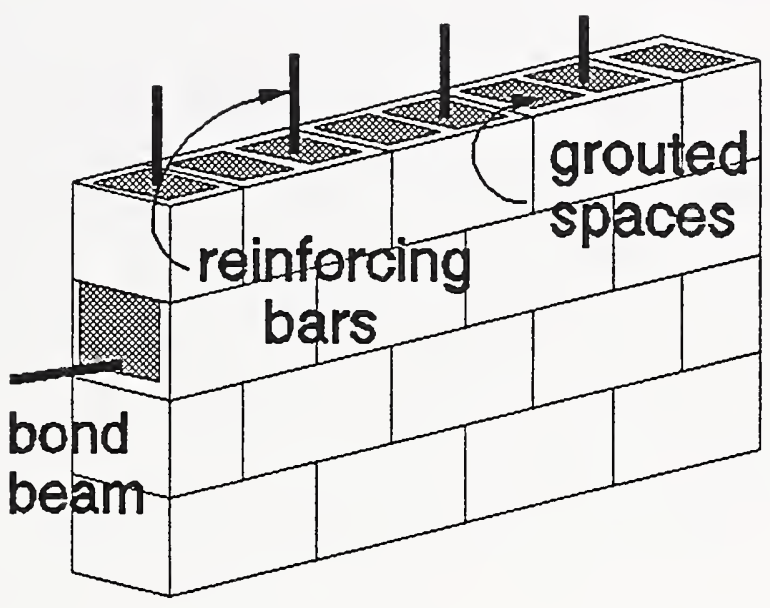
among them. Although these sites were apparently on the local public housing administration's list of earthquakedamaged facilities, the BFRL inspection teams found no evidence of earthquake damage at the three sites. Minor cracking was observed in the masonry in some locations but it appeared to be unrelated to the earthquake.

The other two sites had one building each. Casa La Merced is a 5-story building about $46 \mathrm{~km}$ from the epicenter which suffered only hairline cracks to interior nonstructural wall surfaces and no damage to structural or mechanical systems. Pledgerville Senior Citizens Villa is a 6-story building about $13 \mathrm{~km}$ from the epicenter that suffered vertical cracks in the walls near the base of the door openings (fig. 18).

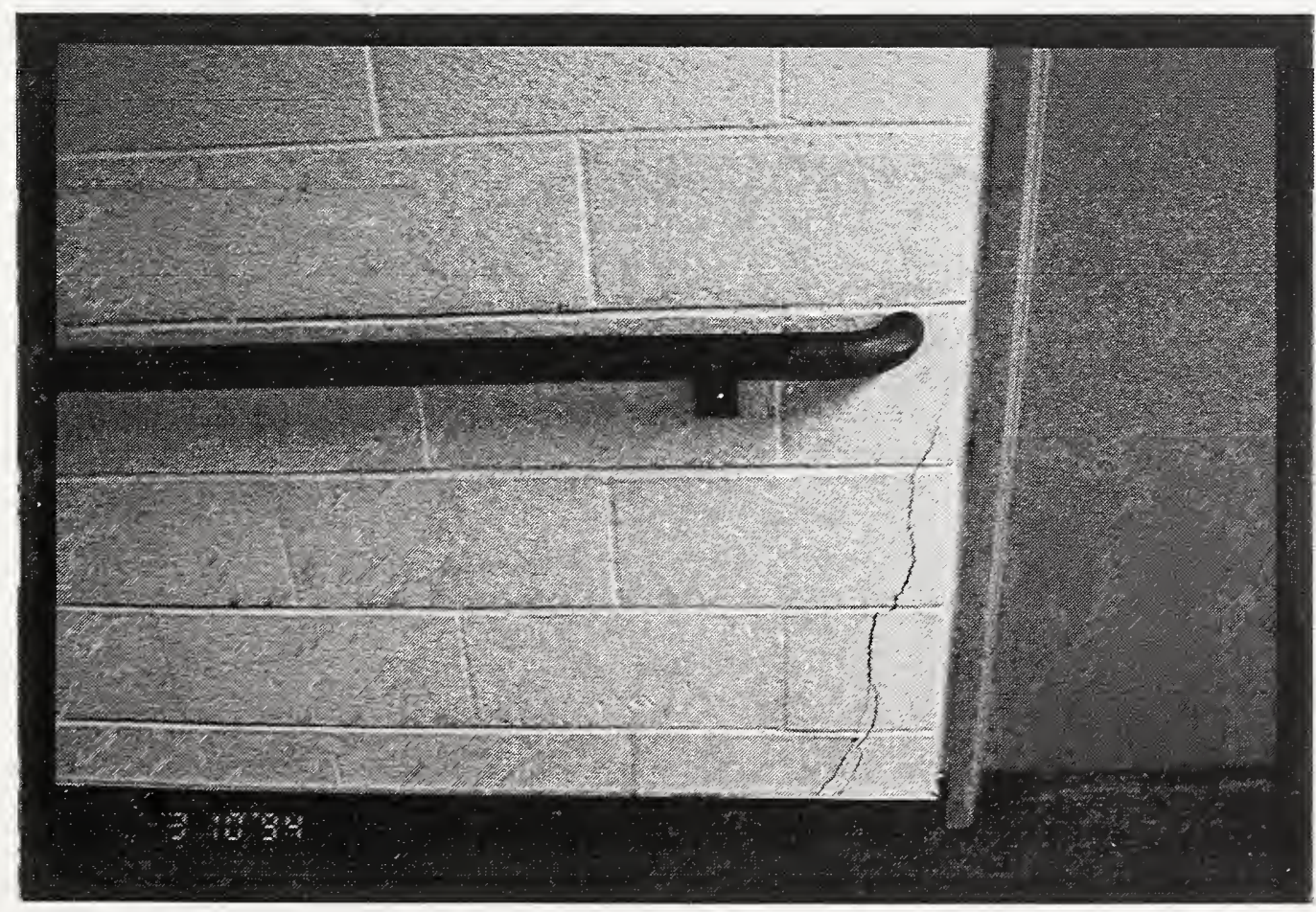

Figure 18 At Pledgerville Senior Center, a 9-year old reinforced masonry building about $13 \mathrm{~km}$ from the epicenter, inclined vertical cracks were observed adjacent to door openings. 


\section{Unreinforced Masonry Buildings}

Ten unreinforced masonry buildings were in the sample. Precise ages for most of these buildings were not available, but most were estimated to be around 70 years old. All were more than $20 \mathrm{~km}$ from the epicenter. Two of the buildings, Vadehra IV and Vadehra $\mathrm{Vb}$, were so badly damaged that they were already under demolition by the time the BFRL team reached the site (figs. 19 and 20). In contrast, two other unreinforced masonry buildings of similar vintage, each $28 \mathrm{~km}$ from the epicenter, (Vadehra IIIb and Villa Park Merridy, fig. 21), suffered no structural damage at all and only moderate nonstructural damage. The rooftop wood frame elevator penthouse on Vadehra IIIb was racked and twisted, causing damage to its stucco cladding (fig. 22), but the operation of the elevator was not affected. All four of these buildings had earthquake bolts at the lines of the floors and roofs.

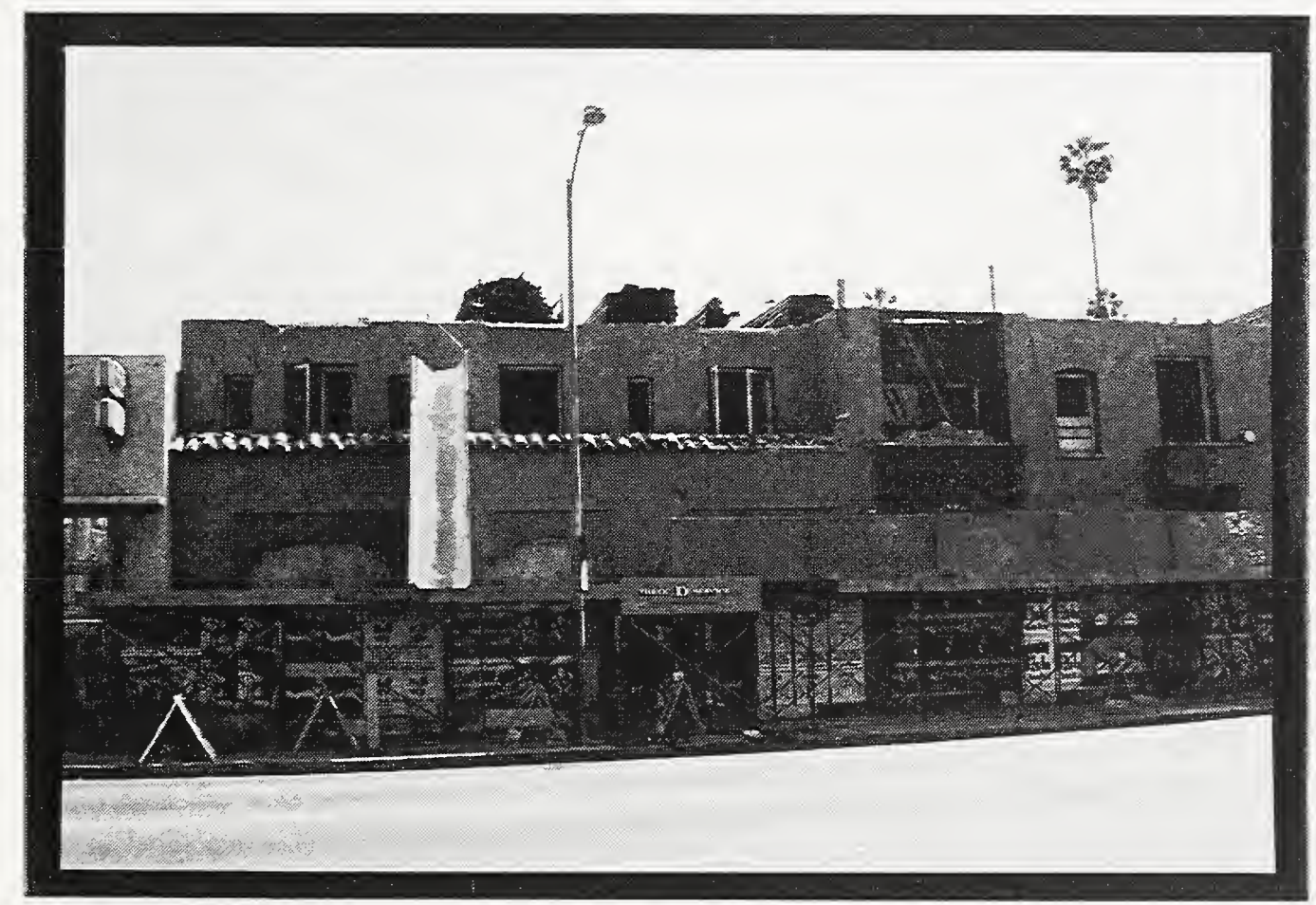

Figure 19 Vadehra $\mathrm{Vb}$, an unreinforced masonry building, was already under demolition at the time of this study. The top floor of this four story building had already been removed at the time this photograph was taken. 
The condition of the most badly damaged buildings in this category could not be accurately assessed because they were already partly demolished when the team reached the site. However, neither had collapsed. A 70-year old four-story building about $25 \mathrm{~km}$ from the epicenter (Vadehra IVb) had been yellow tagged by the building department, because of potentially hazardous damage. The building, with a T-shaped floor plan, had badly cracked exterior walls at the short sides of the setbacks (fig. 23). The interior walls had moderate cracks in the plaster at all levels (fig. 24). This damage was typical of the moderately damaged unreinforced masonry buildings in the sample. None of the other unreinforced masonry buildings were uninhabitable, although several top-story units of a four-story building about $21 \mathrm{~km}$ from the epicenter (Uptown Manor) were evacuated because of damage (fig. 5).

Lightly damaged unreinforced masonry buildings suffered minor cracks in the exterior masonry, and cracks in plaster at corners of openings in interior walls.

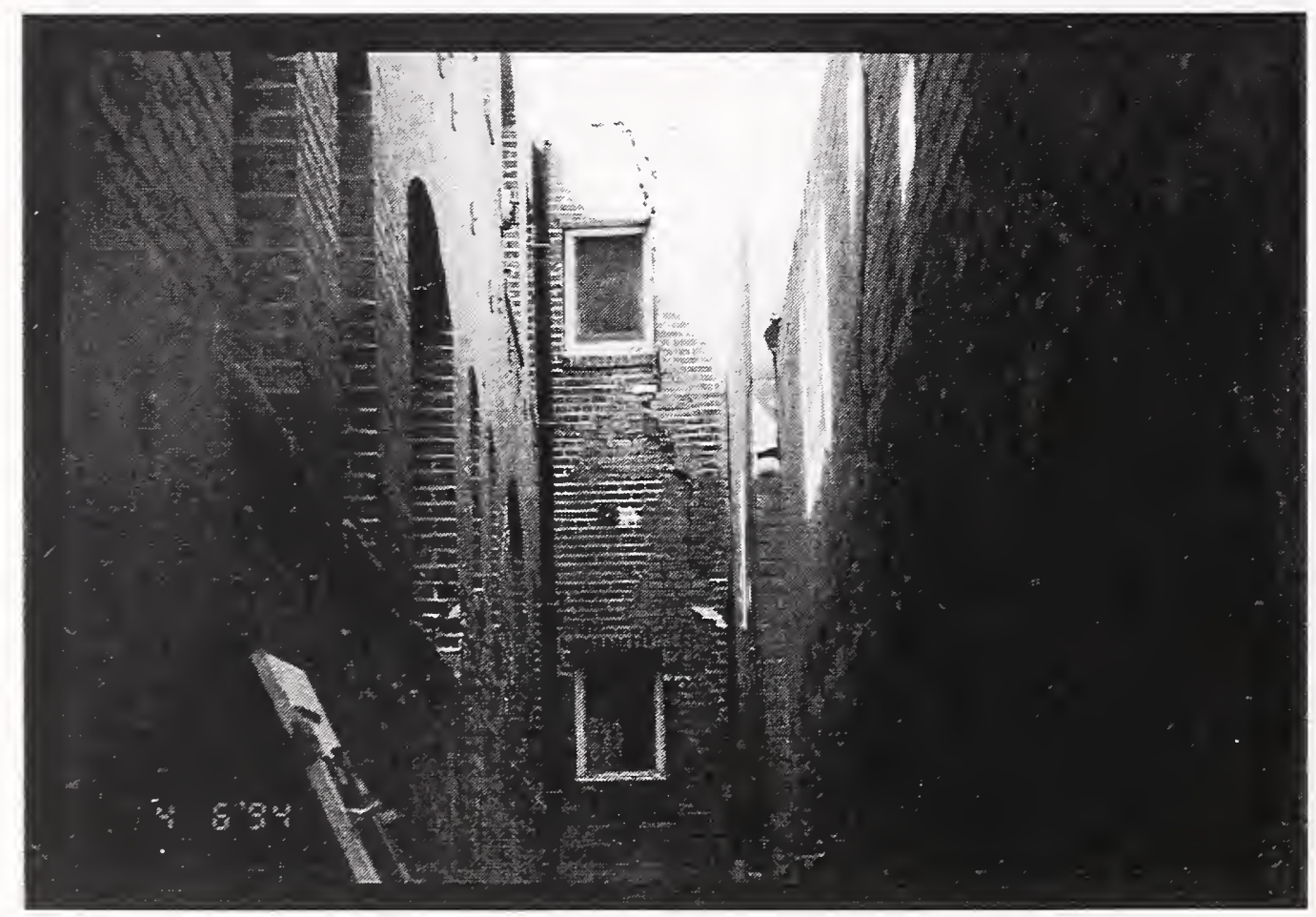

Figure 20 This view of an the inside corner of the T-shaped Vadehra $\mathrm{Vb}$ building shows substantial vertical cracks and movement of portions of the wall. Note that this building, which had been condemned and was under demolition, had been rehabilitated before the earthquake with throughbolts. 


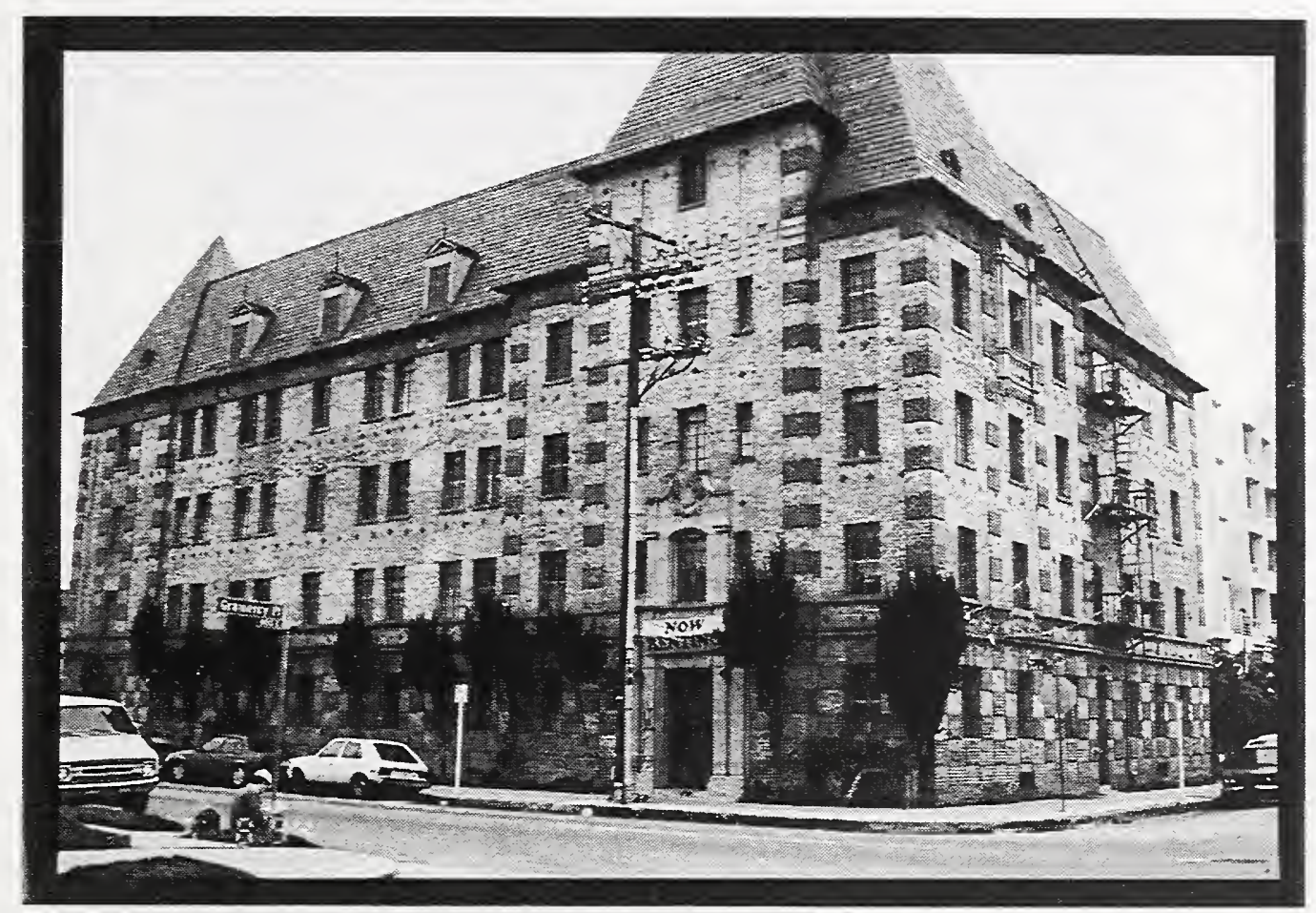

Figure 21 Villa Park Merridy, an unreinforced masonry building that had been rehabilitated prior to the Northridge earthquake, suffered no structural damage and only minor nonstructural damage.

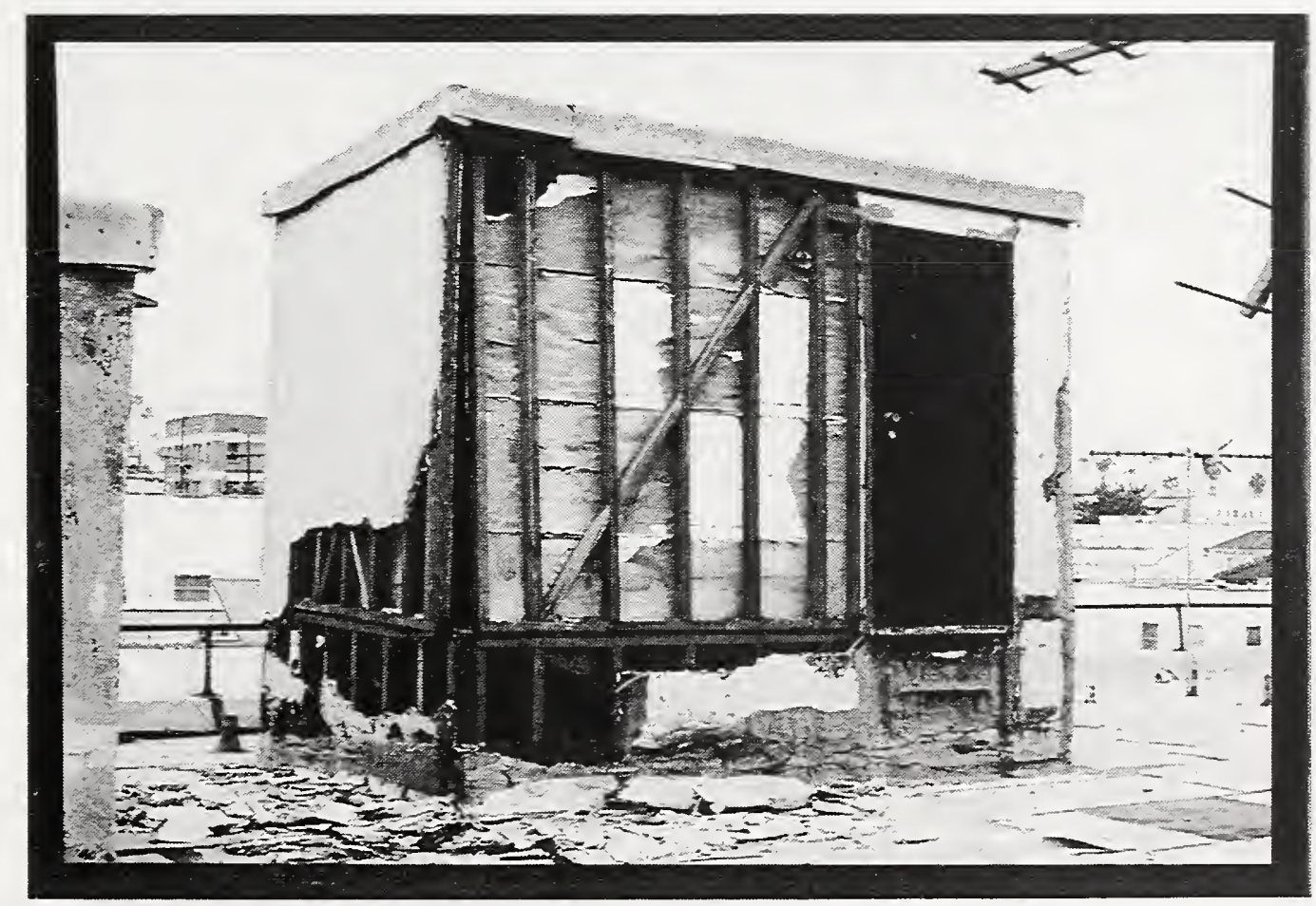

Figure 22 The wood-framed, stucco-clad elevator penthouse on the roof of the 3-story Vadehra IIIb building experienced extensive damage to the stucco, but the operation of the elevator was not affected. 


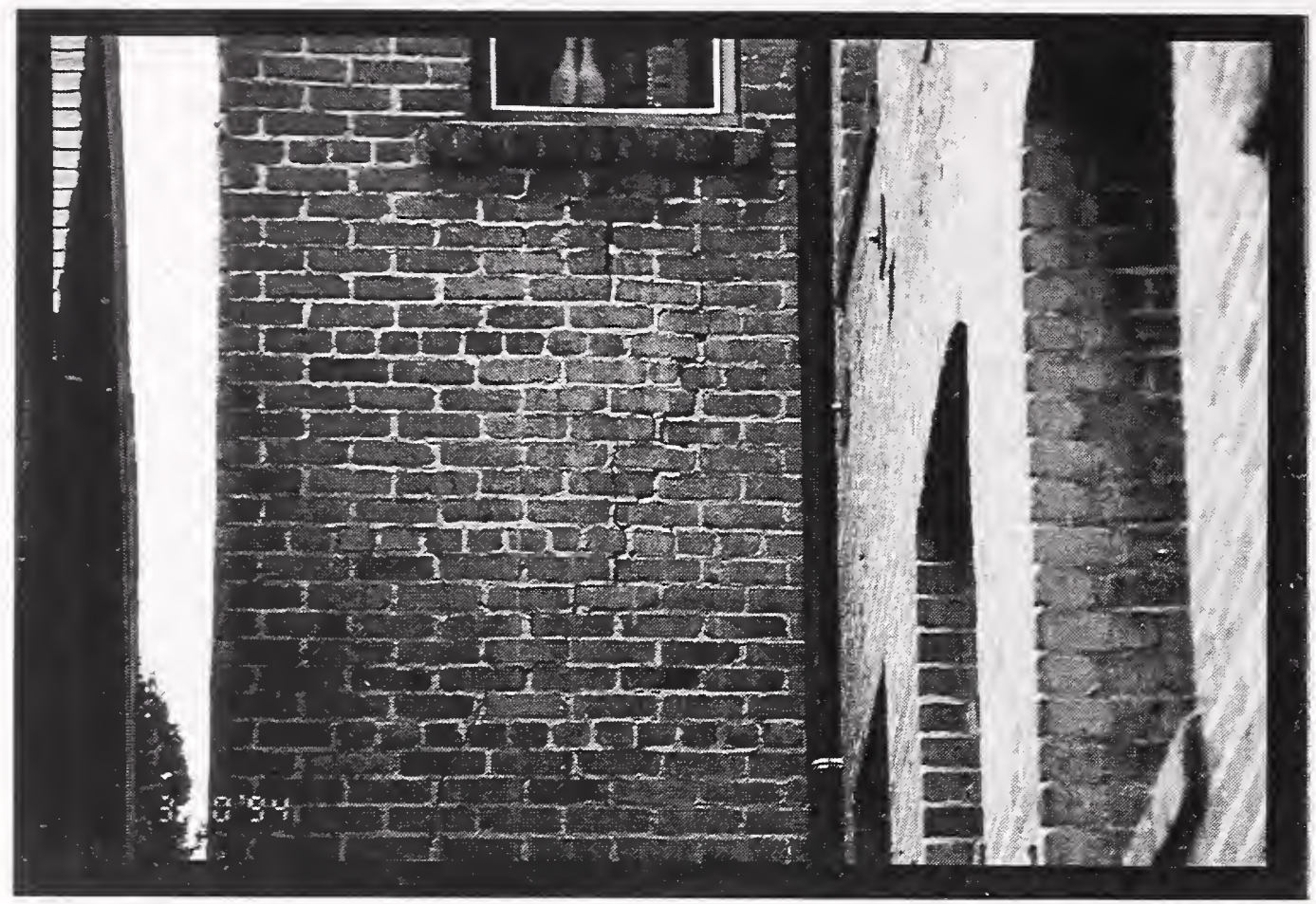

Figure 23 Vadehra IVb, a T-shaped unreinforced masonry building, suffered cracks in the short walls at the inside corner of the $T$ that in some locations followed the line of the mortar and in other locations cracked brick units.

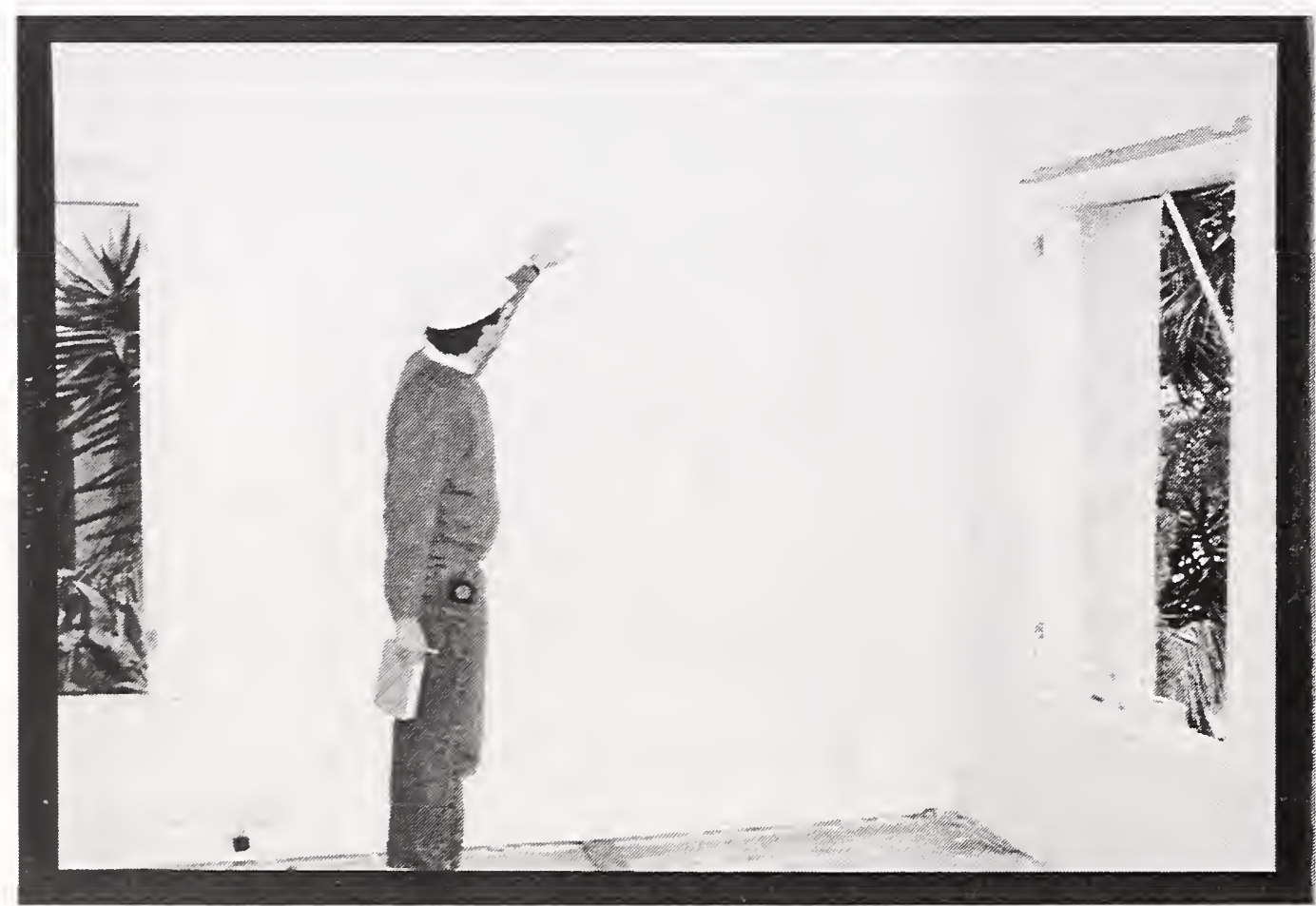

Figure 24 Damage observed in unreinforced masonry buildings included cracks in the interior plaster. 


\section{Wood Frame Buildings}

Thirty-four sites with wood frame buildings were included in the sample. Of these, only three had buildings with more than 10 percent structural damage (Grenada Gardens, Sherman Park Apartments, and Oakwood Van Nuys). At the other end of the scale, 14 of the sites had buildings with no structural damage and only minor nonstructural damage. The local public housing authority had selected nine sites with wood frame buildings for inspection by the BFRL team. Two of these (Estrada Courts and Estrada Courts Extension) had no earthquake damage that was apparent to the investigators.

The most spectacular damage occurred at Grenada Gardens, a 51-building complex about $6.5 \mathrm{~km}$ from the epicenter: 120 out of 169 units were vacated. Those buildings with the first story open for parking underwent large displacements relative to the foundation, creating permanent offsets (fig. 25). Relative lateral displacements of 0.35-0.45 $\mathrm{m}$ were measured. None of the buildings suffered a complete collapse of the first story. The second story apartments in those buildings with first floor parking suffered less nonstructural damage, such as dislodged commodes, cracked gypsum wallboard (fig. 26), and broken glass in sliding doors, than did the apartments in buildings with living units on both levels.

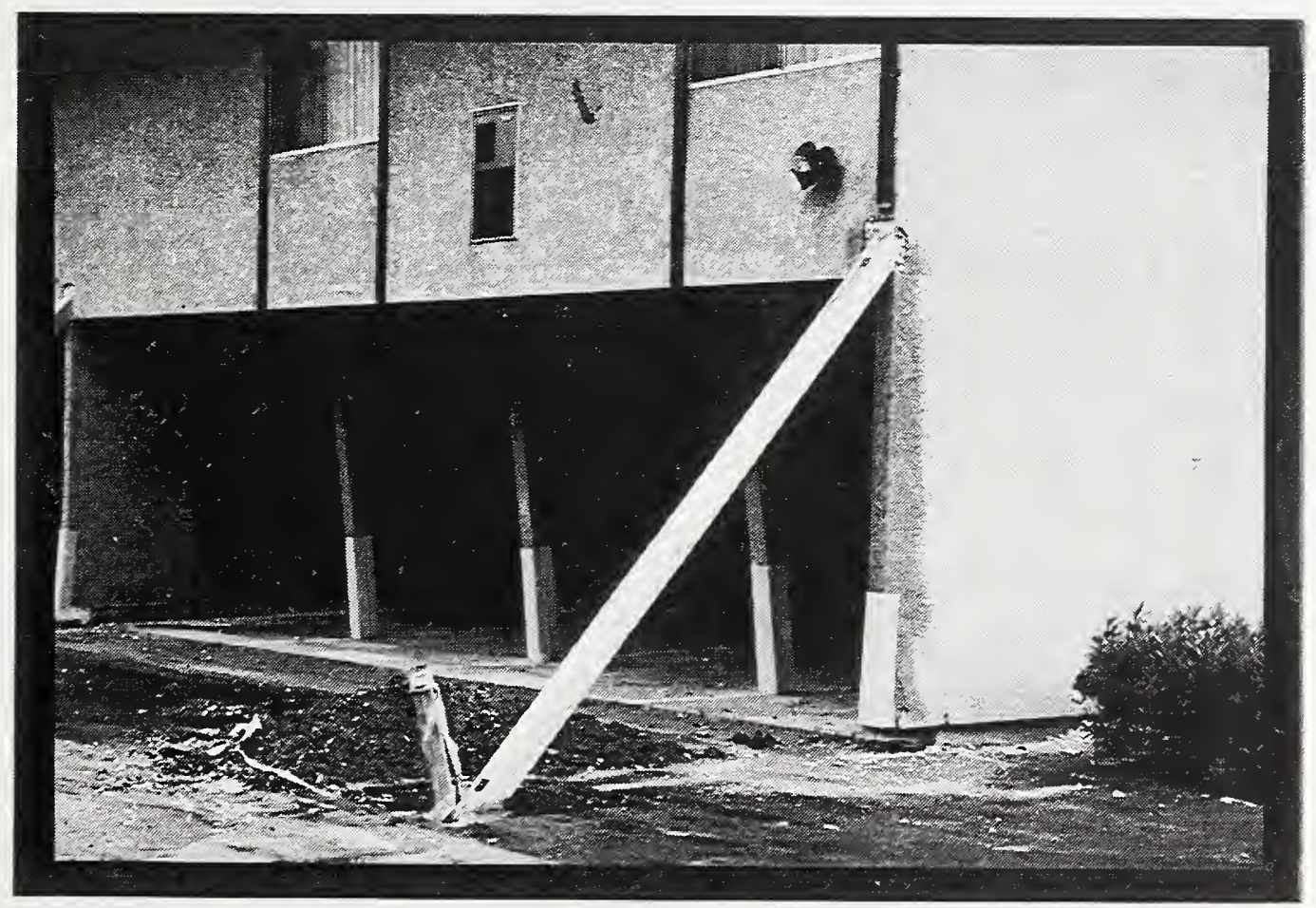

Figure 25 At Granada Gardens, many of the two-story wood frame buildings that had open first levels for parking experienced significant racking and permanent offsets. 
Figure 26 Interior damage at Granda Gardens included cracks in the gypsum wallboard.
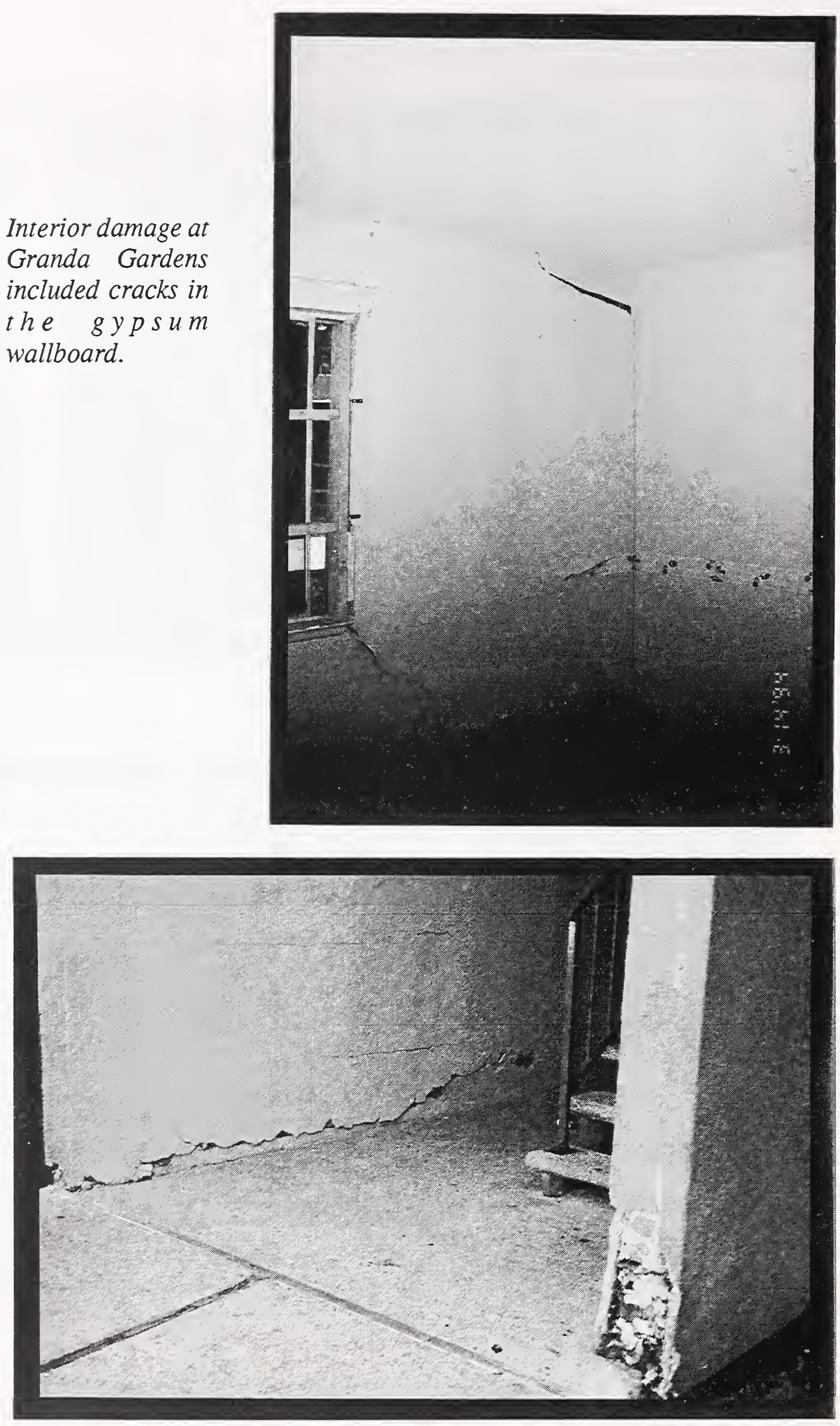

Figure 27 Horizontal cracks in exterior stucco occurred where the relatively flexible wood frame walls joined the more rigid concrete foundation walls. 
Cracks in concrete foundation walls or slabs occurred in some of the moderately damaged wood frame buildings. A common problem was cracking of the stucco cladding, particularly at the interface between rigid concrete foundation walls and more flexible wood stud walls (fig. 27) and at the corners of window openings (fig. 28). Although stucco and gypsum wallboard are sometimes relied upon by the designer to resist lateral loads, damage to these surfaces was classified as nonstructural in this study, to maintain consistency with the classification in buildings of other structural systems, where stucco and gypsum wallboard are clearly nonstructural. Other nonstructural damage included cracked plaster in ceilings and fallen ceiling tiles.

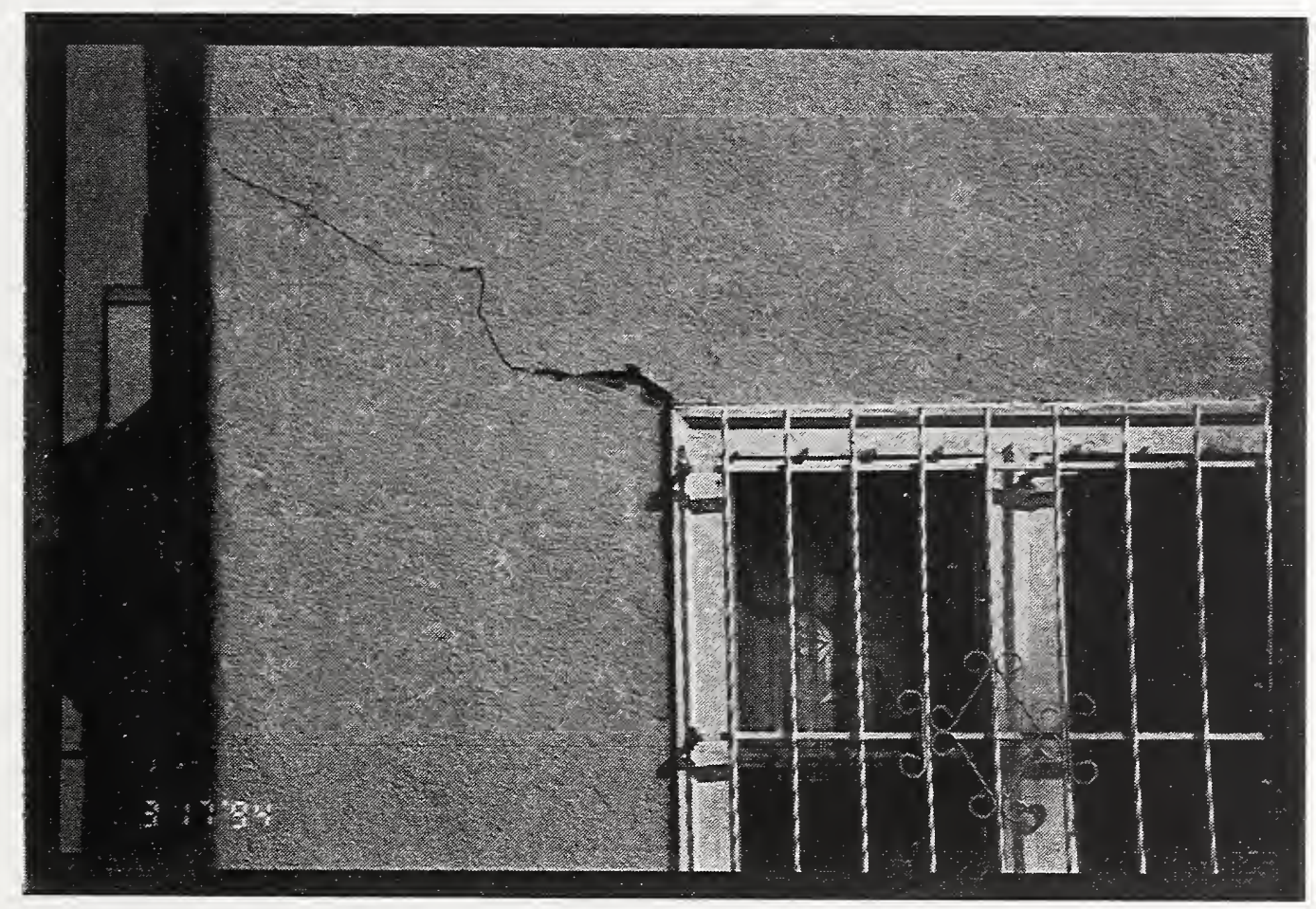

Figure 28 Diagonal cracks in exterior stucco at window openings in wood-framed buildings occurred in many locations, such as at this window at Miramar Manor. 
Table C - Values of Evaluated Parameters by Building Site

NAME

HUD

AGE $\mathrm{km}$ TO

ATC 13 NUMERICAL RATINGS

DAMAGED STRUCTURES

\begin{tabular}{|c|c|c|c|c|c|c|c|c|c|c|}
\hline 1. Angelus Plaza N & HA & FC. & 330 & 1. & 17. & ..11. & 32.5 & 2. & .2. & ... \\
\hline .2. Beverly Mills Sonior. & HA & $w$ & 151 & 1. &. .3 & $\ldots$ & 20.0 & . & 2. & 2. \\
\hline 3 Boyeny.Mano Apts. & HA. & $w$ & 59 & .... & 3. & 50. & 27.0 & 2. & 4. & \\
\hline 4 Beventy Towers & HA & c & 189 & 1 & 8 & 18 & 46.0 & 2 & 3 & 2 \\
\hline 5 Casa de la Paloma & HA & ㄷ. & 167 & 1. & 9 & 1.4 & 28.0 & 3. & 3. & 3 \\
\hline 6 Casa La Morcod & MA. & RM. & 130 & 1. & .5 & ....9. & 46.0 & 1. & 3. & ... \\
\hline 7 Casto Argyle Apts. & HA & c... & .98 & 1. & 6 & 77 & 23.5 & 3. & 3 & 1. \\
\hline 8 Cathay Manor & HA & c & 270 & 1 & 16 & 9 & 33.0 & 2 & 2 & 2 \\
\hline 9. Fairtax Towers & HA. & c. & 153 & 1. &. .8 & ..11. & 21.5 & 3 & .4. & $?$ \\
\hline 10. Fallbrook Square. & HA & $w$ & ....16 & ... & ... & 15 & 8.0 & 1 & 2 & 2. \\
\hline 11 Foxett Towers & HA. & c. & 306 & 1. & ...2. & 20 & ...8.0. & 4. & 4. & 3. \\
\hline 12 Foothills Gardens & HA & $w$ & 54 & 1 & 3 & 11 & 22.5 & 1 & 2 & 1 \\
\hline 1.3. GenevaPRaza & HA & . & ...100. & ...!. & . & ...... & 2....5. & .3. & 3. & ?. \\
\hline 14 Granada Gardens. & HA & w.. & 169 & $5 !$ & 2. & 13 & $\ldots 6.5$ & 6 & .5. & 3 \\
\hline 15. HarvardPlaza & HA & Fe. & .150. & ...!. & ... & .13 & .21 .5 & .3. & 3 & 3. \\
\hline 16 Hollywood East Apts. & HA & $w$ & 22 & 1 & 2 & 40 & 25.5 & 1 & 2 & 1 \\
\hline 17. Hollymood East.Apts..... & HA & W. & 43 & 1. & 3 & 40. & 25.5 & 2. & .4. & .1. \\
\hline 1.8 Hollywood Fountain No. N. & HA & $w$. & 88. & !. & 4. & ...!. & 24.0 & ... & 4. & 4. \\
\hline 19. Hollywood Fountain So. & HA. & $w$. & .73 & ... &. .4. & ..10. & 24.0 &.. & 3. & 2. \\
\hline 20 Hollywood Knickertocker & HA & c & 284 & 1 & 11 & 63 & 23.5 & 1 & 3 & 1 \\
\hline 21 Hollywood Plaza & HA & c. & 153 & 1. & 10 & 61 & 23.5 & 1 & 4. & 1. \\
\hline 22. Marine Manor -A* & PH & c. & 112 & 1. &. .8 & $\ldots 9$. & 27.5 & 2 & . & 2 \\
\hline 23. Marina Manor.":5.. & 요. & w. & ....1.. & .... & .4. & ...9. & .27 .5 & ?. & .2. & .2. \\
\hline 24 Menorah House & HA & $w$ & 51 & 1 & 3 & 16 & 2.0 & 1 & 3 & 2 \\
\hline 25. Miramar Manor............... & HA & w. & .49 & .2. & 3. & 40 & 31.0. & ... & ?. & !.. \\
\hline 26 Mountain Viow Estates & HA & $w$ & .23. & 1 & 3. & 13 & 23.5 & 2 & 2. & 1. \\
\hline 27 oakwood Tolugsa & 느스. & w. & $115 !$ & 23. & 3 & .20. & .20 .5 & 2. & . & 2. \\
\hline 28 Oakwood Van Nurs & HA & $w$ & 390 & 4 & 3 & 23 & 7.0 & 4 & 4 & 1 \\
\hline 29.9akwood Wood Hills. E. & HA. & ..... & - & .26. & .3. & .20 & .7.0. & .?. & .4 & .4. \\
\hline 30 Oakwood Wood Hils W. & HA & $w$ & 446 & 17 & 3 & 20 & 7.0 & 2. & 3 & 3 \\
\hline 311.Orchard Arms & 요. & w. & - &. .4 & ?. & ...13. & 20.0 & 1 & .2. & .4. \\
\hline 32 Owensmouth Gardens & $P A$ & $w$ & 381 & 6 & 3 & 14 & 6.0 & 3 & 4 & 2 \\
\hline 33 Pacific Manor & HA & PC. & 169 & ... & 10 & 19. & 21.5 & 1. & 2. & .2 \\
\hline 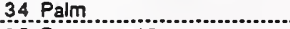 & An. & ..... & ...?2?.. & ..!. & $\ldots 6$. & .15 & .20.5. & .? & .2 & .?. \\
\hline 35 Panorama Viow. & HA & $w$ & 87 & 3. & 3 & .23 & 9.0 & 1. & 2 & 1. \\
\hline 36. Park Pasoo & HA & EC & 98 & 1 & 8 & 1 & 28.0 & 2 & 3 & 3 \\
\hline 37 Parthenia Manor & HA & $w$ & 89. & 6 . & 3. & 23 & 8.0 & 1. & . & 1. \\
\hline 38 Pledgerville Serior. & HA & PM. & 94 & .... & 6 & ....9. & 13.0 & .2 & 1 & !. \\
\hline 3.9.Plummer Park Apts. & HA. & w... & 40. & !. & ?. &. .12 &.. .4 .5 & ? & 3 & .4. \\
\hline 40 Rosoda East & PH & $w$ & 70 & 1 & 3 & 16 & 1.0 & 3 & 4 & 4 \\
\hline 41. Roseda Maror. & 요묘. & w. &. .40. & .... & 3 & ..16. & ...? & ... & .4 & ... \\
\hline 42. Roseda Pak & $H A$ & $w$ & 156 & 2 & 3 & 24 & 3.5 & 1 & . & 2. \\
\hline 43 Santa Monica Christ. & HA & c.. & 167 & 1. & .13 & .29 & 22.0 & .4 & 3 & 3. \\
\hline 44 Sherman Park Apts. & HA & $w$ & 135 & 2 & 3 & 23 & 2.5 & 5 & 5 & 3 \\
\hline 45 Simpson Saticoy..... & PH. & w. & 35 & $\ldots !$ & 3. & 20 & $14: 0$ & 1 & 2. & $\ldots$ \\
\hline 46 Sundand Park ....... & HA & w. & ..120. & ..!4. & 2. & 22?. & .16 .5$. & ... & 3 & .... \\
\hline 47 Sunset Apts b & HA & w. & 24 & $\ldots !$ & .2. & 40 & 27.0 & 3 & .4. & ... \\
\hline 48 Sunset Apts. $\theta$ & HA & $w$ & 18 & 1 & 3 & 50 & 29.0 & 3 & 5 & 2 \\
\hline 49. Tujungá Gardens. & HA & w. &. .54 & ... & $\ldots$ & ..13. & .24 .5 & ... & .2. & ..!. \\
\hline 50. Union Towers & PH. & C....... & 2000. & 1. & .15. & ...19. & 31.0. & ? & .3. & .?. \\
\hline 51 Uptown Manor. & HA & UPM. & 60 & .... & $\ldots$ & 69 & 21.0 & 4. & .4 & ?. \\
\hline 52 Vadohra III & HA & UPM & 44 & 1 & 5 & 70 & 29.5 & 2 & 2 & 1 \\
\hline 53. Yadetra!!!! & HA & بPM. & .30. & !. & 3. & .7. & 28:0. & ... & .3. & \\
\hline 54 Yadohra IV & HA & UPM. & 72 & ... & 4. & 70 & 24.5 & 6. & & \\
\hline 55 Yadohra Va. & HA & UT:M. & 40 & 1 & .5 & 65 & 24.5 & 4 & 1 & .1. \\
\hline 56 Vadelra Vb & HA & UPM & 40 & 1 & 4 & 70 & 25.5 & 6 & & \\
\hline 57 Vadehra $\mathrm{V}$ & HA & UPM. & 39 & 1. & 4. & 56 & 29.5 & ?. & .2. & !. \\
\hline 58 Vadhera IV b & HA. & UPM. & 40. & 1. & .4. & .... & 25.0 & .4 & .4. & \\
\hline 59 Villa Park Morridy. & HA & UPM. & 20 & 1. & 4. & 65. & 28.0 & 1. & 3 & ... \\
\hline 60 Villa Raymond & HA & UPM & 23 & 1 & 4 & 67 & 37.0 & 3 & 3 & 1 \\
\hline 61 Vista NPH Adult Ret CT: & HA & R.... & .84. & ... & .5. &. .7 & ...8.5. & 3. &. .4 &. .4 \\
\hline 62 West Valley Towers & HA & EC. & 97 & 1. & .8 & 10 & ..9. & 2. & 2 & .? \\
\hline 63. Westminster Towers & HA & C... & 285. & ... & 17 & .23 & 20.5 & .4 & .6. & \\
\hline 64.Wilshire Villa Nornh & HA. & U...... & .... & ...! & ...... & ....?. & .24.0. & ?. & ..? & \\
\hline
\end{tabular}

UNDAMAGED STRUCTURES

\begin{tabular}{|c|c|c|c|c|c|c|c|c|c|c|}
\hline 65 Aliso Apts & $\mathrm{FH}$ & FM & 336 & 22 & 3 & 39 & 35.0 & 1 & 1 & 1 \\
\hline 66 Estrada Courts & PH & $w$ & 214 & 30 & 2 & 51 & 38.0 & 1. & 1. & 1. \\
\hline 67 Estrada Couts Extonsion & PH. & $w$ & 200 & 37. & 2 & 39 & 38.0 & 1. & 1. & 1. \\
\hline 68 Ramona Gardens & AH. & RM. & 610 & 101 & 2 & 52. & 36.0 & 1. & ... & ... \\
\hline 69 William Moado & Pिi & вM & 449 & 24 & 3 & 51 & 33.0 & 1 & 1 & 1 \\
\hline
\end{tabular}

o willam Moado

UNITS BLDGS

\begin{tabular}{|l|l|}
\hline TOTALS 11239 & 425 \\
\hline
\end{tabular}

NOTES

HUD Column indicates imrolvement by HUD as:

$H A=H U D$ Affilited

$P H=$ Putbic Housing

TYPES: $C=$ Concre

$P C=$ Procast Concrete

RM = Reinforced Masonrs

UPM = Urreintorced Masonry

$W=$ Wood Frame 


\section{B. Comparison of technical subsets}

In order to determine whether identifiable trends existed, the data were sorted by building age, number of stories, distance from the epicenter, and structural type. The numerical ratings for the ATC-13 damage states for structural and nonstructural damage were examined to see if trends could be identified. The five sites at which there was no evident earthquake damage (ATC damage state ratings of 1 for all systems) were removed from the database prior to the analysis. Table $C$ presents the values of these parameters for each site.

Scatter plots were produced, evaluating each site as one data point. The scatter plots showed a wide distribution of damage states for each of the variables considered (fig. 29). Note that, as can be seen from the data in Table $C$, each of the dots shown in figure 29 may represent more than one data point. Regression analysis confirmed that no statistically valid trends existed in the data for age, number of stories, or epicentral distance (considered individually and ignoring the influence of the other parameters) when measured against structural and nonstructural damage states. The correlation coefficient, $\mathrm{r}$, was greatest for the correlation between age and structural damage, but, with a value of only 0.23 , the correlation cannot be considered significant. The correlation coefficient $r$ always has a value between -1 and 1 ; these values imply perfect correlation. A value of zero indicates no correlation whatsoever.

Table D: Coefficient of Correlation $r$

\begin{tabular}{||l|c|c||}
\hline & structural damage & nonstructural damage \\
\hline Age & 0.23 & 0.07 \\
\hline Epicentral Distance & -0.13 & -0.19 \\
\hline Number of Stories & 0.15 & 0.04 \\
\hline
\end{tabular}

This attempt to identify trends in the data through regression analysis should not be considered precise or conclusive. Among the limitations to the analysis are:

- the assigned damage state values are based on the engineering judgement of the investigator, and cover a range of damage rather than specific values, and

- each site is treated as one data point, although the number of living units per site varied considerably.

It is possible that strong trends do exist in more narrowly defined groupings of data which consider the combined effects of multiple variables, for example, age-todamage state correlations for each different structural system, rather than for all systems considered together. However, the relatively limited number of data points available from this study does not justify more finely partitioned analyses. Given a larger set of data points, trends may well become apparent. 

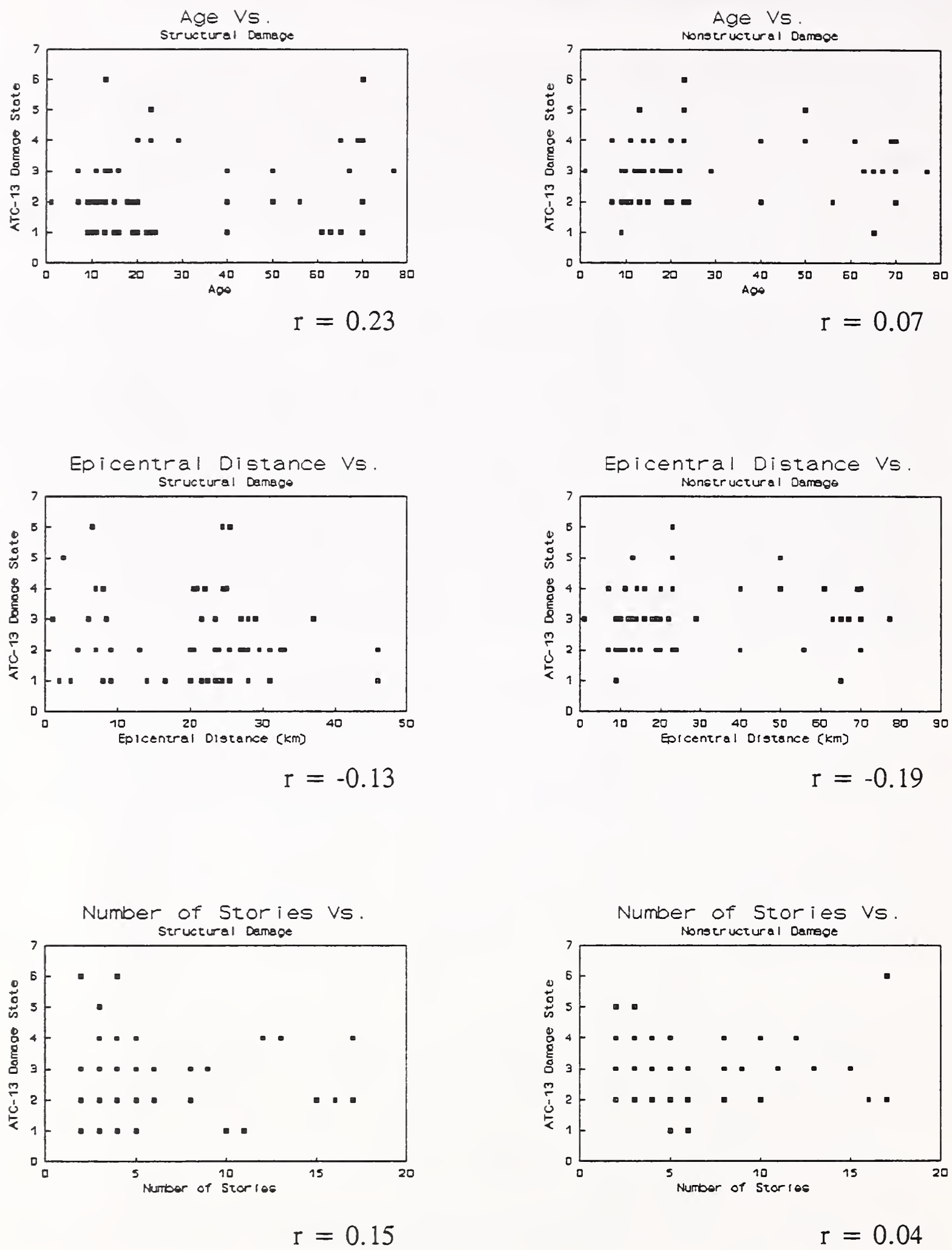

Figure 29

Scatter Plots and Coefficients of Correlation

Age, Epicentral Distance and Number of Stories

Compared to Structural and Nonstructural Damage States 
It is not possible to generate regression analyses of the plots of structural type against damage states because structural type is not a numeric variable. Instead, average structural and nonstructural damage states were calculated. The averages were weighted to account for the number of living units at a site. This calculation assumes that all living units were equally damaged, which was clearly not the case at many sites. However, the ATC-13 damage states are assigned based on percent of the total building(s) that is damaged, therefore, the assumption is not invalid. The averages are given in Table $\mathrm{E}$.

Table E: Average ATC-13 Damage State by Structural System (weighted by number of living units at each site)

\begin{tabular}{|l|c|c|c|}
\hline & Structural & Nonstructural & Number of Units \\
\hline Concrete & 2.6 & 3.5 & 2217 \\
\hline Precast & 2.3 & 2.6 & 1195 \\
\hline Reinf. Masonry & 1.4 & 2.2 & 224 \\
\hline Unreinf. Masonry* & 3.4 & 2.6 & 496 \\
\hline Wood Frame & 2.2 & 3.3 & 5298 \\
\hline
\end{tabular}

* Almost all unreinforced masonry buildings in the sample had been rehabilitated to some degree.

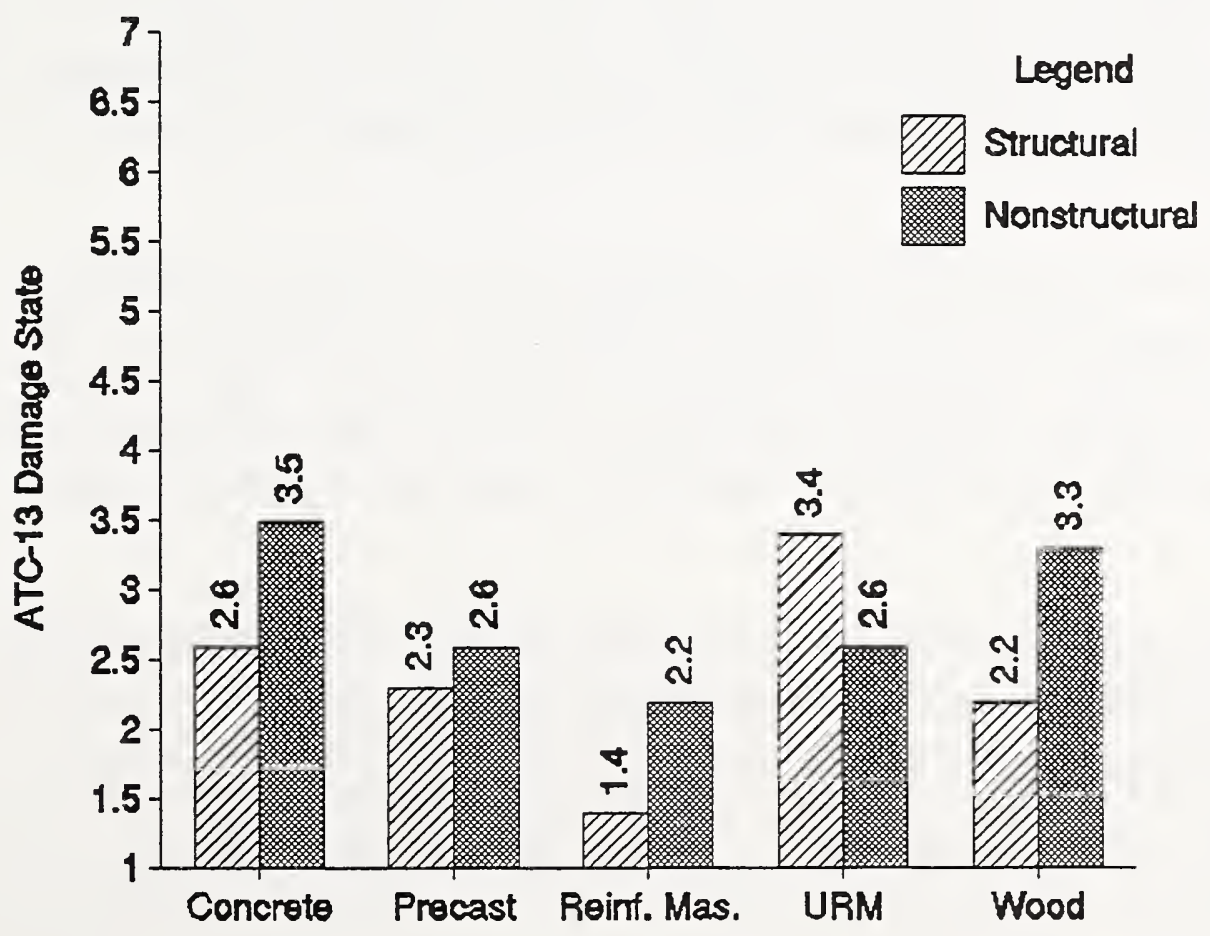

Figure 30 Bar graph showing weighted averages of ATC-13 structural and nonstructural damage states by structural system. 
The highest average damage state was 3.5, for non-structural damage in concrete buildings, which is between "light" (1\%-10\%) and "moderate" (10\%-30\%) damage. The lowest average value, 1.4, for structural damage in reinforced masonry buildings, is between damage rated as "none" (0\%) and "slight" (0\%-1\%).

Although at first glance the average numbers suggest that reinforced masonry buildings performed better than other buildings of other systems, both for structural and nonstructural damage, it is important to remember that only two buildings of this type were in the sample, located at 13 and $46 \mathrm{~km}$ from the epicenter. Both buildings were nine years old.

The average structural damage per living unit was worse for unreinforced masonry buildings than for any other system. However, nonstructural damage in unreinforced masonry buildings was not extreme. The highest average nonstructural damage occurred in wood frame and concrete buildings.

These analyses emphasize the difficulty in predicting earthquake damage at any given site. Anecdotal evidence supporting this supposition was found at several sites by the BFRL investigators. An example is Sunland Park, a complex of three-story wood frame apartment buildings located about $16 \mathrm{~km}$ from the epicenter. The fourteen buildings on the site were apparently identical in age, configuration, and construction. However, three of the buildings suffered extensive cracking of the exterior stucco and interior gypsum partitions. Two buildings had only minor damage. The nine other buildings at the site were virtually undamaged. The differences in performance possibly may be attributable to soil conditions, building orientation relative to the direction of earthquake wave propagation, undetectable variations in the quality of construction or materials, or some other factor. This variation in damage at a single site of virtually identical buildings illustrates the problems inherent in attempting to predict which buildings will be damaged by a future earthquake and the extent of that damage.

ATC-13 damage levels, recorded by the investigators for structural, nonstructural, and equipment damage, were also compared to each other for each site. For the two buildings that were under demolition at the time of the survey, no information on nonstructural or equipment damage was available. These two buildings were removed from the database prior to the analysis, leaving 62 points in this portion of the analysis.

The analysis showed that, in buildings that suffered damage in the earthquake, nonstructural damage tended to be more extensive than structural damage. At 37 of the 62 sites in the database (nearly 60 percent), the level of nonstructural damage exceeded the level of structural damage. The levels of damage were the same at 21 sites. At only four sites was the level of structural damage worse than the nonstructural damage. Twenty sites suffered no structural damage, but had light to moderate nonstructural damage. 
Also evident was that level of damage to equipment tended to be equivalent to or less significant than the structural damage level. Only 14 of the 62 sites had equipment damage that was rated as higher than the structural damage. The levels of structural and equipment damage were the same at 26 sites. At 22 sites, the equipment performed better than the structural system. 


\section{CONCLUSIONS AND RECOMMENDATIONS}

\section{A. Conclusions}

The study examined earthquake-damaged multi-family residences three-story or more in height affiliated with HUD programs. Approximately three percent of the 9,430 living units located in 211 buildings at 64 sites at which damage occurred were rendered uninhabitable by the Northridge earthquake. At sites where damage occurred, 97 percent of the living units remained useable.

No strong correlations were found between level of structural or nonstructural damage and building age, height, or distance from the epicenter. This does not prove that such correlations do not exist, but it does indicate that the data in this sample do not reveal a strong trend. Factors which limit the usefulness of the database for statistical analysis include:

- the sample includes a limited number of buildings representing certain combinations of structural system, age, distance, and number of stories,

- the assigned damage state values are based on the engineering judgement of the investigator, and cover a range of damage rather than specific values, and

- the number of buildings and living units per site varied considerably, and the condition of all buildings and living units at each site was not uniform.

Damage almost always included cracks in plaster and gypsum surfaces of interior nonstructural partitions, usually at corners of door and window openings and along vertical and horizontal joints. Damage to structural systems was generally less severe.

The level of damage to building equipment, such as water distribution and air handling systems, was generally lower than the level of nonstructural damage and about the same as the level of structural damage. Occasionally, collateral damage occurred due to water or gas leaks. However, only two buildings in the sample were damaged by fire.

The average structural damage per living unit was higher in unreinforced masonry buildings than buildings of other systems. Living units in concrete and wood frame buildings suffered relatively higher levels of nonstructural damage than did buildings of other systems.

A large variation in performance, even among apparently identical buildings at a single site, was observed in this study. This finding is not an unusual feature of the Northridge earthquake; wide variations in performance have been typically observed following earthquakes.

The unreinforced masonry buildings included in the sample had generally been seismically rehabilitated before the quake. In Los Angeles, this rehabilitation had been mandated. In Santa Monica and other non-Los Angeles jurisdictions, rehabilitation is not mandatory, but is common nevertheless. While no unreinforced 
masonry building in the sample collapsed, two were condemned because of the severity of the earthquake damage. The goal of seismic rehabilitation for this class of structures is to protect human life. That goal was achieved during this earthquake; no one was killed in an unreinforced masonry building. Because there were very few unreinforced masonry buildings in the affected area that had not been rehabiliated to some degree before the earthquake, it is not possible to compare the behavior of rehabilitated to un-rehabilitated buildings in this event. However, the behavior of unrehabilitated unreinforced masonry buildings in other earthquakes has demonstrated the vulnerability of this class of structure. Therefore, considering the small number of unreinforced masonry buildings that lost protions of walls and suffered other partial collapses in the Northridge earthquake, it is reasonable to conclude that the rehabilitation efforts had a positive effect in improving the life-safety of this class of buildings. The usefulness of the rehabilitations in reducing economic damage cannot be ascertained from the buildings in this sample.

Poor performance of wood frame buildings with open first-stories used for parking was observed in some of the buildings in this sample and in other non-HUD-affiliated buildings. Based on this observed behavior, buildings with this type of vertical configuration can be identified as potentially vulnerable to earthquake damage.

Among the residential facilities observed in this study, no particularly vulnerable aspects of structural systems could be identified in concrete, precast concrete, and reinforced masonry buildings. Vulnerable nonstructural components common to most types of residential buildings included gypsum board and plaster coverings on nonbearing walls and exterior stucco, which often cracked at corners of door and window openings and along horizontal and vertical joints.

Damage to building contents was not included in the scope of this study, however, anecdotal evidence suggests that personal losses and some injuries could be reduced if several precautionary steps were taken by residents. The Federal Emergency Management Agency publishes brochures and booklets aimed at the general public [7, 8], outlining some of these actions such as anchoring bookcases and outfitting cabinet doors with secure latches. 


\section{B. Recommendations}

Damage caused by earthquakes gives the building community an opportunity to study the efficacy of current practices. The lessons learned can be used to make improvements in the design and construction of new buildings and the seismic enhancement of existing buildings. Public and private organizations can also benefit from the lessons learned by modifying their programs and policies to create a more earthquake-safe environment.

In considering the potential lessons that can be learned from the performance of structures during the Northridge earthquake, it is important to consider the larger context of seismicity nationwide. The lessons learned from Northridge should not be considered "California-only" lessons. Earthquakes of this magnitude (6.8) can potentially occur in many other areas of the country. Larger earthquakes can also occur. For example, it is generally accepted that a rupture along the San Andreas fault could generate a magnitude 8 or greater event.

The results of this study suggest several actions that HUD may wish to consider.

\section{Learning from Northridge}

\section{Study the cost of repairing the earthquake-induced damage in residential} buildings. How much was spent repairing the structural damage caused by the Northridge earthquake? How much was spent repairing the nonstructural damage? This information, combined with similar information collected after other earthquakes, will help HUD to estimate future losses from earthquakes. It will also provide insight into the potential for avoiding economic losses by implementing pre-earthquake risk-reduction measures.

2. Collect information on a statistically-valid sample of residential structures in the affected area. Information on a statistically-valid sample of HUD-affiliated and non-HUD multi-family residential structures in the affected area, including data on structural system, age, epicentral distance, number of stories, and level of (or absence of) earthquake damage, would provide a rich source of information for study. For example, analysis of such an inventory would allow investigators to determine whether some types of residential buildings were more vulnerable to this earthquake's ground shaking characteristics than others. Comparison with similar studies conducted after other earthquakes would help identify building response characteristics that were unique to this earthquake, and those that are common to many earthquakes. By comparing the statistics on the inventory of non-HUD buildings to the inventory of HUD-affiliated buildings, HUD would be able to determine whether structures in their programs performed worse or better than non-HUD buildings. This may provide information useful in assessing technical requirements of HUD programs.

3. Begin including information on physical characteristics of buildings in HUD program files. By beginning now to systematically collect information on 
engineering aspects of buildings in HUD programs, some of the vital information needed for rapid assessment of the engineering impact of future natural or manmade disasters will be immediately available when the need arises. For example, having information on age, number of stories, structural system, number of occupants and location would enable HUD to rapidly screen the buildings in their programs to determine relative seismic risk exposure. Over the next year, the Interagency Committee on Seismic Safety in Construction will be developing guidelines for Federal agencies to use in developing seismic inventories of their owned and leased buildings. HUD may wish to consider collecting the same types of information on its assisted buildings as they enter HUD programs.

\section{Improved Materials. Techniques, and Practices}

4. Encourage the implementation of known simple and effective earthquake lossreduction measures in HUD-affiliated buildings. Some of the economic losses could have been avoided if simple earthquake-resistant measures had been taken. For example, improved restraint and anchorage of mechanical units, especially water tanks, could have reduced some losses.

5. Support the development of improved construction materials, techniques, and practices, by identifying and funding specific research needs. This study suggests several areas that are worthy of increased research and development. 1) Many residents reported being temporarily trapped in their apartments by jammed doors. The potential impact of door frame racking on exiting capabilities merits further study. 2) Reducing cosmetic cracks in interior and exterior wall surfaces would eliminate a significant amount of postearthquake repair expense. For example, fiber-reinforced gypsum wallboard and joint tape have been suggested as possible new materials that could reduce cracking. Research into sheathing and wall surfacing materials should be supported.

\section{Existing Buildings}

6. Assess the accuracy of currently available seismic evaluation and rehabilitation techniques. The data from this study are insufficient to support a recommendation of mandated seismic evaluation and rehabilitation for HUD-affiliated buildings. However, HUD could benefit by using this opportunity to investigate the validity of currently available seismic evaluation and rehabilitation techniques. Such an assessment would provide insight into whether a mandated rehabilitation program is reasonable given the current state-of-the-art. It would also point out any shortcomings in available methods, which could lead to improvements. The evaluation methods that could be studied are FEMA 178, NEHRP Handbook for the Seismic Evaluation of Existing Buildings [5], and the rehabilitation guidelines and commentary currently under development by the Building Seismic Safety Council (BSSC) and the Applied Technology Council (ATC). These analysis methods could be used to assess the pre-earthquake capabilities of a cross-section of earthquake-damaged and undamaged buildings. Can these methods accurately predict which buildings will perform well and which buildings will be damaged? 
Can they identify the weak links in the damaged buildings? Studying the performance of buildings that had been rehabilitated prior to the earthquake will give insight into the effectiveness of currently available pre-earthquake rehabilitation techniques. There were not enough pre-earthquake rehabilitated HUD-affiliated buildings in this study to make such a study possible. Examples would have to be gleaned from non-HUD buildings.

7. Evaluate the cost effectiveness of pre-earthquake seismic rehabilitation. HUD could benefit by examining the cost and benefit impacts of seismic evaluation and rehabilitation. (A method for estimating rehabilitation costs and a database of cost and technical information on over 2000 rehabilitation projects is about to be published by FEMA as Typical Costs of Seismic Rehabilitation, Second Edition [6].) Combining information on the costs of pre-earthquake rehabilitation with information on effectiveness of currently available rehabilitation techniques and costs to repair earthquake damage, from the studies recommended above, could aid HUD in determining the most cost-effective approach to dealing with potential earthquake damage.

\section{New Buildings}

8. Study the social and economic costs of requiring more stringent earthquake design and construction requirements. As a significant stakeholder in the country's housing inventory, HUD should seek to participate in the process of improving building codes. Of particular interest to HUD should be the question of whether building codes should go beyond requirements for life safety and require some additional level of property protection. A comparison of the social and economic costs of repairing earthquake-induced damage (gleaned from Northridge and other earthquakes) to the social and economic costs of requiring more stringent earthquake protection in new buildings should be performed. Such a study could indicate whether the increased social and economic costs of more stringent seismic requirements are more or less disruptive than earthquake-induced damage to efforts to provide affordable housing. 


\section{REFERENCES}

[1] Procedures for Postearthquake Safety Evaluation of Buildings (ATC 20), Applied Technology Council, Redwood City, CA, 1989.

[2] Rapid Visual Screening of Buildings for Potential Seismic Hazards: A Handbook (FEMA 154), prepared by Applied Technology Council, published by Federal Emergency Management Agency, Washington, DC, 1988.

[3] Earthquake Damage Evaluation Data for California (ATC 13), Applied Technology Council, Redwood City, CA, 1985.

[4] A Benefit-Cost Model for the Seismic Rehabilitation of Buildings, Volume 1: A User's Manual (FEMA 227), prepared by VSP Associates, published by Federal Emergency Management Agency, Washington, DC, 1991.

[5] NEHRP Handbook for Seismic Evaluation of Existing Buildings (FEMA 178), prepared by Building Seismic Safety Council, published by Federal Emergency Management Agency, Washington, DC, 1992.

[6] Typical Costs of Seismic Rehabilitation of Existing Buildings, Volume 1Summary (FEMA 156), prepared by Hart Consultant Group, published by Federal Emergency Management Agency, Washington, DC, publication pending.

[7] Earthquake Safety Checklist, FEMA 46, Federal Emergency Management Agency, Washington, DC, 1985.

[8] Family Earthquake Safety Home Hazard Hunt and Drill, FEMA 113, Federal Emergency Management Agency and the American Red Cross, Washington, DC, 1986. 
APPENDIX A

Data Collection Form 



\section{POST-EARTHQUAKE BUILDING PERFORMANCE ASSESSMENT FORM - INSTRUCTIONS}

This form should be filled out as fully as possible by the Field Inspeclion Team. Put slashes of "N/A" where itcms do nol apply;

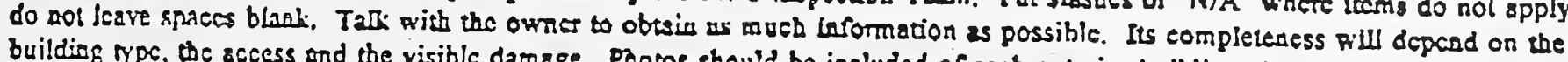
buildirg typc. the access and the visible damage. Paoros should be included of cach exterior building elcvation, and any locations

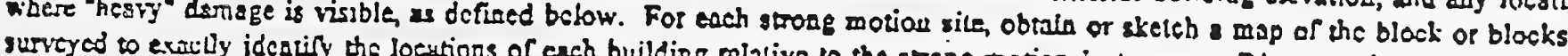
to the iestrment should be delemained wherever possible.

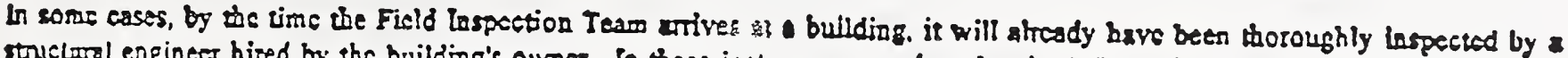
Ituclersl engineer hired by the building's owner. Io these instunces, complcte the site lofornation, give the building an

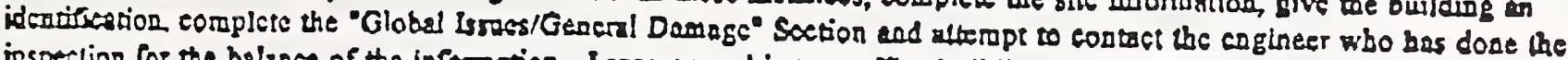
inspection for the bilance of the informetion. Lage or maldi-story office buildiogr, ralls, factories, hospitals and city facilities are most lizely to hrve bad these inspections. Smaller buildings such as siogle family houses, low-rise apartracals, and wood or light stael froned buildings are bess likely to have been thoroughty examiacd.

The Porr-Extherate Boildieg Assessemeat Form inclodes seven uctions as deseribed below:

1. Buifling Stre Infinmation. This informstion wust be completed on inftial visit and correcthy identify whether the strest nose is wy, "Srect" of "Boulevard" Lo avoid confosion. Inclade tbe ctty as well

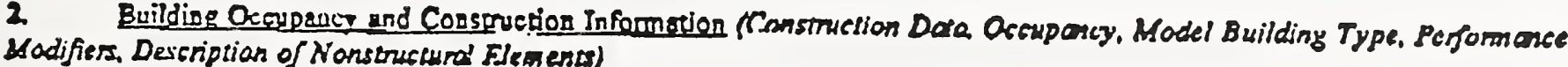

Model Buileting Type ieformation is requested in this setion and in the Dethiled Damagc Dexcriprion section. The building belag asessed may bave the differcat Madel Bullding Type framiog in the NS and EW plan directions and Oa different Doore. As accessary, in cach section, eater the appropriate Model Boilding Type abbreviations, es described in the "Glossery of Terms," into one to fow solumar correspondisg the plas directions and sange of noors.

3. Building Plon Sketeh Space is provided Sor a glan skeleb of the building footprial Nore on the akctel the essumed east. wesl and borh-sonth directions and a north arow. Euch Field Team chould cary a compase.

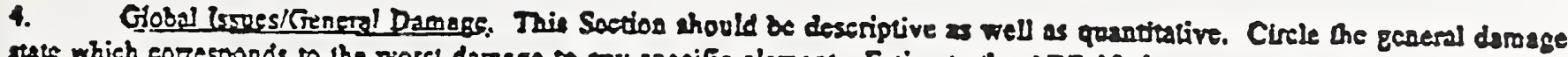
rtate whieb coresponds to the porst damage to any specifie clemeal Estimste the ATC-13 damage state as defincd in the Glossary of Tems for cach building arez as sbown. If the building complctely of partially collapsed. complete and alkeb the Collopsed Building Description section to docuneal the collapac, including thoughts as to why it occurred. The Dehiled Damage Description and Description of Heave Davlage sectons need aol be fllled nut if there is do darage or if a total collapse bas occured. Under Funcriondity, estimate the percentage uf building space whith can of will be nsable for its pre-carthquale purpose for cach rime period storz. If the space can be accopied for cleanup or repsirs osly. put "OC" in the speces provided

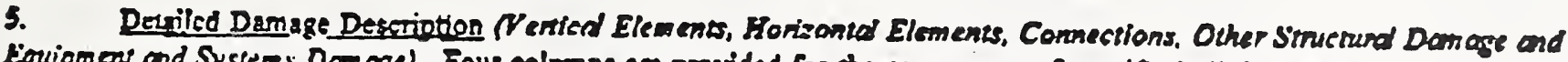
Liquipmast and Systems Demege). Foup colomns are grovided for the ascessmeat of spocific building damage. As ncecseary to

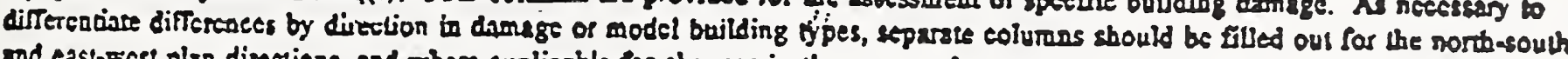
and east-Fest plan directions, sod wbere applicable for changes in the struetaral grstem over the building beight (i.e., as woodhamed aporment strecture over a concrete parking garage). Por exch colusa, idently the direction, the level for which each ppecific tructural type applies (ic.. Bacemeot, Cond-6th, cte.) and be atroctural model type as unted below.

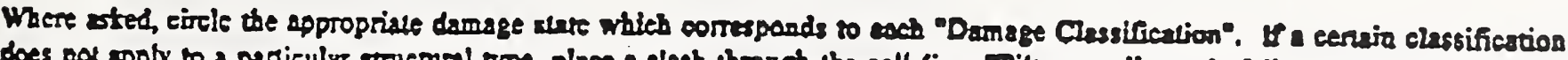

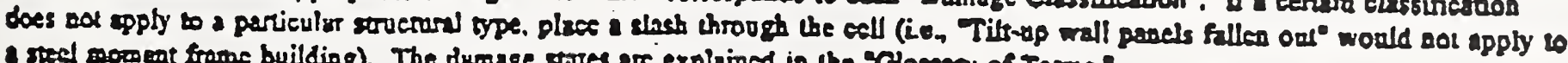
atred mowent franc building). The dumage sures ar explained in the "Otoseary of Tecms."

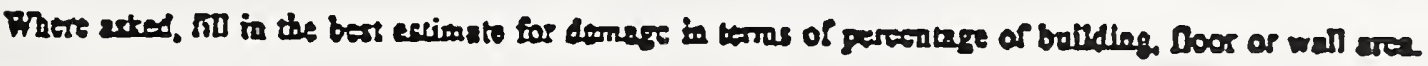

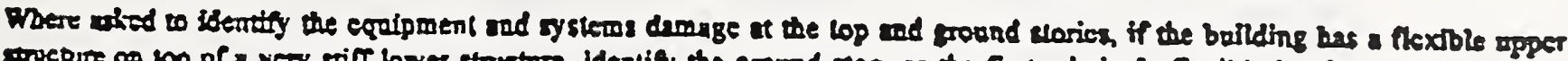

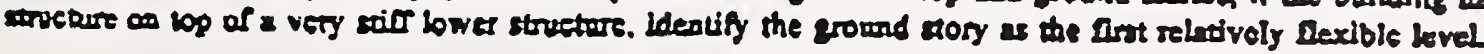

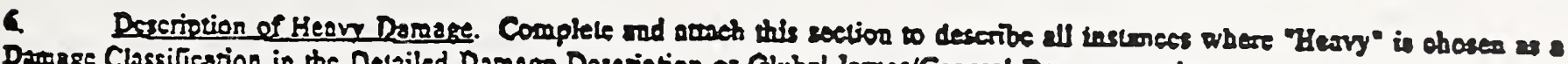

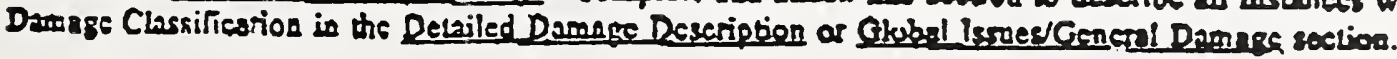

7. Collapsed Brilding If formacion. If the bailding has completely or partially collapsed, complete and atnet this section to

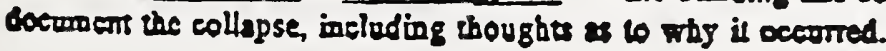




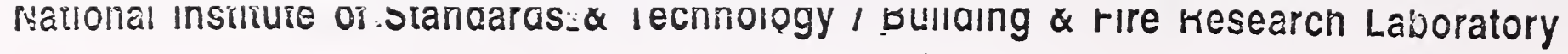

Gossary of Tems

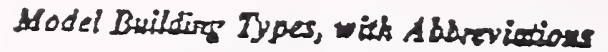

SLeel Moment Frame:

Siccl Braced Frame:

Steel light Frames:

Stoel Fromes w/ Conctete Sher W/alts.

Sieel Frames w/ Trofll Masom Sheas Wallec

Concrele Mowear Fromes:

Concrele Soess Wull Buildines

Concsere Frotnsa w/ Iofill Marsong Walls:

Reinforsed Masonry Bearing Walls:

Unreinforced Masoary Besring Wals

Prefestilitas Conctcie Ster Walls:

Precast Concrete frames w/ Concrete Srar Walle

Wood Light Fane:

Commerejal $\propto$ Long Spar Wood Frame:

\author{
S1 - Stif Diaphragms \\ S2 - Stiff Disphragras \\ S4 - Stifr Diaghayms \\ S5 - Stit Diaphraems \\ Cl - Stiff Dixpiragms \\ C2 - Sriff Diaphregress \\ C3 - Stiff Disphngms \\ RM1 - Flexible Diaphragms \\ URM - IIxxible Diaphragms \\ $\mathrm{PCl}$ - Fexible Diaphrigms \\ PC2 \\ $\mathbf{S 3}$
}

SIA - Flexiblc Diaphragms

S3A - Flexible Diaphragms

S4A - F lexible Dlaphragms

SSA - Flexible Disphragms

C1A: - Flexible Diaphracens

C2A - Fexible Diuphragms

C3A - Flexible Diaphragms

RM2 - StifT Diaphrogms

URMA - SUECT Diaphragms

PCIA - StifT Diaphragms

\section{Deseoge Seres, with Absrrienions}

N: None No damage in visobles either cosmetic ar struetral

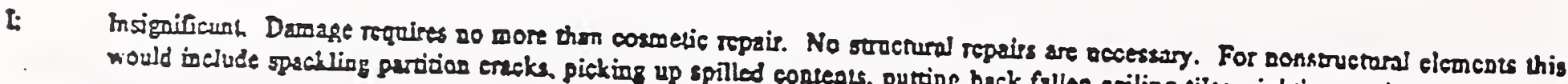

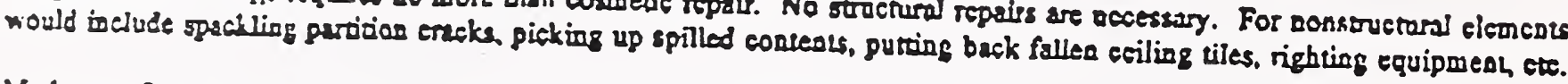

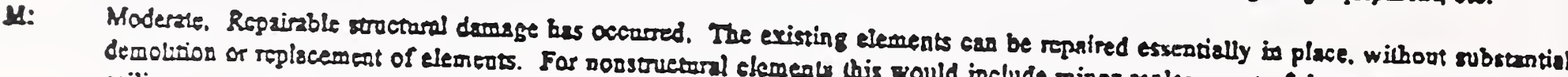
demolition or replacement of elements. For nonstructural elemeolu this would include minor replacement of dernaged partitions,

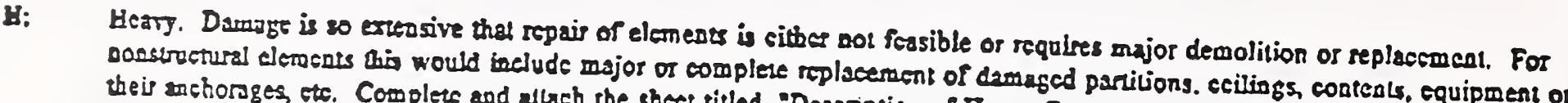
"Heavy" is cboses. Include photos where possible.

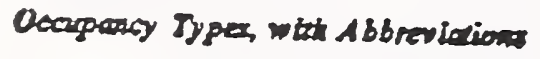

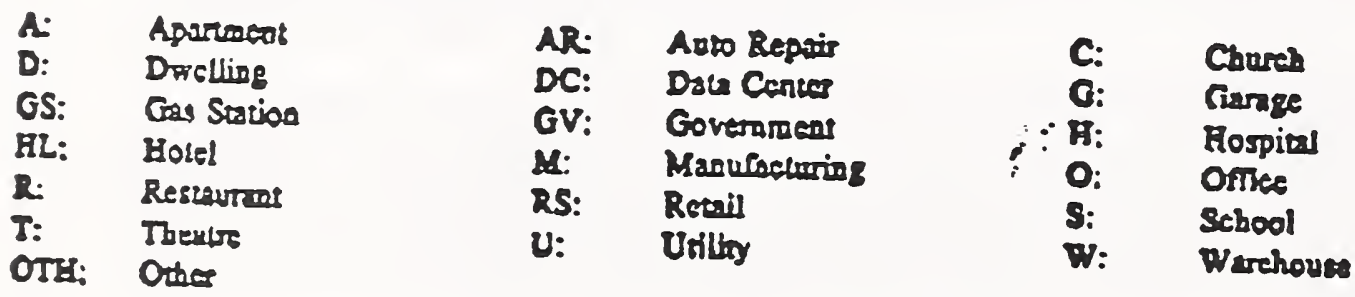

\section{Building Learifiontion Nanber}

Eonn: Sustion - Inspector - Sequantial Number

Eor Exprols: S386-ER-1

Surtios:

lespector.

Sequertial Number.

Apency and Seavion Number

Use letials of Tean Leades

ATC-13 Dernege simes

7
Noae

Moderase

Destroyed
Number in the ordar inspected
$S=$ CSNRP $\quad O S=U S O S \quad U=U S C$

$S=$ CSNRP $\quad O S=U S O S \quad U=U S C$ 
National Institute of Standards \& Technology / Building \& Fire Research Laboratory

\section{ATC-38 POSTEARTHQUAKE BUILDING PERFORMANCE ASSESSMENT FORM}

Building Site Infomation [1]

Inspector(s) Date Bidg. ID\# Page ﹎. of _

Exact Address City Building Name

Exterior Survey only Ext. and int. Survey

Related Strong Motion Record (Station ID)

Existing Posting Placard Photo I.D.

Building OwnerManager Contact Phone

Civil/structural Engineer for Repair, If Known Phone

General Damage Classification [2L N I M H Repeat on next shee)

Buildina Occupancy and Construction Information

Construction Data [3]

\begin{tabular}{|l|l|l|l|l|l|l|l|l|l|l|}
\hline$C D$ & $D D$ & $N$ & $N B$ & $L U$ & $F D N$ & $P L A N T$ & PLAN2 & AREA & OC & OCC \\
\hline & & & & & & & & & & \\
\hline
\end{tabular}

$C D=$ Construction date

$D D=$ Design date

FDN = Foundation type, if known

$N=$ Number of stories PLAN1, $2=$ Overall plan dimensions, $\chi \chi$ by $X \times \AA$.

NB = Number of basememt levels AREA $=$ Approximate overall building area

$L U=$ Number of living units, if applicable $O C=$ Occupancy type (see instructions)

OCC = Occupied prior to earthquake? - Y or $N$

Model Bullding Type [4]

Indicate below the Model Building Type (MBT) abbreviation for each plan direction and for each range of foors. Range of floors may be the same for side-by-side differing MBT's.

(Enter this information again, as needed, in the "Detailed Damage Description" section.)

Plan Direction

Floor Levels

Model Building Type
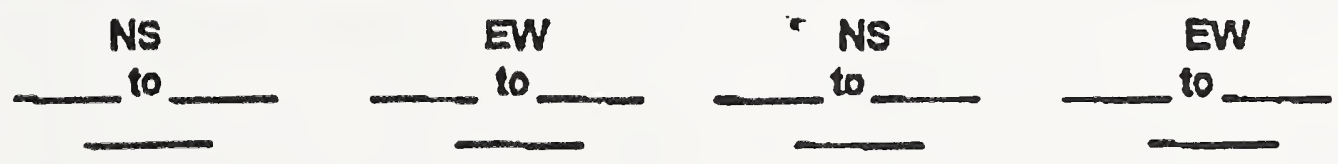

\section{Performance Modfifiers}

Describe Seismic Structural Retrofit, if present and known

Vertical Conditions [5] - Y or N

- Discontinuous Columnswalls

- Plan setbacks Potential for pounding Selsmic expansion joints Other
Plan Vutherabithies [6] - Y or N Open Front Plan Other Torsional imbalance Plan Imegularities Other

Preearthquake Eldg. Condition IJ- Y or N . Deterioration of Structure Previous Earthquake Damage Other

Comments - Reference bracketed [] heading number 
National Institute of Standards \& Technology / Building \& Fire Research Laboratory

Building Occupancy \& Construction Information (cont.)

Blidg. ID \#

Page of

Description of Nonstructural Elements [8]

Exterior Cladding/Glazing: Stueco Wood Product Cunain Wall

Partitions: Gypsum Board on Studs __ Plaster on Studs __ Other
Ceilings: Gypsum Board __ Plaster__ Suspended Acoustical Tile Other

Existence of Flxed Building Systems and Equipment - $Y$ or $N$ Standard Plumbing. Electrical, Lighting, HVAC Flre Protection Elevators Major Fixed Equipment

Describe Unusual Contents

GLOBAL ISSUES / GENERAL DAMAGE

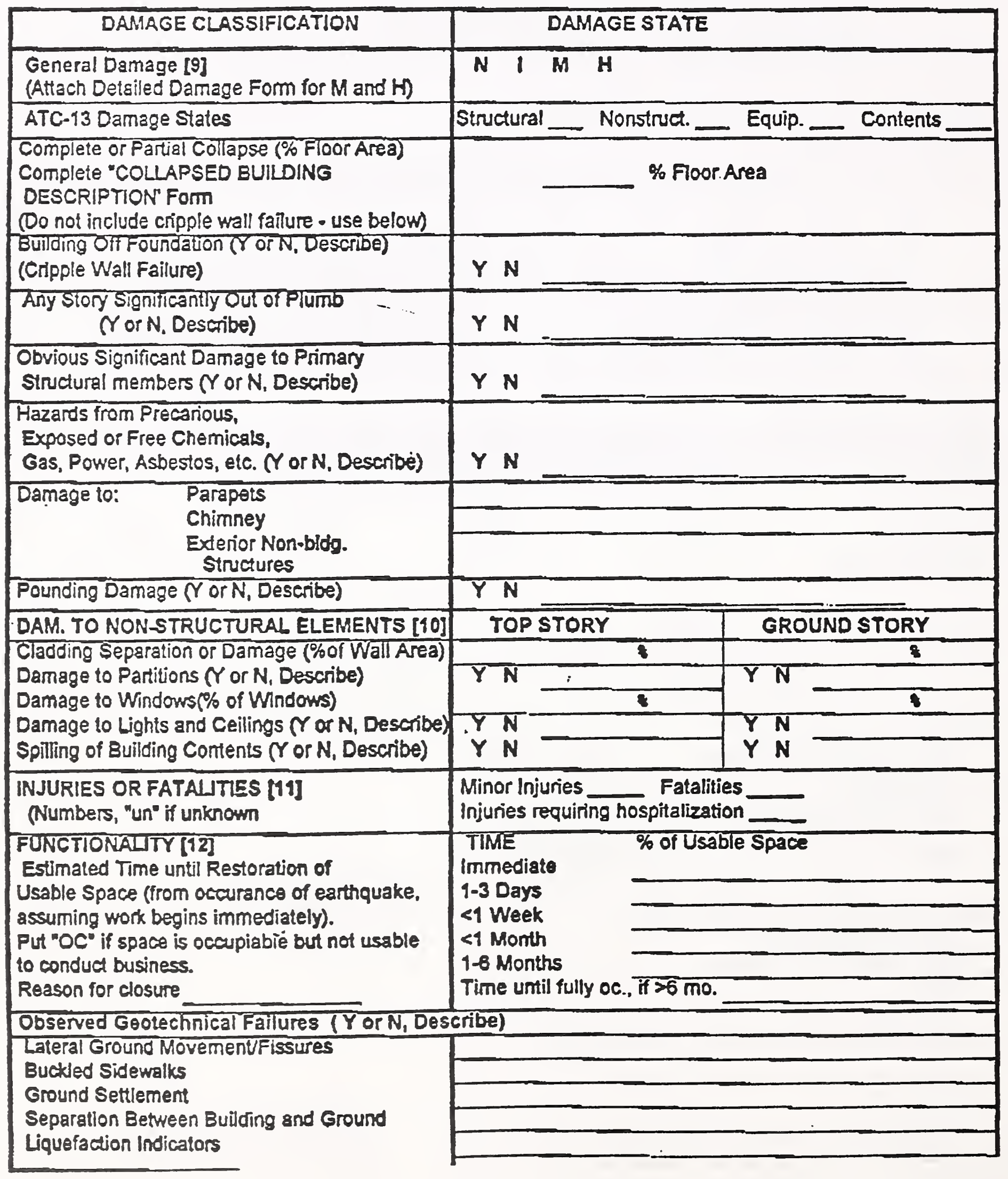


National Institute of Standards \& Technology / Building \& Fire Research Laboratory ATC-38 - DETAILED DAMAGE DESCRIPTION

\begin{tabular}{|c|c|c|c|c|}
\hline & \multicolumn{3}{|c|}{ Bldg. ID\#_ } & \\
\hline DAMAGE CLASSIFICATION & $\begin{array}{l}\text { Dir. } \\
\text { Level二 } \\
\text { Type _ }\end{array}$ & $\begin{array}{l}\text { Dir. } \\
\text { Level } \\
\text { Type _ }\end{array}$ & $\begin{array}{l}\text { Dir. } \\
\text { Level二 } \\
\text { Type 二 }\end{array}$ & $\begin{array}{l}\text { Dir. } \\
\text { Level } \\
\text { Type _ }\end{array}$ \\
\hline
\end{tabular}

VERTICAL ELEMENTS

\begin{tabular}{|c|c|c|c|c|}
\hline Racking of Main Walls & $N / M H$ & $N \quad \mathrm{I} M \mathrm{M}$ & $\begin{array}{lllll} & 1 & M & H \\
\end{array}$ & $\mathrm{~N} / \mathrm{MH}$ \\
\hline Racking of Cripple Walls & $N \mid M H$ & $N \mid M H$ & NIMH & $N / M H$ \\
\hline $\begin{array}{l}\text { Buckling. Crippling, Tearing of } \\
\text { Steel Beams, Columns or Braces }\end{array}$ & $\mathrm{N} / \mathrm{MH}$ & $\mathrm{N} / \mathrm{MH}$ & $N \mid M H$ & $\mathrm{~N} \perp \mathrm{MH}$ \\
\hline $\begin{array}{l}\text { Spalling or Cracking of } \\
\text { Concrete Columns or Beams }\end{array}$ & $N \mid M H$ & $N \mid M H$ & $\mathrm{~N} I \mathrm{MH}$ & N I MH \\
\hline $\begin{array}{l}\text { Column Crushing Due to Overtuming or } \\
\text { Discontinuous Lateral Resisting Elements }\end{array}$ & $\mathrm{N} I \mathrm{MH}$ & $N \mid M H$ & $N \mid M H$ & $N \mid M H$ \\
\hline Shear Cracking in Short Columns & $N / M H$ & $N I M H$ & $N / M H$ & $\mathrm{NIMH}$ \\
\hline \multirow{3}{*}{$\begin{array}{l}\text { Cracked Shear Walls } \\
\text { (\% of Walls with Cracks) } \\
\text { (\% of: Construction Cracks / Dlagonal Cracks) } \\
\text { (Damage State of Cracked Walls) }\end{array}$} & $\%$ & $\%$ & $\%$ & $\%$ \\
\hline & $\% / \%$ & $\% l$ & $\%$ & $\% 1$ \\
\hline & $N \mid M H$ & $N I M H$ & N I M H & $N \mid M H$ \\
\hline Evidence of Shear Wall Rocking & $\mathrm{N} / \mathrm{MH}$ & $N \mid M H$ & $\mathrm{~N} / \mathrm{MH}$ & $\mathrm{N} / \mathrm{M}$ M \\
\hline Damage to Shear Wall Boundary Elements & $N \mid M H$ & N I M H & $N \mid M H$ & $\mathrm{~N} / \mathrm{MH}$ \\
\hline Shear Wall Coupling Beams Damaged & $N \mid M H$ & $N \mid M H$ & $\mathrm{~N} / \mathrm{MH}$ & NIMH \\
\hline $\begin{array}{l}\text { \# of Tiltup Wall Panels Leaning or Fallen Out } \\
\% \text { of Trtlup Wall Panels Leaning or Falling Out }\end{array}$ & \% & $\%$ & $\%$ & \\
\hline Infill Walls Damaged or Fallen Out & $N: M H$ & $N \mid M H$ & N I M H & $N \mid M H$ \\
\hline
\end{tabular}

HORIZONTAL ELEMENTS

\begin{tabular}{|c|c|c|c|c|}
\hline Roof Collapse (\% of Diaphragm) & \multicolumn{4}{|c|}{$\%$ of Diaphragm } \\
\hline Floor Collapse (\% of Diaphragm) & \multicolumn{4}{|c|}{$\%$ of Diaphragm } \\
\hline $\begin{array}{l}\text { Loss of Vertical Roof Support } \\
\text { (\% of Roof Area Affected) }\end{array}$ & \multicolumn{4}{|c|}{$\%$ of Roof Area Affected } \\
\hline Damage at Re-entrant Comers & $N / M H$ & $\mathrm{~N} / \mathrm{MH}$ & $\mathrm{N} / \mathrm{MH}$ & $N \mid M H$ \\
\hline $\begin{array}{l}\text { Tearing of Diaphragms at Other Points of } \\
\text { High Stress of at Openings (\% of Diaphragms) }\end{array}$ & \multicolumn{4}{|c|}{$\%$ of Diaphragm } \\
\hline Failures of Collectors at Wanls & $N \mid M H$ & NIMH & $N \mid M \quad M$ & $N \mid M$ \\
\hline $\begin{array}{l}\text { Cross Grain Bending Damage at Roofito-Wall } \\
\text { connections (\% of Connection Length) }\end{array}$ & $\%$ & $\%$ & $\%$ & * \\
\hline Other Damage in Diaphragms (Describe) & & & & \\
\hline
\end{tabular}

Note: Attach sheet titled"Description of Heavy Damage" to describe instances where "H" is selected. 
National Institute of Standards \& Technology / Building \& Fire Research Laboratory

Bldg. 10\#

Page __ of

DAMAGE CLASSIFICATION

\begin{tabular}{l|l|l|l}
\hline Dir. & $\begin{array}{l}\text { Dir. } \\
\text { Level _- }\end{array}$ & $\begin{array}{l}\text { Dir. } \\
\text { Level } \\
\text { Type }\end{array}$ & $\begin{array}{l}\text { Dir. } \\
\text { Type }\end{array}$
\end{tabular}

\section{CONNECTIONS}

\begin{tabular}{|c|c|c|c|c|}
\hline $\begin{array}{l}\text { Girder-Column Connection Damage, } \\
\text { Including Panel Zones }\end{array}$ & $\mathrm{N} / \mathrm{MH}$ & $N \mid M H$ & $N \perp M H$ & $N \perp M H$ \\
\hline Column Splice Damage & $N \mid M H$ & $N \mid M H$ & $N \backslash M H$ & $N \mid M H$ \\
\hline Damage to Brace Connections & $N \mid M H$ & $N$ I $M H$ & $N \backslash M H$ & $N \mid M H$ \\
\hline $\begin{array}{l}\text { Failure of Column-to-Foundation } \\
\text { Connections }\end{array}$ & $N \mid M H$ & $N \mid M H$ & $N \mid M H$ & $N \perp M H$ \\
\hline $\begin{array}{l}\text { Damage to Connections of Precast Elements } \\
\text { that are Part of the Lateral Force Resisting System }\end{array}$ & $N \mid M H$ & $N \mid M H$ & $N \mid M H$ & $N \perp M H$ \\
\hline
\end{tabular}

FOUNDATION DAMAGE

\begin{tabular}{|c|c|c|c|c|}
\hline Foundations Cracked or Otherwise Damaged & $N \mid M H$ & $N \mid M H$ & $N \mid M H$ & $N \perp M H$ \\
\hline Slabs-on-Grade Cracked or Othenvise Damaged & $N \mid M H$ & $N \mid M H$ & $N \mid M H$ & $N \perp M H$ \\
\hline
\end{tabular}

EQUIPMENT AND SYSTEMS DAMAGE

\begin{tabular}{|l|l|l|}
\hline $\begin{array}{l}\text { Electrical Equipment Damage Including } \\
\text { Backup Generators }\end{array}$ & TOP STY: N I M H & GND STY: N I M H \\
\hline Damage to Boilers, Chillers, Tanks, etc. & TOP STY: N I M H & GND STY: N I M H \\
\hline HVAC Damage (Fans, Ducts) & TOP STY: N I M H & GND STY: N I M H \\
\hline $\begin{array}{l}\text { Damage to Water and Sprinkler Lines } \\
\text { and Fire Pumps }\end{array}$ & TOP STY: N I M H & GND STY: N I M H \\
\hline $\begin{array}{l}\text { Elevator Equipment Damage (Car and } \\
\text { Countenweight Rails, Cars, Penthouse Equipment) }\end{array}$ & $\begin{array}{l}\text { PENTHOUSE EQUIP: N I M H } \\
\text { CARS AND RAILS: N I M H }\end{array}$ \\
\hline
\end{tabular}

Note: Attach sheet titleo "Description of Heavy Damage" to describe instances where "H" is selected.

Notes : 
National Institute of Standards \& Technology / Building \& Fire Research Laboratory

\section{DESCRIPTION OF HEAYY DAMAGE}

INCLUDE PICTURES OF HEAW DAMAGE WHERE POSSIBLE

Buileing 10:

Page of

DAMAGE CLASSIFICATON:

DESCRIPTION OF DAMAGE:

DAMAGE CLASSIFICATION:

DESCRIPTION OF OAMACE:

DAMAGE CLASSIFICATION:

, DESCRIPTION OF DAMAGE:

$\bullet$ 
National Institute of Standards \& Technology / Building \& Fire Research Laboratory COLLAPSED BUILDING DESCRIPTION

MODEL BUILOING MPE:

NUMBER OF STORIES ORIGINALLY.

BUILDING OESCRIPTION:
Building ID:

Page __ of ___

COLLAPSE DESCRIPTION

SPECLUATED REASON FOR COULAOSE: " 
National Institute of Standards \& Technology / Building \& Fire Research Laboratory Bldg. ID _ Page of 


